\title{
The Role of Bench-Scale Test Data in Assessing Real-Scale Fire Toxicity
}

Vytenis Babrauskas, Richard H. Harris, Jr., Emil Braun, Barbara Levin, Maya Paabo, and Richard G. Gann 



\section{NIST Technical Note 1284}

\section{The Role of Bench-Scale Test Data in Assessing Real-Scale Fire Toxicity}

Vytenis Babrauskas

Richard H. Harris, Jr.

Emil Braun

Barbara C. Levin

Maya Paabo

Richard G. Gann

Center for Fire Research

National Engineering Laboratory

National Institute of Standards and Technology

Gaithersburg, MD 20899

January 1991

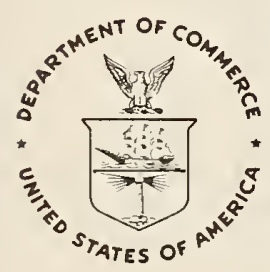

U.S. Department of Commerce

Robert A. Mosbacher, Secretary

National Institute of Standards and Technology

John W. Lyons, Director 
National Institute of Standards and Technology

Technical Note 1284

Natl. Inst. Stand. Technol.

Tech. Note 1284

110 pages (Jan. 1991)

CODEN: NTNOEF
U.S. Government Printing Office

Washington: 1991
For sale by the Superintendent of Documents U.S. Government Printing Office Washington, DC 20402 


\section{Table of Contents}

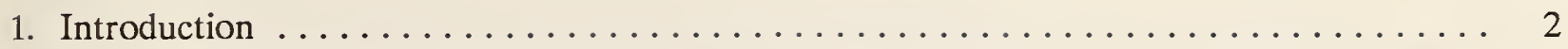

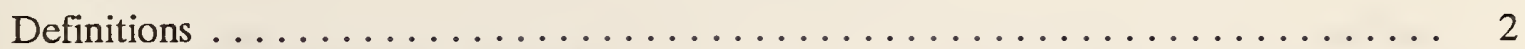

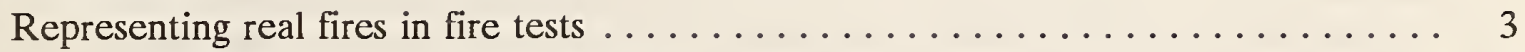

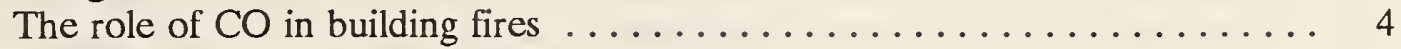

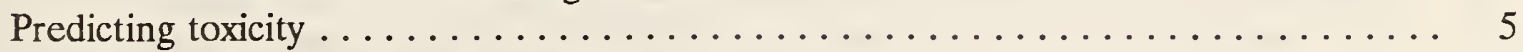

Assumptions, objective, and scope of work $\ldots \ldots \ldots \ldots \ldots \ldots \ldots \ldots \ldots$

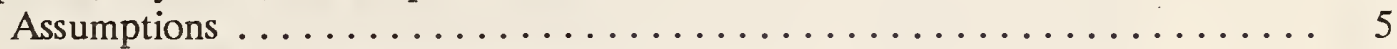

The pilot project objective and scope $\ldots \ldots \ldots \ldots \ldots \ldots \ldots \ldots$

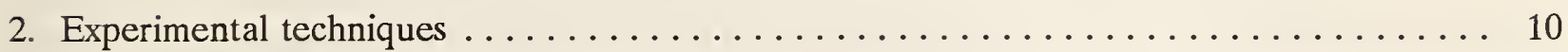

Test Materials . . . . . . . . . . . . . . . . . . . . . . . . 10

Bench-Scale measurement methods $\ldots \ldots \ldots \ldots \ldots \ldots \ldots \ldots \ldots \ldots \ldots \ldots \ldots$

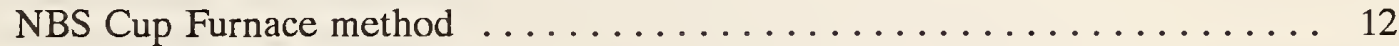

The SwRI/NIST Method $\ldots \ldots \ldots \ldots \ldots \ldots \ldots \ldots \ldots \ldots \ldots \ldots \ldots$

Cone Calorimeter ............................ 22

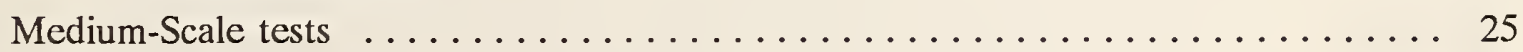

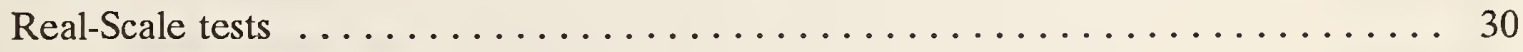

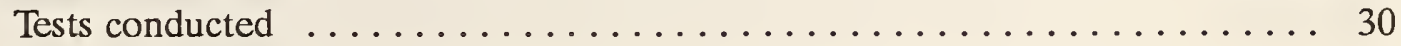

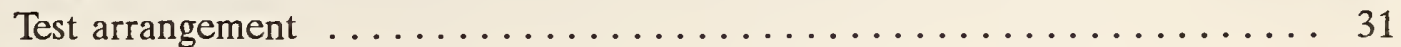

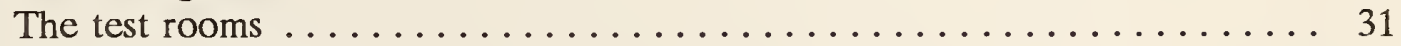

Measurements taken ........................... 31

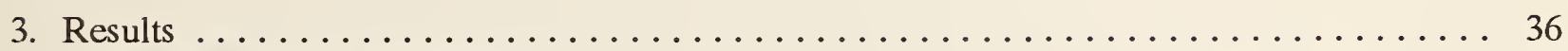

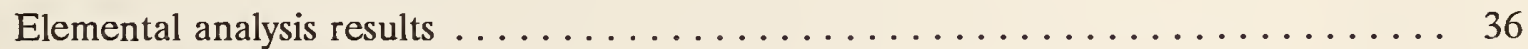

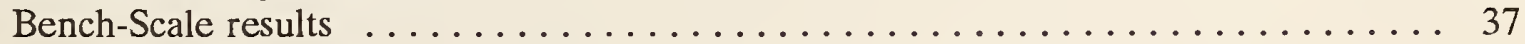

NBS Cup Furnace Method . . . . . . . . . . . . . . . . . 37

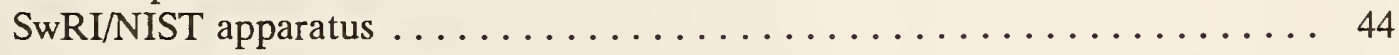

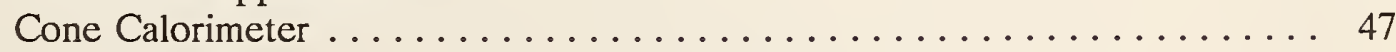

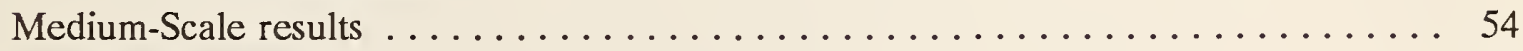

Real-Scale results . . . . . . . . . . . . . . . . . . . . . 56

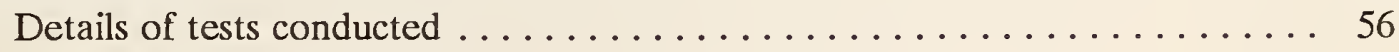

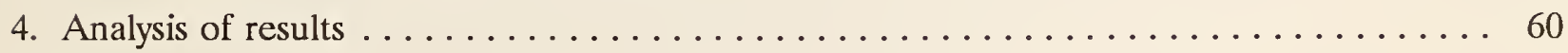

5. Discussion ................................... 69

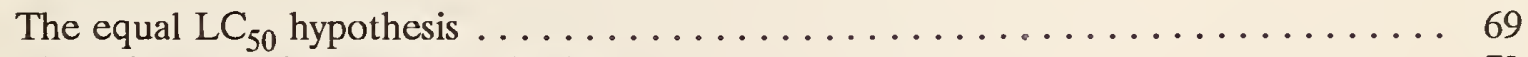

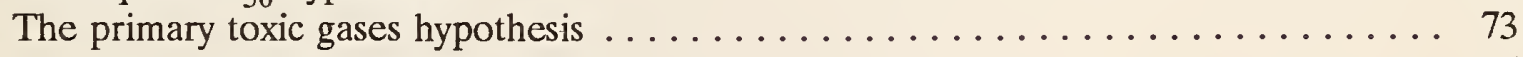

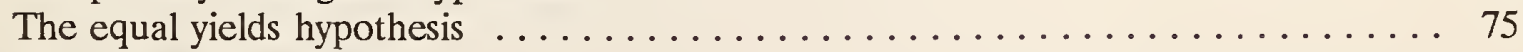

The N-Gas hypothesis $\ldots \ldots \ldots \ldots \ldots \ldots \ldots \ldots \ldots \ldots \ldots \ldots \ldots \ldots \ldots$

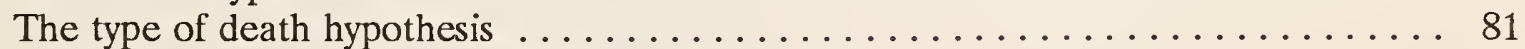

Alternative acceptable levels of agreement .................... 84 


\section{Table of Contents (continued)}

Page

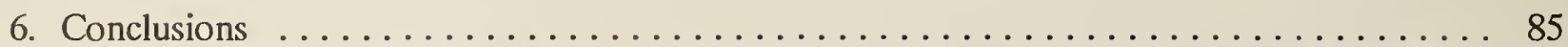

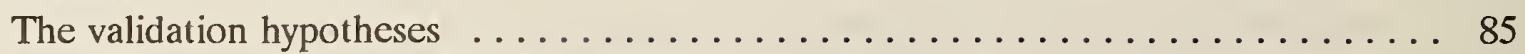

Assumption as to the level of agreement $\ldots \ldots \ldots \ldots \ldots \ldots \ldots \ldots \ldots \ldots . \ldots \ldots$

The bench-scale toxicity methods $\ldots \ldots \ldots \ldots \ldots \ldots \ldots \ldots \ldots \ldots \ldots . \ldots \ldots$

The NBS Cup Furnace method $\ldots \ldots \ldots \ldots \ldots \ldots \ldots \ldots \ldots \ldots$

The SwRI/NIST method . . . . . . . . . . . . . . . . . 87

General remarks ........................ 87

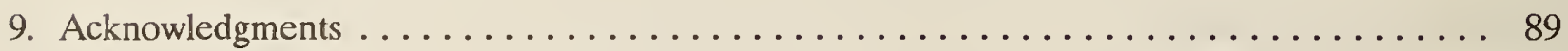

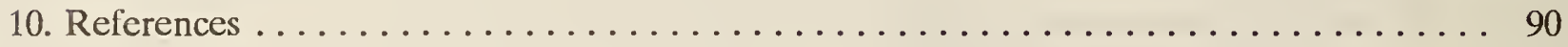

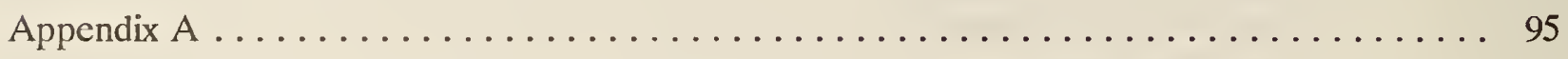

Appendix B . . . . . . . . . . . . . . . . . . . . . 99

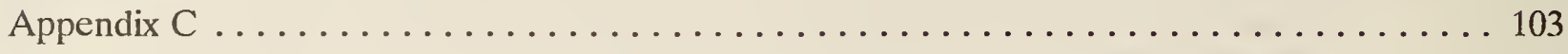




\section{List of Figures}

Page

Figure 1. General view of the NBS Cup Furnace method . . . . . . . . . . . 13

Figure 2. Gas sampling arrangements in the NBS Cup Furnace method . . . . . . . . 15

Figure 3. Impinger gas sampling in the NBS Cup Furnace method . . . . . . . . 16

Figure 4. General view of the SwRI/NIST method . . . . . . . . . . . . . . . 18

Figure 5. Major dimensions of the SwRI/NIST method . . . . . . . . . . . . . 19

Figure 6. General view of the Cone Calorimeter . . . . . . . . . . . . . . . . 23

Figure 7. General view of the Furniture Calorimeter . . . . . . . . . . . . . . 26

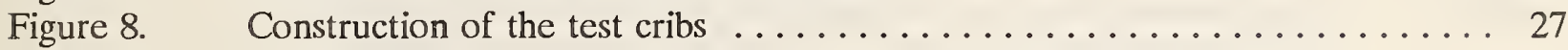

Figure 9. Layout of the burn room/corridor/target room used for real-scale tests . . . . 32

Figure 10. Installation of animal boxes in the real-scale tests . . . . . . . . . . 34

Figure 11. Typical time variation of gases within the $200 \ell$ animal box ..........4 42

Figure 12. Heat release rates measured in the Cone Calorimeter for DF . . . . . . . . 50

Figure 13. Heat release rates measured in the Cone Calorimeter for RPU . . . . . . . 51

Figure 14. Heat release rates measured in the Cone Calorimeter for PVC . . . . . . . 52

Figure 15. Heat release rates measured in the Furniture Calorimeter for cribs . . . . . . . 55

Figure 16. Heat release rates measured for DF in the real-scale tests . . . . . . . . 65

Figure 17. Heat release rates measured for RPU in the real-scale tests . . . . . . . . 66

Figure 18. Heat release rates measured for PVC in the real-scale tests . . . . . . . 67 


\section{List of Tables}

Page

Table 1. Elemental analysis of the materials in the study $\ldots \ldots \ldots \ldots \ldots$

Table 2. Chemical results for DF using the NBS Cup Furnace method . . . . . . . . 38

Table 3. Toxicological results for DF using the NBS Cup Furnace method . . . . . . . 39

Table 4. Chemical results for RPU using the NBS Cup Furnace method . . . . . . . . 40

Table 5. Toxicological results for RPU using the NBS Cup Furnace method . . . . . . 41

Table 6. Chemical results for PVC using the NBS Cup Furnace method . . . . . . . . 43

Table 7. Toxicological results for PVC using the NBS Cup Furnace method . . . . . . 45

Table 8. Chemical and toxicological results for DF using the SwRI/NIST

Toxicity method ............................. 46

Table 9. Chemical and toxicological results for RPU using the SwRI/NIST

Toxicity method ......................... 47

Table 10. Chemical and toxicological results for PVC using the SwRI/NIST

Toxicity method . . . . . . . . . . . . . . . . . . . . . 48

Table 11. Cone Calorimeter data summary . . . . . . . . . . . . . . . . . . . . . 49

Table 12. Carbon balance for Cone Calorimeter results . . . . . . . . . . . . . . . 53

Table 13. Comparison of crib results to predicted values ............... 54

Table $14 . \quad$ Summary of real-scale tests . . . . . . . . . . . . . . . . 57

Table 15. Release rates, yields, and related quantities measured in the

Table 16. Chemical and toxicological results for DF in real-scale tests ........... 62

Table 17. Chemical and toxicological results for RPU in real-scale tests ........ 63

Table 18. Chemical and toxicological results for PVC in real-scale tests . . . . . . . . 64

Table 19. Comparison of results for $\mathrm{LC}_{50} \ldots \ldots \ldots \ldots \ldots \ldots \ldots \ldots \ldots$

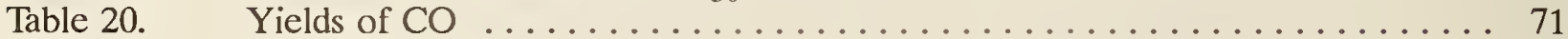

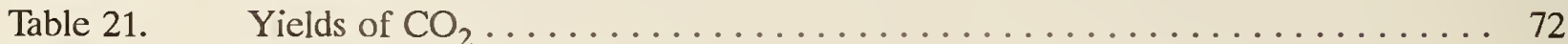

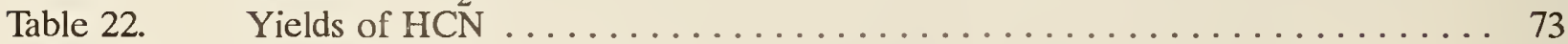

Table 23. Yields of $\mathrm{HCl} \ldots \ldots \ldots \ldots \ldots \ldots \ldots \ldots \ldots \ldots \ldots \ldots \ldots \ldots \ldots \ldots \ldots \ldots$

Table 24. Comparison of the lists of primary gases $\ldots \ldots \ldots \ldots \ldots \ldots \ldots \ldots \ldots$

Table 25. Comparison of bench- and real-scale toxicity results for DF . . . . . . . 78

Table 26. Comparison of bench- and real-scale toxicity results for RPU . . . . . . . . 79

Table 27. Comparison of bench- and real-scale toxicity results for PVC . . . . . . . 80

Table 28. Types of animal deaths ...................... 82 


\title{
The Role of Bench-Scale Test Data in Assessing Real-Scale Fire Toxicity
}

\author{
by \\ Vytenis Babrauskas, Richard H. Harris, Jr., Emil Braun, \\ Barbara C. Levin, Maya Paabo, and Richard G. Gann
}

\begin{abstract}
The need was seen for establishing a methodology by which bench-scale fire toxicity methods could be validated against real-scale room fires. The present study is the result of a pilot project in this area. Appropriate validation hypotheses have been put forth and examined in the context of some initial data. Three materials - Douglas fir, rigid polyurethane foam, and PVC - were examined in real-scale and bench-scale methods. The real-scale test environment was a post-flashover fire in a three-compartment (room, corridor, room) geometry, with the test specimens comprising wall lining materials. The bench-scale methods examined were the NBS cup furnace method and a new developmental protocol referred to as the 'SwRI/NIST' method. The N-gas Model was applied to the analysis of the data and was found to be consistent with most of the data. The methods were compared for similarity of gas yields, of primary gases, and of types of death. Differences were found in individual cases, but most of those were readily explainable on the basis of an understanding of the test conditions. As a result of these studies, a factor-of-3 agreement between bench-scale and realscale results was established as both useful and practical.
\end{abstract}

KEYWORDS: fire tests; fire toxicity; poly(vinyl chloride); radiant heat; rigid polyurethane foam; room fire tests; wood materials. 


\section{1}

\section{Introduction}

In recent years, bench-scale testing for the toxicity of combustion products has been assuming a significant role. For example: (1) Some governmental bodies have mandated testing of certain product classes [1]. (2) Manufacturers have been exploring the use of these tests to try to judge the quality of their products. (3) Fire protection engineers have been demanding suitable tests so that they could use them in the course of providing state-of-the-art building fire safety analyses. In response to such needs, a number of bench-scale toxicity methods have been designed over the last 10 or 15 years. Kaplan et al. discuss most of these methods in detail [2]. These methods were generally developed empirically and intended only for the screening against 'supertoxicants,' with little thought as to whether their data could be validly used in mathematical computations of building fire histories. More recently, it is becoming accepted in the profession that arbitrary bench-scale fire tests, not validated against real-scale fires, have little value [3]. This need for validation, of course, pertains just as well to fire toxicity tests as to flammability tests. In recent years, NIST has conducted three investigations [4] in this area. Two [5], [6] focused on the special problems of upholstered furniture toxicity, while the third [7] examined the issues associated with fire-retardant (FR) treated products. During the course of 1989, Congress provided a special appropriation to NIST to begin examining these issues in a systematized way. The role of this pilot study, as developed in the present report, has been to establish the logical basis for validation of bench-scale toxicity methods and to obtain some preliminary experimental data towards that validation. The present report will discuss the needed hypotheses. Based on a single real-scale scenario and on a relatively small number of test materials, several bench-scale toxicity tests will be examined for validity. The role of the work for completing the study, if funded, will be to examine further test materials and, possibly, additional real-scale scenarios and additional bench-scale tests.

\section{Definitions}

The discussion of fire toxicity requires that the meaning of certain terms be made clear. For our purposes here, we will focus exclusively on inhalation toxicity, since inhalation is the primary means through which toxicants enter the body during exposure to fire smokes. There is not yet universal 
agreement on terms; for clarity, in this report, we will define the following, which are in general agreement with current usage:

Toxic potency - toxicity of the smoke from a specimen of material or product, taken on a perunit-specimen-mass basis. When the testing is for a lethality end-condition, the toxic potency is determined as an " $\mathrm{LC}_{50}$," which stands for the concentration which will be lethal to $50 \%$ of the exposed animals during a specified exposure time. The units are in concentration, i.e., mg/ . It must be emphasized, however, that toxic potency is not an inherent property of a material. The $\mathrm{LC}_{50}$ is a variable which depends upon the test animal, the test apparatus and specimen combustion conditions, and the length of the exposure time. The latter is particularly important, since for many substances the value of the $\mathrm{LC}_{50}$ tends to be inversely dependent on the exposure time [8]. For fire toxicity, a 30-minute exposure time (along with a 14-day post-exposure observation period) has often been specified [9].

Fire hazard - generally, this is taken to be a measure of the seriousness of the exposure conditions which threaten the physical well-being of the occupant. The hazard may come from various sources, for example, smoke inhalation, direct flame burn, injuries due to ceiling collapse, or inability to escape due to lack of visibility.

Toxic fire hazard - this term is a sub-set of "fire hazard," occurring when the hazard being considered is due to inhalation of toxic combustion products alone. Toxic potency is one, but not the only, factor in toxic fire hazard. Mass loss rate and flame spread rate, among other factors, also play a dominant role [10].

Bench-scale tests commonly referred to as 'toxicity tests' are tests for toxic potency alone. For judging the effects of fires in real scale, however, considerations of toxic potency alone are not sufficient - only the assessment of fire hazard, or at a minimum, toxic fire hazard can satisfy the true needs of the building designer, regulator, engineer, or other person who needs to quantify the effects of fire.

\section{Representing real fires in fire tests}

The courses of real-scale building fires can be dramatically diverse. Most fires will change their character as time goes on - some phases of the fire can be smoldering, others can consist of open flaming; some can be fuel-rich, others can be fuel-lean. Thus, there is certainly no such thing as a standard fire. To simplify, a British Standard [11] classifies fires into six types:

Decomposition

(a) Smoldering (self-sustained)

(b) Non-flaming (oxidative)

(c) Non-flaming (pyrolytic)

Developing fire (flaming)

Fully developed (flaming)

(a) Relatively low ventilation

(b) Relatively high ventilation. 
For each, it describes in general terms certain combustion conditions. Such a framework is quite useful when discussing fire scenarios. What is important to realize is that just by selecting one of the six fire types, one does not end up with unique, well-described, widely applicable combustion conditions.

If designed according to current engineering views [3], bench-scale property measuring methods are, by contrast, designed for a single, unique combustion condition (e.g., a fixed specimen heating flux, fixed form of ignition, specified oxygen concentration of the combustion air, etc.). The reason for this is, of course, that only by such simplification is there any hope of being able to use their data in the modeling of fires. Such a bench-scale test can, then, only correspond to one limited combustion condition among all the possible real-scale combustion conditions. The bench-scale test can, instead, be designed so that the specimen combustion conditions are either non-constant during the test, e.g., [12], or are modified by the behavior of the specimen under test (feedback boundary conditions). In such a case, there is, from the very start, no real way of relating any of the test output to the realscale fire to be modeled. For the purposes of the present study, we will assume that we are concerned with bench-scale tests which are, essentially, of the fixed-combustion-conditions type.

To avoid the above dilemma, two solutions might be considered. (1) Re-run the bench-scale test at numerous test conditions, so as to span the domain of real-scale combustion conditions of interest. For practical reasons, this is normally an unaffordable option. (2) Determine which real-scale fire the single, selected bench-scale combustion conditions do correspond to, then study only that fire. The disadvantage is that by making such a limitation most fires of practical interest shall have been excluded. Instead, we will try to define a proper role for bench-scale tests which is useful and which does have generality.

\section{The role of $\mathrm{CO}$ in building fires}

Due to the overwhelming importance of carbon monoxide (CO) in fire deaths [13], efforts have recently been focused on understanding the production of $\mathrm{CO}$ in building fires. Much is still unknown, however, one of the conclusions to be drawn from a recent workshop organized on this subject [14] is that this toxicity is not primarily a materials issue. Instead, the available data point to the interpretation that for large-scale fires, during room flashover, most materials produce the same yield ${ }^{1}$ of $\mathrm{CO}$. The data scatter in this observation is to within about a factor of two. Furthermore, it requires that we consider the same ventilation conditions (with air supply expressed as a fraction of what is required to completely combust the fuel in question) and consider neither very tiny nor extremely well-ventilated fires. Under those conditions - which correspond to the fires most likely to cause death or injury, in any case - the present experimental data state that the type of fuel being burned is a minor factor in determining the $\mathrm{CO}$ yield. We emphasize that two different materials showing the same $\mathrm{CO}$ yield may represent very different toxic hazard levels if the burning rate is different, however!

1 The yield of a chemical species $\mathrm{x}$ is defined as $(\mathrm{kg}$ species $\mathrm{x}$ produced $) /(\mathrm{kg}$ specimen mass lost). 


\section{Predicting toxicity}

A tool that we have available to help us make sense of the toxicity of building fires is a concept which has recently come to be called the 'N-Gas Model.' According to the N-Gas Model [15], the toxic potency of most materials is determined by measuring the concentrations of a relatively small number of toxic gas species. Since such a chemical analysis cannot flag obscure, but toxicologically potent contributing species, it must be followed by a biological check test. Results from this check test are then used to decide if the chemical analysis of the principal toxic species correctly included all the gases actively contributing towards the toxicity, or whether a significant fraction of actual toxicity is not accounted for. This concept of attempting to predict as much as possible from gas concentration measurements is applicable to both large- and small-scale fire tests. Whenever possible we will attempt to use this principle in our present work, to minimize the testing effort, to reduce the usage of animals, and especially, to increase our understanding of actual fire mechanisms.

The toxic potency data also have to be placed in the larger context of hazard. In the most advanced design case toxic potency data are supplied to a full-featured building fire model [16]. Copious other data are also provided to this model, so that complete predictive calculations can be produced. Practical applications of fire modeling have not quite reached this level yet, and certainly existing building codes and regulatory requirements have not. Thus, in trying to answer the question of how the toxic potency data will be put to use, we must establish a realistic context of engineering methodologies which are viable today. An example of such an approach is using the N-gas model, coupled to a set of engineering formulas for combining toxic potency with burning rate into a unified expression of toxic fire hazard [10]. We will try to place the work done here in that context.

\section{Assumptions, objective, and scope of work}

\section{Assumptions}

With the above discussion in mind, we start with some fundamental assumptions.

Assumption 1. Real-scale fires can have fire growth stages showing various combustion regimes.

Note: The six BSI types discussed above are a reasonable point of departure for the scenarios, although some simplification may be possible. For example:

- 'non-flaming (pyrolytic)' and 'non-flaming (oxidative)' are rarely a problem, since the smoke mass is likely to be small compared to the smoke from the flames causing the pyrolysis. Pyrolysis from a non-flaming source (e.g., electrical overheating) produces little smoke, but would need to be considered separately if that pyrolysate were especially toxic.

- 'developing fire (flaming)' is likely to be similar to "fully-developed, relatively high ventilation."

- 'smoldering' requires a physically larger sample than can be accommodated by the current bench-scale toxic potency measurement devices. 
This leaves two principal scenarios:

- flaming (low ventilation) and

- flaming (high ventilation).

Considering now the flaming fires, we can narrow our interest to growing fires. (The converse, flaming fires which burn at a slow but constant rate, are rare enough to be considered special cases.) The common situation of a growing, flaming fire is that until flashover occurs, the hot gas layer is confined to the upper half of the room of the fire and of the corridor or the adjoining room into which the gas may be flowing. Thus, occupants of these adjoining rooms are not likely to be threatened until after flashover has occurred. Once flashover has occurred, the hot gas layer drops much lower and the combustion products are likely to threaten occupants of the adjoining spaces. (With such fires, of course, any occupants of the room of fire origin are highly at risk from thermal exposure and cannot be expected to survive a flashed-over fire.) We do not elaborate here further on the dynamics of building fires, since comprehensive references, e.g., [17], are available. With this typical fire course in mind, we will place the emphasis in this study on post-flashover behavior. This is consistent with the conclusions of the National Institute of Building Sciences (NIBS), who have determined that the problem of toxicity in fire deaths is primarily with post-flashover fires [18].

We wish to emphasize that while the fire scenario chosen above is a very common one, it is certainly not the only one of concern. For most other scenarios, however, generalization is not possible and specific details must be considered. As an example of such specialized analysis, Ref. [19] is especially instructive.

Assumption 2. Real-scale tests, even without animals, are not affordable for each potential fire scenario.

Note: A real-scale fire test is the only one which can have intrinsic validity, i.e., if the fire scenario was correctly chosen and proper instrumentation was provided, its data do not require any further proving to accept their validity. All other tests must be validated in comparison to such a real-scale test. The real-scale fire test will normally be a fully-furnished room fire test. The word 'real-scale' is used here to denote a test fire which not only uses full-sized test items, but also reproduces other features of the real building fire (such as appropriate ventilation, or the presence of other nearby surfaces or combustibles). Because the real-scale fire test cannot include all features of all building fires, it will yield results that only can be generalized with care.

Assumption 3. The purpose of a bench-scale toxic potency measurement is to provide data for a calculation (model) of fire hazard.

Note: Bench-scale tests are also sometimes used for direct product selection or as go/no-go regulatory implements; applications of this kind are outside of the scope of the present work.

From the above three assumptions it is useful to draw some corollaries. 
Corollary A. A bench-scale toxic potency measurement protocol is necessary that, for each type of fire scenario, provides:

- [Primary] Data sufficient to construct an $\mathrm{LC}_{50}$ that portrays the real-scale value to within an accepted uncertainty. This is the major concern that underlies the present study.

- [Secondary] Data sufficient to:

(i) follow the change in toxic potency that occurs as the smoke moves through the building and

(ii) combine the contributions of several burning materials during the fire.

Discussion: The functions (i) and (ii) above can be performed by calculational means ("N-Gas Model'). In such a case, the following demands are then placed on the data from the bench-scale protocol:

- The principal toxicants must be identified and must be the same in the bench-scale test as at real-scale.

- A valid calculation method must use these toxicants and their concentrations to produce the real-scale $\mathrm{LC}_{50}$, within an accepted uncertainty.

A small failure rate is acceptable for the above two demands, especially if there is guidance as to how to recognize error-prone situations.

Corollary B. Either a different apparatus, a different set of operating conditions, or a different calculation method may be necessary for generating $\mathrm{LC}_{50}$ values for the same burning materials for different stages of a fire.

Assumption 4. Agreement to within a factor of two between predicted and real-scale toxic potency measurements shall be considered acceptable.

Note: For those validation hypotheses which are computational in nature (as opposed to yes/no), a specific, numeric criterion is needed so that validation success could be judged. This factor is to be derived from considering the actual data needs. For any particular application of toxic potency data, computations will not be useful unless certain limits to uncertainty are met. The purpose of this study is not to develop procedures for computations of fire hazard or risk. Thus, a value for the above factor will be taken as a given and will not be derived. Depending on the applications considered, factors of greater or less than two may also be appropriate.

\section{The pilot project objective and scope}

The long-term objective for much of today's toxicity research is to produce fully-validated test methods and calculation protocols whereby the toxicity component of fire hazard could be computed numerically to a known, acceptable uncertainty. 
The objective for this pilot project has been to make material advances in determining the validity of bench-scale tests and procedures. Specifically, it was desired to express clearly the assumptions of and the expectations from the validation procedure. The validation exercise was then to be started in the pilot project for:

- only one real-scale fire scenario

- a small number of bench-scale protocols, and

- a limited, initial set of test materials.

We note that for both this project and for the long-term objective, the validation exercise constitutes proof by enumeration. This, of course, is a weak form of demonstration and requires considerable data to be amassed before credence can be placed.

Conversely, proof by logic can only be applied in very limited areas of fire toxicity. The main prior example has been in excluding bench-scale methods from use in representing those fire regimes where the actual combustion conditions are widely different from those in bench-scale [20].

VALIDATION HYPOTHESES Based on the above background and assumptions, and on the findings of the preceding studies [4],[7], we now put forth several validation hypotheses. The results amassed in the pilot project will then enable us to reflect on which of these hypotheses are the most useful. We further note that it may be that a combination of hypotheses, rather than a single one, is needed.

The equal $L C_{50}$ hypothesis: $\mathrm{LC}_{50}$ values, as measured in the bench-scale test and in the real-scale one, agree to within the acceptable uncertainty.

The primary toxic gases hypothesis: The bench-scale test shows the same primary toxic gases as the real-scale test.

[To use this hypothesis, we will have to define precisely what we mean by 'primary gases.' This we do in the Discussion Chapter, below.]

The equal yields hypothesis: The yields of the primary toxic gases are the same, to within the acceptable uncertainty, in the bench-scale and in the real-scale tests.

The N-Gas hypothesis: The real-scale and the bench-scale results agree, to within the acceptable uncertainty, with predictions based on measured gas concentrations and computations made according to the N-Gas Model.

The type of death hypothesis: The type of death (within- or post-exposure) is similar for the benchscale and for the real-scale tests.

With the data generated here, we will then propose a unified (hypothetical) protocol of measurements at bench-scale and of calculation procedures to predict real-scale toxic potency within the accepted uncertainty.

FIRE SCENARIO In accordance with the description of the fire types above, we will select a single real-scale fire scenario. This is a fire which starts small, grows until it reaches flashover, continues 
burning in flashover, then gradually decays. Wall coverings are chosen as the combustibles here. A future paper will re-analyze prior data, such as in [4]-[7] to enlarge the data base.

TEST METHODS ENCOMPASSED The work reported in this publication comprises the following experimental studies:

Bench-scale toxicity tests: $\quad$ NBS Cup Furnace Method

A developmental method using a radiant heat source

Other bench-scale tests: Cone Calorimeter

Medium-scale test:

Furniture Calorimeter

Real-scale test:

Room/corridor/room experimental facility 


\section{Experimental techniques}

\section{Test Materials}

The choice of the materials to be used for the initial validation was based on the desire to have at least three materials which behave substantially differently, both in their toxicological action and in their combustion behavior. For ease of analysis of the data and of relating to fire models, it was decided that wall lining materials would make the best choice. Thus, the materials selected needed to be well-behaved when used as a wall lining, i.e., they should not show excessive propensity to melt, delaminate, or prematurely fail structuraliy. The three materials selected were:

- Douglas fir (DF) planking, $45 \mathrm{~mm}$ thick, $550 \mathrm{~kg} / \mathrm{m}^{3}$ density

- Rigid polyurethane (RPU) foam, $25 \mathrm{~mm}$ thick, $96 \mathrm{~kg} / \mathrm{m}^{3}$ density

- Polyvinyl chloride (PVC) sheets, $12.7 \mathrm{~mm}$ thick, $1490 \mathrm{~kg} / \mathrm{m}^{3}$ density

None of the products tested was described as being fire-retardant treated.

The DF was obtained from a local lumber company. It was received as 'green' lumber and was conditioned for several months in our laboratories to reduce moisture content to a suitable level.

The RPU was obtained from General Plastics Manufacturing Co., Tacoma, WA ${ }^{2}$ as Last-A-Foam R-9306. The manufacturer describes the thermal conductivity as being $0.030 \mathrm{~W} \cdot \mathrm{m}^{-1} \cdot \mathrm{K}^{-1}$. We note

2 Certain commercial equipment, instruments, or materials are identified in this paper in order to specify the experimental procedure adequately. In no case does such identification imply recommendation or endorsement by the National Institute of Standards and Technology, nor does it imply that the equipment or material identified is necessarily the best available for the purpose. 
that the results of ultimate analysis (see Results, below) appear to raise doubts as to whether the material supplied could be properly considered as non-flame-retardant treated.

The PVC sheets were supplied by BFGoodrich. These were made from a commercial, weatherable, thermoformable rigid PVC sheet compound, based on a medium molecular weight poly(vinyl chloride) homopolymer and stabilized with tin mercaptide. It contains weatherable acrylic impact modifiers and weatherable pigments (mainly titanium dioxide and calcium carbonate). It does not contain any acrylonitrile derivative. While the exact formulation is proprietary, the manufacturer states the overall composition, by weight, as being approximately:

$\begin{array}{lr}\text { PVC } & 78 \% \\ \text { Acrylic impact modifiers } & 7 \% \\ \text { Tin mercaptide } & 2 \% \\ \text { Titanium dioxide } & 2 \% \\ \text { Calcium carbonate } & 8 \% \\ \text { Processing aids } & 3 \%\end{array}$

In mounting the PVC material in the real-scale tests (see below), it was necessary to use a glue. The glue used was $3 \mathrm{M}$ Fastbond 30 , which is a nonflammable contact cement.

\section{Bench-Scale measurement methods}

The validation method, as developed here, can be used for assessing the pertinence of numerous bench-scale methods. In this pilot study, we selected two bench-scale test methods ${ }^{3}$. One was selected because of the large amount of experience with the method, both at our laboratories and at others. The second one was selected since it represents a concurrently ongoing effort into developing a bench-scale method with an improved combustion module. This list does not include additional methods not because we could find none other of merit, but rather because this is only a pilot study.

- The NBS Cup Furnace method [9]. This method prescribes both flaming and non-flaming test conditions. In the present work, only the flaming tests were relevant.

- A procedure newly developed at NIST, based on the Southwest Research Institute (SwRI) apparatus [21]. This will be referred to as the SwRI/NIST method in this report.

In the experiments using the SwRI/NIST method, sufficient number of tests were not run to determine $\mathrm{LC}_{50}$ values by standard statistical procedures. The objective was, instead, to identify a range within which the $\mathrm{LC}_{50}$ would occur.

3 Our institution was involved in the development of both of the bench-scale toxicity methods described in this study. To clearly distinguish between them, we describe the first as the "NBS Cup Furnace Method' and the second as the 'SwRI/NIST Method.' The SwRI/NIST Method is still in the process of development and neither the name nor all of the protocol particulars have been finalized. 


\section{NBS Cup Furnace method}

GenEral: The acute inhalation toxicity of the combustion products of the Douglas fir, rigid polyurethane foam, and PVC was assessed using the combustion system, the chemical analysis system and the animal exposure system (Figure 1) that was designed for the NBS Cup Furnace Method [9]. The materials are decomposed in a cup furnace located directly below the animal exposure chamber such that all the combustion products from the test materials are evolved directly into the chamber.

In these experiments, all tests were conducted in the flaming decomposition mode. The flaming mode in this method was not designed to simulate post-flashover conditions; it is not clear how one would modify the method to achieve such representation. Thus, the 'standard' operating conditions were used. The autoignition temperatures of the materials were determined according to the procedure described in the NBS Cup Furnace Method and the furnace was set at approximately $25^{\circ} \mathrm{C}$ above this autoignition temperature. During the animal tests, a sparker was used to ensure that the material would flame as early as possible.

The animal exposure system (Figure 1) is a closed design so that most of the gases and smoke are kept in the 200-L rectangular chamber for the duration of the experiment. For some chemical compounds (e.g., $\mathrm{HCN}, \mathrm{HCl}$, and $\mathrm{NO}_{\mathrm{x}}$ ), atmospheric samples taken for analysis were not returned (explained in detail below). In each animal exposure experiment, six rats were placed in restrainers which were then inserted into the six portholes located along the front of the exposure chamber such that only the heads of the animals were exposed. Insertion of the material sample into the preheated cup furnace started the exposure. The animals were exposed to the test atmospheres for $30 \mathrm{~min}$.

The toxicological endpoint was death which occurred either during the 30-min exposures or the postexposure observation period (at least 14 days). If the animals were still losing weight at the end of the 14-day observation period, they were kept and weighed daily until they showed signs of recovery ( 3 days of weight gain) or died. The percentage of animals dying in each experiment was plotted to produce a concentration-response curve from which $\mathrm{LC}_{50}$ values were calculated. The $\mathrm{LC}_{50}$ in these cases is defined as the mass of material placed in the furnace divided by the exposure chamber volume $(\mathrm{mg} / \ell)$ which caused $50 \%$ of the animals to die during the exposure only or during the exposure plus the post-exposure observation period. The $\mathrm{LC}_{50}$ values and their $95 \%$ confidence limits were calculated by the statistical method of Litchfield and Wilcoxon [22]. All animals (including the controls) were weighed daily from the day of arrival until the end of the post-exposure observation period.

ANIMALS: Fischer 344 male rats, weighing 200-300 g, were obtained from Taconic Farms (Germantown, NY). They were allowed to acclimate to our laboratory conditions for at least 7 days prior to experimentation. Animal care and maintenance were performed in accordance with the procedures outlined in the National Institutes of Health's "Guide for the Care and Use of Laboratory Animals." Rats were housed individually in suspended stainless steel cages and provided with food (Ralston Purina Rat Chow 5012) and water ad libitum. Twelve hours of fluorescent lighting per day were provided using an automatic timer. 


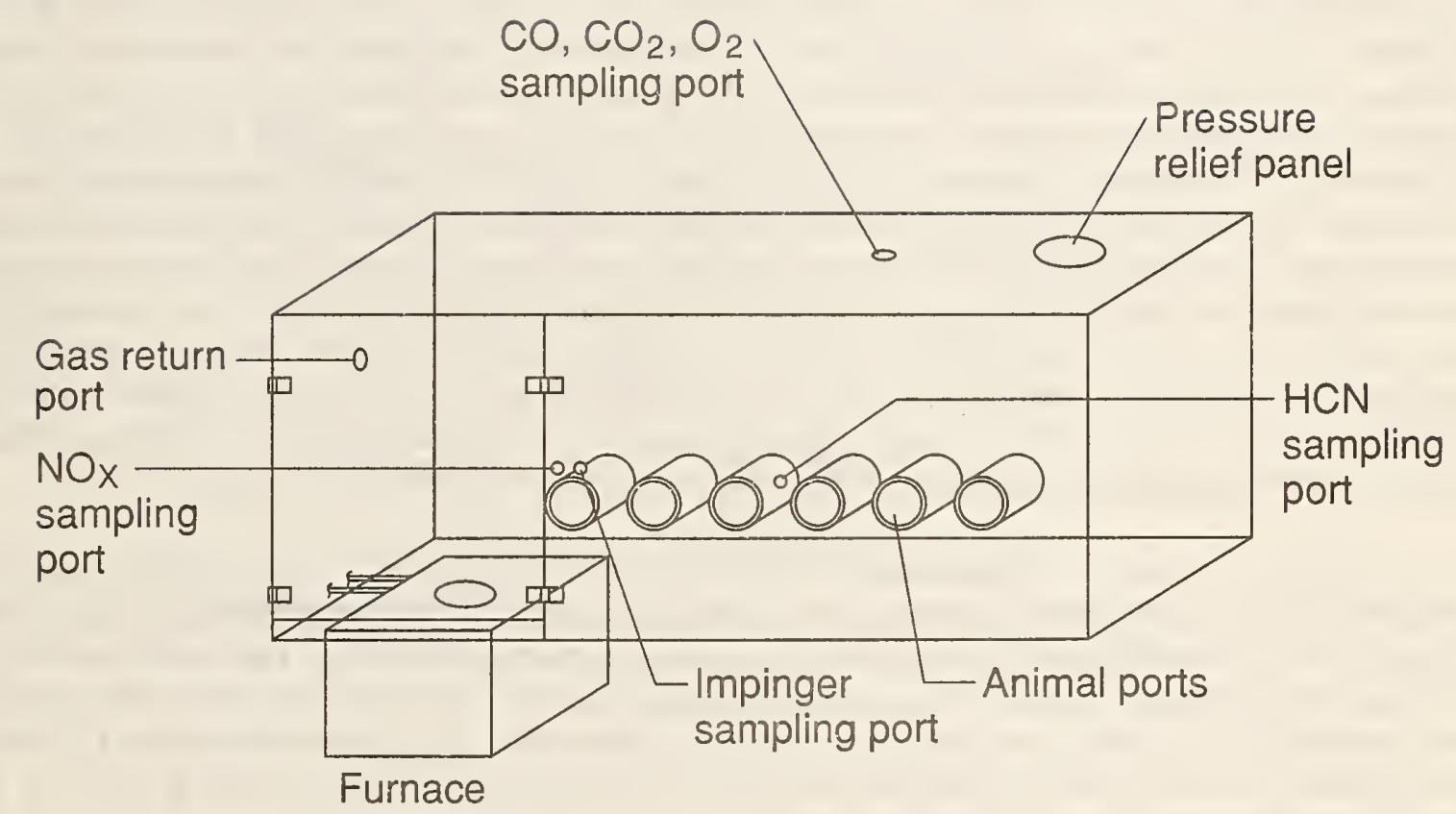

Figure 1. General view of the NBS Cup Furnace method 
Exposure Chamber Atmospheric Gas Measurements: The following gases: $\mathrm{O}_{2}, \mathrm{CO}, \mathrm{CO}_{2}$, $\mathrm{HCN}, \mathrm{NO}_{x}, \mathrm{HCl}$, and $\mathrm{HBr}$ were monitored by extraction from the animal exposure chamber of the NBS Cup Furnace Method (Figure 2).

Carbon monoxide and $\mathrm{CO}_{2}$ were measured continuously by non-dispersive infrared analyzers and the obtained values were accurate to within 100 and $500 \mathrm{ppm}$, respectively. Oxygen concentrations were measured continuously with a paramagnetic analyzer and were accurate to within $\pm 0.1 \%$ of the $\mathrm{O}_{2}$ concentration. The $\mathrm{CO}, \mathrm{CO}_{2}$, and $\mathrm{O}_{2}$ data were recorded by an on-line computer every $15 \mathrm{~s}$. All combustion products and gases that were removed for these analytical measurements were returned to the chamber. For measurement of $\mathrm{HCN}$, a $100 \mu \ell$ sample was taken approximately every $3 \mathrm{~min}$ with a gas-tight syringe and analyzed with a gas chromatograph equipped with a thermionic detector [23] and the results were accurate to within $10 \%$ of the $\mathrm{HCN}$ concentration.

The concentration of $\mathrm{HCN}$ was also determined by ion chromatography (IC) using the same Ion Chromatograph and detectors described in Appendix A of [7]; $\mathrm{HCl}$ was also determined by the same technique. The IC measurements were done by two alternative methods. The first method involved bubbling a portion of the gases generated in the animal exposure chamber through tared, $25 \mathrm{~m} \ell$ impingers containing approximately $20 \mathrm{~m} \ell$ of an appropriate eluent $(90 \% 5 \mathrm{mM} \mathrm{KOH} ; 10 \%$ acetonitrile). The apparatus is diagrammed in Figure 3 . The PTFE filter $(0.45 \mu \mathrm{m}$ nominal porosity) in this test was $25 \mathrm{~mm}$ in diameter. The flow was generated with a sampling pump and regulated with a rotameter. The flow was nominally $30 \mathrm{~m} \ell / \mathrm{min}$ and verified prior to each test with a soap bubble meter attached to the tube that protruded into the animal exposure chamber. The duration of the test was $30 \mathrm{~min}$. After the test, the impingers were weighed and the weights recorded. Initially, each impinger was analyzed separately and the PTFE filter containing the soot was placed in the first impinger. Since the carry over from the first impinger to the second was less than $10 \%$, subsequent tests were analyzed with the contents of the two impingers combined.

The second IC method for determining the concentration of $\mathrm{HCN}$ and $\mathrm{HCl}$ involved the use of gas sampling bulbs. Combustion products were collected in evacuated gas sampling bulbs of known volume, from a sampling port at nose level in the animal exposure chamber. The bulbs were weighed and then approximately $5 \mathrm{~m} \ell$ of the IC eluent was injected into the bulbs; the bulbs were reweighed and the amount of eluent used was recorded. The bulbs were shaken vigorously for 1-2 minutes. The resulting solutions were transferred to plastic bottles, diluted to volume with eluent to a range within the calibration of the IC and analyzed.

The concentration of $\mathrm{NO}_{\mathrm{x}}$ was measured continuously by a chemiluminescent $\mathrm{NO}_{\mathrm{x}}$ analyzer Model 14A (Thermo Environmental Instruments, Franklin, MA). The analyzer is equipped with a molybdenum converter (set at $375^{\circ} \mathrm{C}$ ) which reduces $\mathrm{NO}_{2}$ to $\mathrm{NO}$ before reacting with ozone. The reaction of $\mathrm{NO}$ with ozone produces electronically excited $\mathrm{NO}_{2}$ which relaxes, emitting light that is detected by the instrument. In order to minimize the total gas volume removed during the animal exposure experiments, the chemiluminescent analyzer was modified so that the sample flow was reduced to about $25 \mathrm{~m} / / \mathrm{min}$. The calculated $\mathrm{NO}_{\mathrm{x}}$ concentrations are accurate to within $5 \%$ of the $\mathrm{NO}_{\mathrm{x}}$ concentration. One should note that a molybdenum converter prevents interference from $\mathrm{HCN}$ usually seen with a stainless steel converter. The amount of $\mathrm{NO}$ and $\mathrm{NO}_{2}$ in the $\mathrm{NO}_{\mathrm{x}}$ can be determined from the analyzer data, since two flow modes are available: in the first (NO) mode, a direct path of the sample gas to the reaction chamber is used, with only the NO producing a signal. 


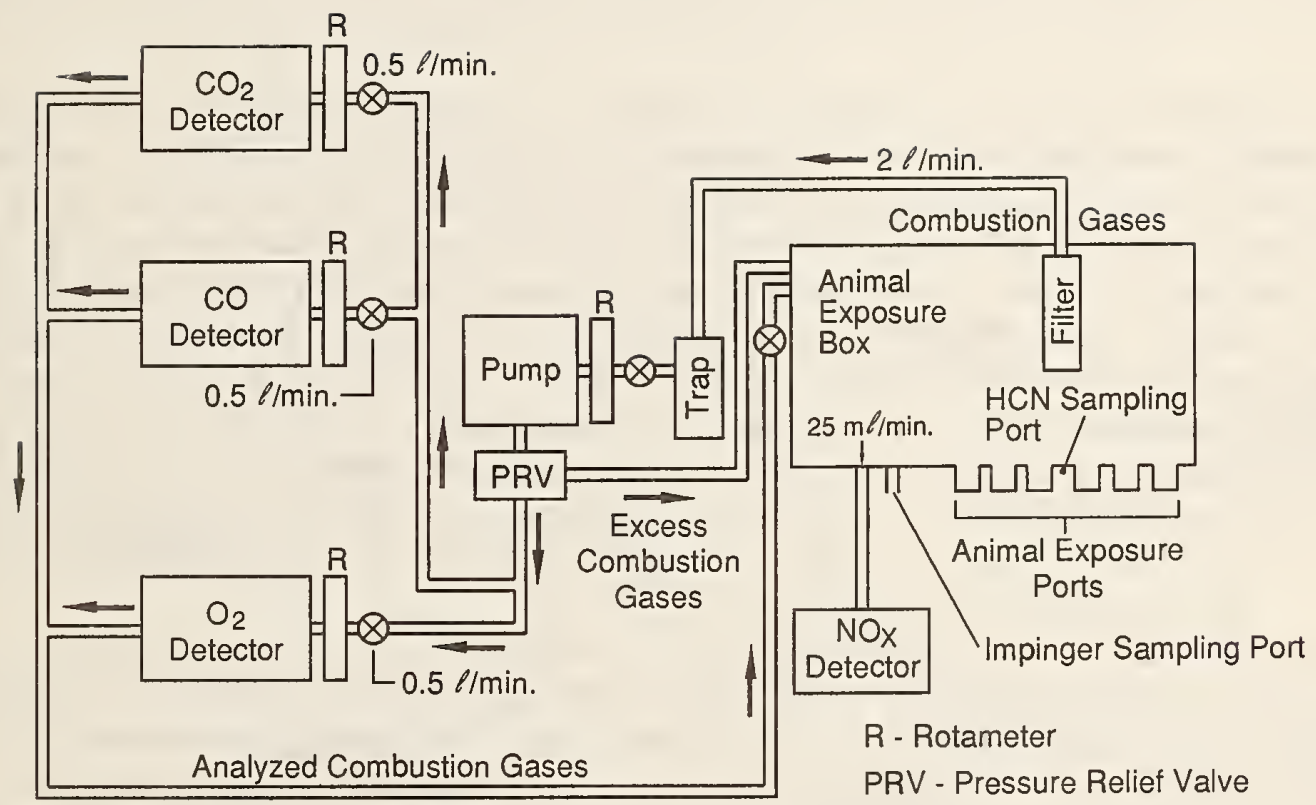

Figure 2. Gas sampling arrangements in the NBS Cup Furnace method 


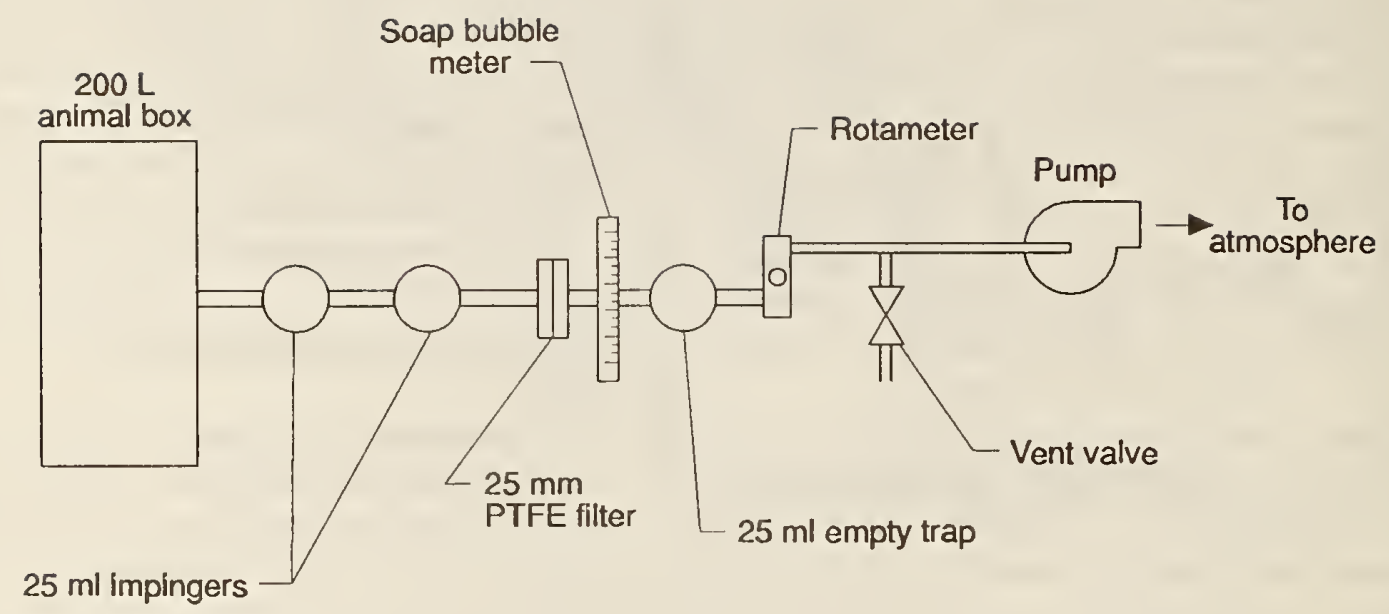

Figure 3. Impinger gas sampling in the NBS Cup Furnace method 
In the second $\left(\mathrm{NO}_{\mathrm{x}}\right)$ mode, the sample gas passes through the Mo converter and is changed to NO. Thus, the instrument responds to the total oxides of nitrogen. The amount of $\mathrm{NO}_{2}$ is estimated from the difference of the two signals.

\section{The SwRI/NIST Method}

GENERAL: This procedure, performed at SwRI, used the same apparatus (but not the same test protocol) as the proposed NIBS protocol (July 27, 1988) for toxicity testing. This method is intended, to a first approximation, to simulate post-flashover fire conditions. Unlike in the NIBS protocol, the procedure used here does not derive an 'irradiation time' or $\mathrm{IT}_{50}$ hazard index. In the section below, we will describe the work done in the present report; the reader should be advised that the procedure is developmental and will, in all likelihood, change in the future.

Figure 4 shows a general view of the apparatus; Figure 5 shows major dimensions. A modified procedure was developed at NIST for conducting tests so that additional needed information is obtained, and also so that the combustion products from the burning of the entire thickness of the specimens are evaluated, not just those from the surface layer. The procedure entails exposing fullthickness specimens to the heaters and allowing them to burn up essentially completely. The amount of pyrolysate generated is adjusted by changing the size of the exposed specimen face, and not its thickness or its time of exposure to heat. This procedure was followed by Grand and Switzer [24] in an exploratory manner. A closed system was used for these tests, consisting of a combustion cell connected to an animal exposure chamber by a chimney. Tungsten quartz lamps were used as the radiant heat source. Preliminary tests were conducted with analytical measurements, followed by animal (rat) exposures.

ANIMAL EXPOSURE CHAMBER: The animal exposure chamber was a clear polymethylmethacrylate chamber with a 200 liter nominal volume. It had inside dimensions of $1.22 \times 0.37 \times 0.45 \mathrm{~m}$. In its critical dimensions it is identical to the chamber used in the NBS Cup Furnace Method. It had a door on one of the longer sides for access to the smoke shutter, for cleaning the inside of the chamber, and for providing fresh air for the animals immediately prior to testing. There were six ports for animals to be exposed in a head-only exposure. A plastic bag with at least a $20 \ell$ volume was attached to an end port of the chamber to provide for gas expansion.

COMBustion CELL: The combustion cell was a horizontal quartz tube with a $130 \mathrm{~mm}$ inside diameter and $324 \mathrm{~mm}$ long. It was sealed at one end and had a large standard taper outer joint at the other end. A sealed inner joint served as a removable plug for the open end. The top of the cell had a rectangular opening parallel to the axis of the cylinder with a 'collar' which allowed it to fit securely into the chimney. The bottom of the cell had a hole for the rod connecting the specimen support and the load cell.

CHImney: The chimney was a stainless steel assembly $30 \times 300 \mathrm{~mm}$ (inside dimensions) and $300 \mathrm{~mm}$ high. It connected the combustion cell to the animal exposure chamber. It was divided into three channels by stainless steel dividers. The effect of the three channels was to create a heat pump action by inducing smoke to flow up the center channel, while air from the animal exposure circulated back down the other two outer channels. 


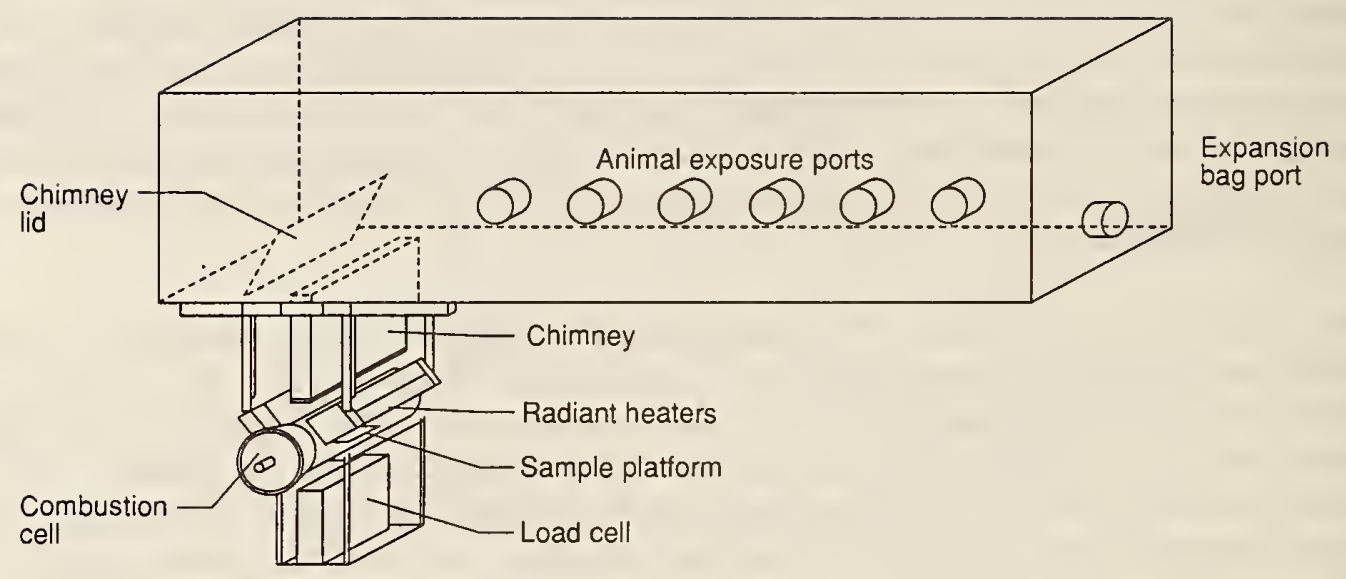

Figure 4. General view of the SwRI/NIST method 

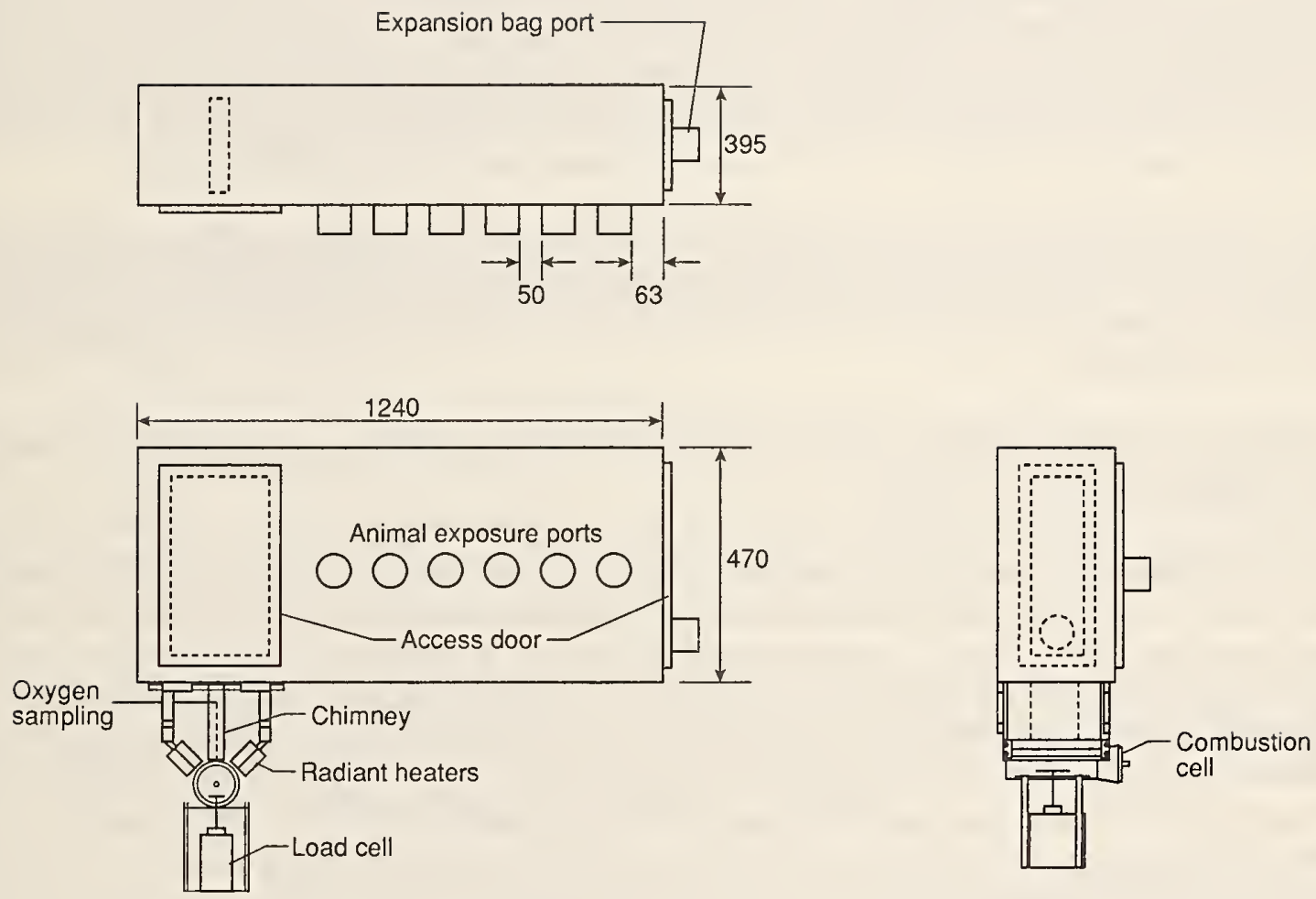

Figure 5. Major dimensions of the SwRI/NIST method 
GAS ANALYZERS: The apparatus was equipped with gas sampling ports, by which the concentrations of $\mathrm{CO}, \mathrm{CO}_{2}$, and $\mathrm{O}_{2}$ were monitored with gas analyzers. These were measured in the animal chamber, although preliminary explorations had shown that the levels in the combustion cell are not greatly different.

ANIMALS: The test animals were young adult male Sprague-Dawley albino rats weighing between 250 and $350 \mathrm{~g}$. The animals were obtained from a reputable supplier that certified its animals to be free of major respiratory pathogens. Maintenance and care of the animals was performed by qualified personnel in accordance with guidelines of the American Association of Laboratory Animal Care and regulations of the U.S. Department of Agriculture. The animals were identified and housed in a separate quarantine area for a minimum of 7 days prior to testing. During the quarantine period, the animals were observed daily and weighed periodically. The animals were housed no more than two to a cage. The environment was properly ventilated and controlled to a temperature of $23 \pm 3{ }^{\circ} \mathrm{C}$ and a relative humidity of $50 \% \pm 15 \%$. The animal room had a 12 -h light/dark cycle.

Setting Up AND Calibrating the Apparatus: The inside of the animal exposure chamber was cleaned prior to each test and a clean gas expansion bag was attached. All lines, filters, and traps for the gas analyzers were checked for satisfactory flow rates. The radiant heaters, gas analyzers, and load cell were calibrated.

TEST PROCEDURE: All specimens were conditioned for 5 days at a temperature of $23 \pm 3^{\circ} \mathrm{C}$ and a relative humidity of $50 \% \pm 10 \%$.

Tests with blackened specimens To get adequate information needed for fire modeling, it is necessary to obtain times to ignition. The heaters used in the apparatus have a spectral distribution which is different from that of real fires. It was considered that the ignitability of the specimens could be measured more realistically by blackening the surfaces of the specimens, thereby making the net heat flux absorbed similar to what occurs from flames in room fires. Initial tests were run on each sample with the surface blackened with a thin layer of carbon black (no organic binders used). These samples were the full maximum specimen size of $76 \times 127 \mathrm{~mm}(3 \times 5 \mathrm{in}$.), with the actual product thickness. The purpose of these initial tests was to determine the time to ignition and the specimen mass loss rate; since the effects of surface blackening could not be discounted as influencing the toxicity, blackened specimens were not used for any toxicity runs. Since it was desired to obtain ignitability and mass loss rate data under ambient air conditions, neither of the doors to the animal exposure chamber was closed, and the specimens were, thus, vented to the outside. The specimen irradiance used was $50 \mathrm{~kW} / \mathrm{m}^{2}$.

Iterative tests for $L C_{50}$ The procedure used can be summarized as an iterative method for determining the $\mathrm{LC}_{50}$ by reducing the surface area of the specimen exposed, but not changing the thickness, which is always the natural product thickness, up to $51 \mathrm{~mm}(2 \mathrm{in}$.) maximum. The procedure, when carried through as described, converges upon a final value of $\mathrm{LC}_{50}$. In the present study, only an approximate determination of $\mathrm{LC}_{50}$ was made, due to the exploratory nature of the work.

Each specimen was wrapped on all sides except the exposed surface with a double sheet of aluminum foil and then mounted into the specimen holder. The specimen surface was not blackened for the 
$\mathrm{LC}_{50}$ tests. The specimens were weighed on a laboratory balance capable of $\pm 0.01 \mathrm{~g}$. The specimens were weighed alone, with the aluminum foil, and with the aluminum foil in the specimen holder. After the specimen was mounted in the holder of the quartz furnace, the spark ignitor was placed $25 \mathrm{~mm}$ ( $1 \mathrm{in}$.) from the top of the specimen and in the center of the specimen surface.

To start the test, the combustion cell was closed and all timing and recording devices were readied. The power to the radiant heat lamps and ignitor were activated simultaneously with the start of the timers and recording devices. The power to the lamps was manually adjusted during the test to the desired $50 \mathrm{~kW} / \mathrm{m}^{2}$ irradiance, in accordance with a predetermined calibration.

The time to ignition of the specimen was recorded. Any unusual characteristics in the spread of flame across the specimen surface were noted. The smoke movement from the combustion cell into the animal exposure chamber was observed. Any unusual actions (e.g., lack of circulation, heavy deposition on the walls or leakage out of the apparatus) were recorded. The spark ignitor was kept on for the duration of the irradiation.

The first test (or several tests) in each series did not use animals, but was for analytical chemical purposes only. By examining the values of $\mathrm{CO}, \mathrm{CO}_{2}$, and $\mathrm{O}_{2}$ recorded during the test, it was possible to decide if the full specimen area of approximately $92 \mathrm{~cm}^{2}$ would be excessive and $100 \%$ animal mortalities might be expected.

The actual first test for $\mathrm{LC}_{50}$ where animals were used, typically involved a reduced specimen surface area, determined from the analytical results. For tests using animals, the rats were placed in their restrainers and placed into the appropriate ports in the animal exposure chamber. The doors of the exposure chamber were closed immediately prior to testing. Fresh air can be supplied by a fan in order to insure ambient conditions to the animals until just prior to exposure.

The oxygen concentration within the animal chamber was monitored during the entire test. During some tests, the oxygen level was adjusted by adding supplemental oxygen, so that the ultimate value of $\mathrm{O}_{2}$ reached would not drop as low as it naturally would. The flow rate of the test atmosphere to the analyzers was checked periodically and adjusted if necessary.

The chimney lid was closed and the power to the radiant heat lamps turned off at approximately 15 minutes, as indicated in test results. This was done to decrease the heating of the animals, since after that there was negligible further specimen mass loss. The animal exposure was continued for a total exposure time of $30 \mathrm{~min}$ (unless all of the animals died in less than $30 \mathrm{~min}$ ). The behavior of the animals was recorded during exposure. The times to cessation of breathing for any and all animals that died during exposure were recorded.

At the end of the 30-min period, the animals were removed from the exposure chamber quickly. The exposure chamber was vented with a high capacity exhaust system. After the specimen holder had cooled sufficiently, it was removed from the combustion cell, placed in a hood, and cooled to ambient temperature. The specimen still wrapped in the aluminum foil was removed from the holder and reweighed and the weight recorded. 
The live animals were carefully observed for any signs of toxic effects (e.g., difficulty in breathing, convulsions) upon removal from the exposure chamber and regularly during the post-exposure period. The number of animals that died during exposure, $1 \mathrm{~h}$ after exposure, and daily for up to 14 days post-exposure was recorded.

Tests with additional specimens of different exposed areas are then done until enough data points are accumulated to permit deriving an $\mathrm{LC}_{50}$ value. In the present study, only an approximate value of $\mathrm{LC}_{50}$ was obtained by bracketing the desired region without obtaining a unique number.

\section{Cone Calorimeter}

The Cone Calorimeter, even though it is not a bio-assay toxicity test method, was included to obtain additional data on specimen combustion behavior. This is convenient to do, since a single test can yield a large number of measurements characterizing specimen performance.

THE APPARATUS: The Cone Calorimeter (Figure 6) was initially presented in 1982 as an improved technique for measuring rate of heat release on bench-scale specimens [25]. Its operation involves an application of the oxygen consumption principle. The oxygen consumption principle [26] states that for most combustibles there is a unique constant, $13.1 \mathrm{MJ} / \mathrm{kg} \mathrm{O}$, relating the amount of heat released during a combustion reaction and the amount of oxygen consumed from the air. Thus, using this principle it is only necessary to measure the concentration of oxygen in the combustion stream, along with the flow rate.

The air flow past the specimen is generally set at $24 \mathrm{l} / \mathrm{s}$. This results in a highly fuel-lean combustion condition. Thus, when operated in the standard mode, the combustion may not be indicative of a post-flashover fire. Experiments are underway to explore the actual effects of widely varied fuel/oxygen ratios in this apparatus.

In the Cone Calorimeter, specimens of a material or product to be tested are cut into a $100 \mathrm{x}$ $100 \mathrm{~mm}$ size. The thickness depends on the type of product tested, and can range from 6 to $50 \mathrm{~mm}$. The specimen edges are protected from burning, and the specimen can be oriented either horizontally or vertically. In the present studies, all specimens were tested horizontally, face up, at full product thickness.

The specimen is heated by an electric heater in the shape of a truncated cone, hence, the name Cone Calorimeter. The irradiance to the specimen can be set to any desired value from zero to 110 $\mathrm{kW} / \mathrm{m}^{2}$. If required, external ignition of the specimen is provided by an electric spark. Since a uniform, controlled irradiance is provided, the ignition times themselves, as measured, constitute a suitable test for ignitability.

The specimen is mounted on a load cell and its mass, along with all other instrument data, is recorded every $5 \mathrm{~s}$.

A few years ago, when shortcomings of existing smoke measuring tests were becoming evident, a smoke measuring system was developed for the Cone Calorimeter. This comprises a He-Ne laser 


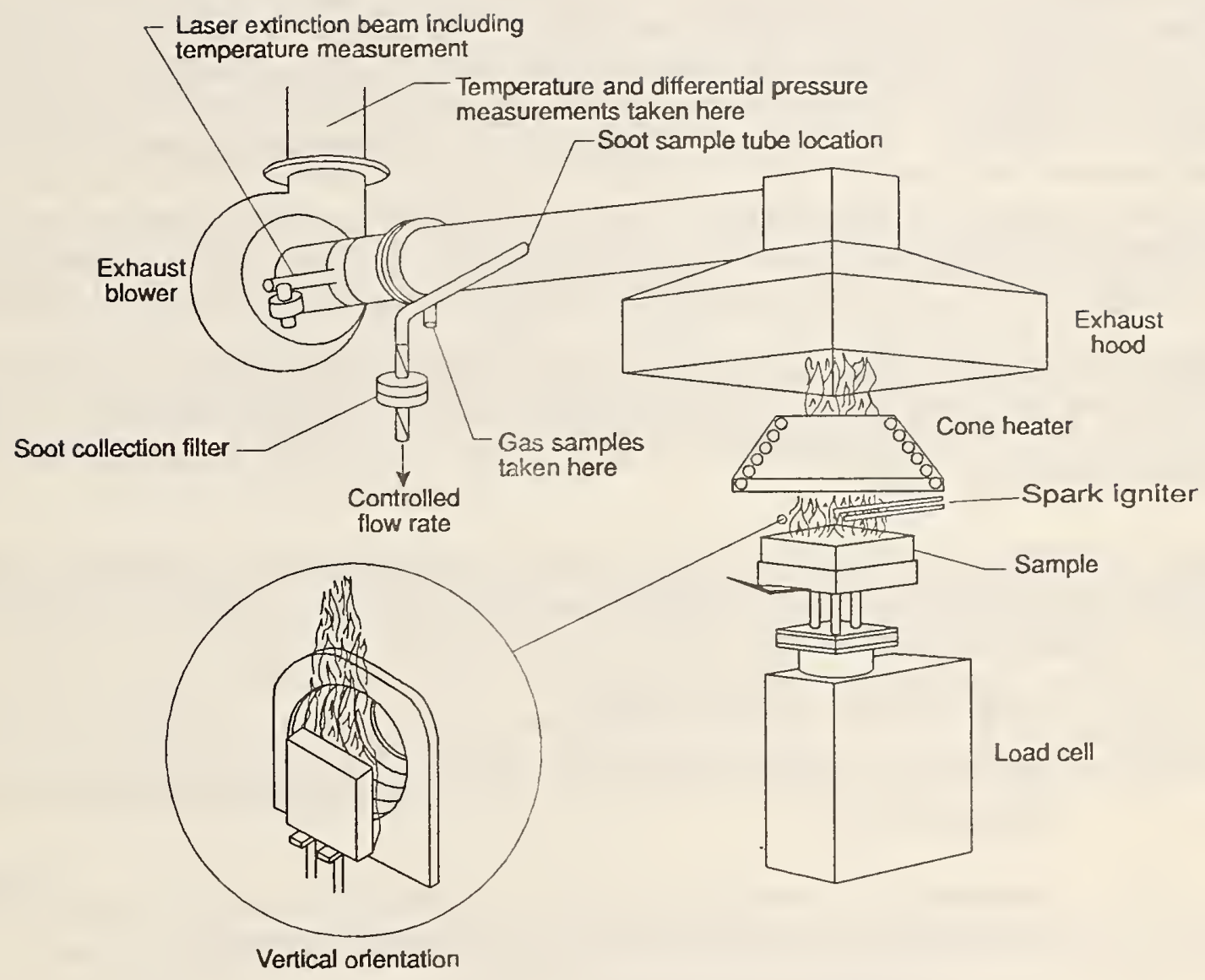

Figure 6. General view of the Cone Calorimeter 
beam projected across the exhaust duct. The monochromatic light is monitored by a solid-state detector. A second detector serves as a reference, to guard against effects of drift and of laser power fluctuations. The optical system is designed to be self-purging, and does not use optical windows. Further details of the smoke measuring system have been given in [27].

An overview of the design features, along with the specifications and limitations of the Cone Calorimeter has recently been published [28].

THE PROCEDURES: The test procedures to be used in the Cone Calorimeter are described in ASTM standard [29] and in an accompanying user's guide [30]. These procedures were followed in the present study. To specify the test conditions fully requires specifying the irradiance, the specimen orientation, the use of spark ignition, the test irradiance and any special specimen preparation techniques. The specimen thickness was, in each case, the actual product thickness. Each specimen was wrapped in a single layer of aluminum foil and tested in the horizontal orientation, using electric spark ignition. A wire grid, intended to restrain intumescing specimens, was found to be needed and was used for the RPU and PVC samples. Three irradiances were used: 35,50 , and $75 \mathrm{~kW} / \mathrm{m}^{2}$. In the typical case, three runs were made under each set of conditions.

Additional measurements were made to determine the yields of $\mathrm{HCl}$ and $\mathrm{HCN}$. A single, test-average yield of these gases was obtained by using impinger sampling and analyzing the solutions by ion chromatography. The instrumentation and the analysis procedures used were identical to those recently reported [7].

Data Collected: The data to be derived from the bench-scale tests in the Cone Calorimeter constitute a very large set, and can be analyzed in a multitude of ways. The most important variables which are presented include the following:

- peak rate of heat release $\left(\mathrm{kW} / \mathrm{m}^{2}\right)$

- rates of heat release averaged over various time periods, starting with the time of ignition $\left(\mathrm{kW} / \mathrm{m}^{2}\right)$

- effective heat of combustion $(\mathrm{MJ} / \mathrm{kg})$. This will be less than the oxygen-bomb value of the heat of combustion, since the combustion is incomplete.

- $\quad$ percent specimen mass lost (\%)

- $\quad$ time to ignition (s)

- average smoke obscuration $\left(\mathrm{m}^{2} / \mathrm{kg}\right)$. Smoke production from a material has the rational units of $\mathrm{m}^{2}$, representing the extinction cross-section of the smoke. This is normalized by the amount of specimen mass lost $(\mathrm{kg})$.

- average yields of each of the measured gas species $(\mathrm{kg} / \mathrm{kg})$. For the purpose of this study, these measurements were of the greatest interest. 


\section{Medium-scale tests}

The medium-scale tests were conducted in the Furniture Calorimeter. It is not appropriate to test wall lining materials, as such, in the Furniture Calorimeter, which is designed only for testing freestanding commodities. However, in the real-scale tests a source of ignition for the room walls was needed. It was judged that the simplest ignition source would be a crib made of the same material and placed next to the wall. (If other, more realistic, ignition sources were used, the analysis of data would have become much more difficult since each test would then comprise two different materials being tested.) It is possible to test cribs in the furniture calorimeter; thus, it was decided to obtain additional information on the performance of the test materials by burning cribs made of these materials in the Furniture Calorimeter. The burning conditions of cribs are quite different from those in a burning wall. Therefore, if these features are factors in the yields of toxicants from fullydeveloped fires, differences should appear in the analysis of the data.

The furniture calorimeter [31] was designed to measure the heat release and mass loss rates of furniture items burning in the open air. The basic principle of the apparatus is very similar to that of the Cone Calorimeter, since oxygen consumption calorimetry is also used here. Unlike in the Cone Calorimeter, however, there is no provision of imposing an overall radiant heat flux on the specimen. The specimen is merely ignited by whatever means are appropriate to the commodity being tested. Since the oxygen inflow is not restricted in this apparatus, the resultant combustion conditions are intended to simulate a fire environment most like a pre-flashover fire. A diagram of the Furniture Calorimeter is given in Figure 7.

The furniture calorimeter was employed to verify crib design in terms of the expected heat release rates and duration of burning. This information was necessary to determine the usefulness of these cribs as ignition sources for the compartment wall burning tests. Each crib was ignited with a $130 \mathrm{~mm}$ diameter pool containing $100 \mathrm{ml}$ of heptane. The ignition fuel was centered below each crib. This was sufficient to ignite the wood and rigid polyurethane foam cribs but not the polyvinylchloride (PVC) crib. The PVC crib never developed any sustained burning and self-extinguished shortly after the ignition fuel was completely consumed.

\section{Crib Design}

A crib is a regular array of sticks, commonly used in fire testing as a controlled source of combustion (Figure 8 ). The heat release rate of a burning crib can be determined by

$$
\dot{Q}=\Delta h_{c} \times \dot{m}_{f}
$$

where

$\Delta \mathrm{h}_{\mathrm{c}}$ effective heat of combustion of the crib material $(\mathrm{MJ} / \mathrm{kg})$

$\dot{\mathrm{m}}_{\mathrm{f}}$ fuel mass burning rate $(\mathrm{kg} / \mathrm{s})$. 


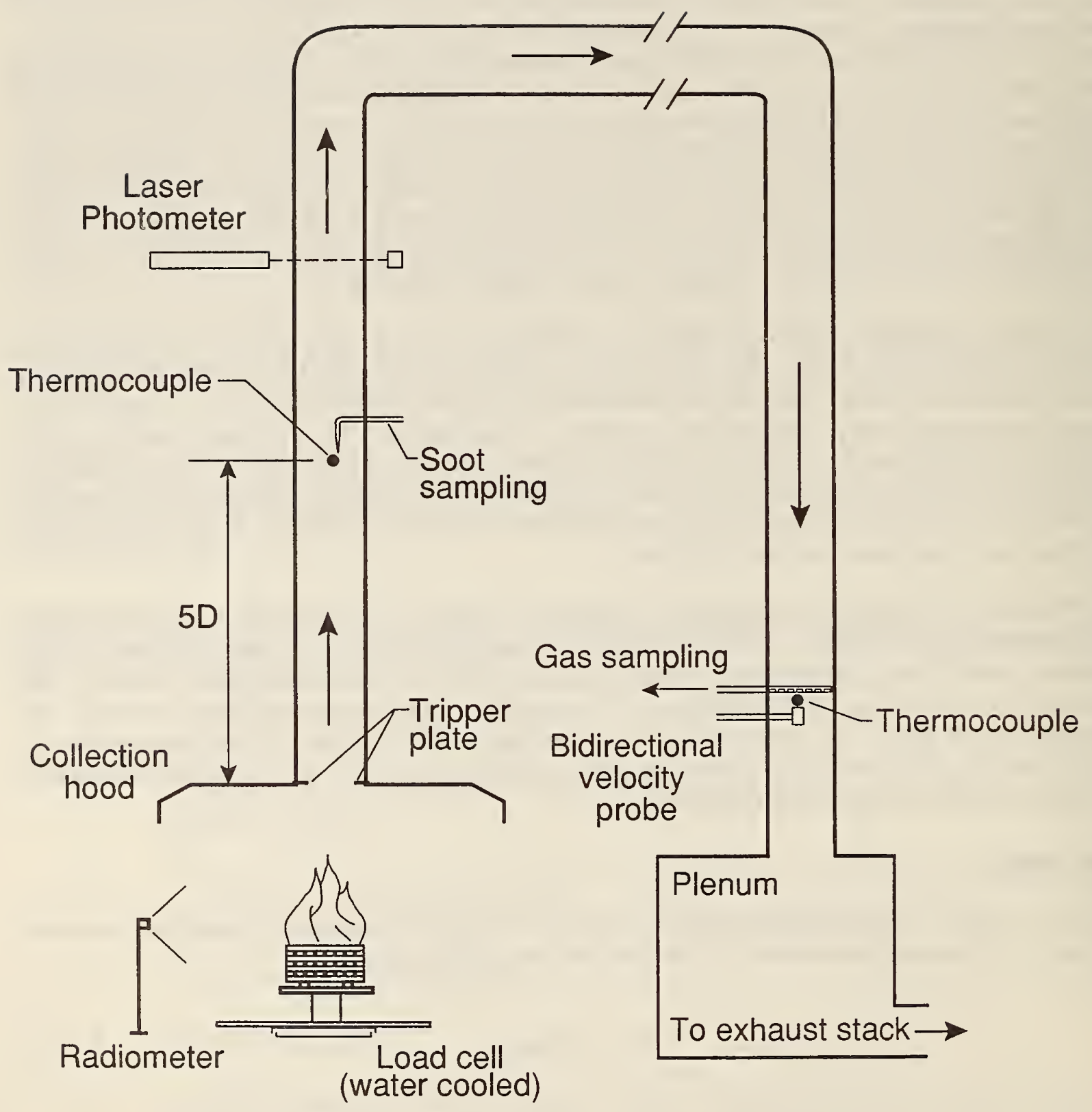

Figure 7. General view of the Furniture Calorimeter 


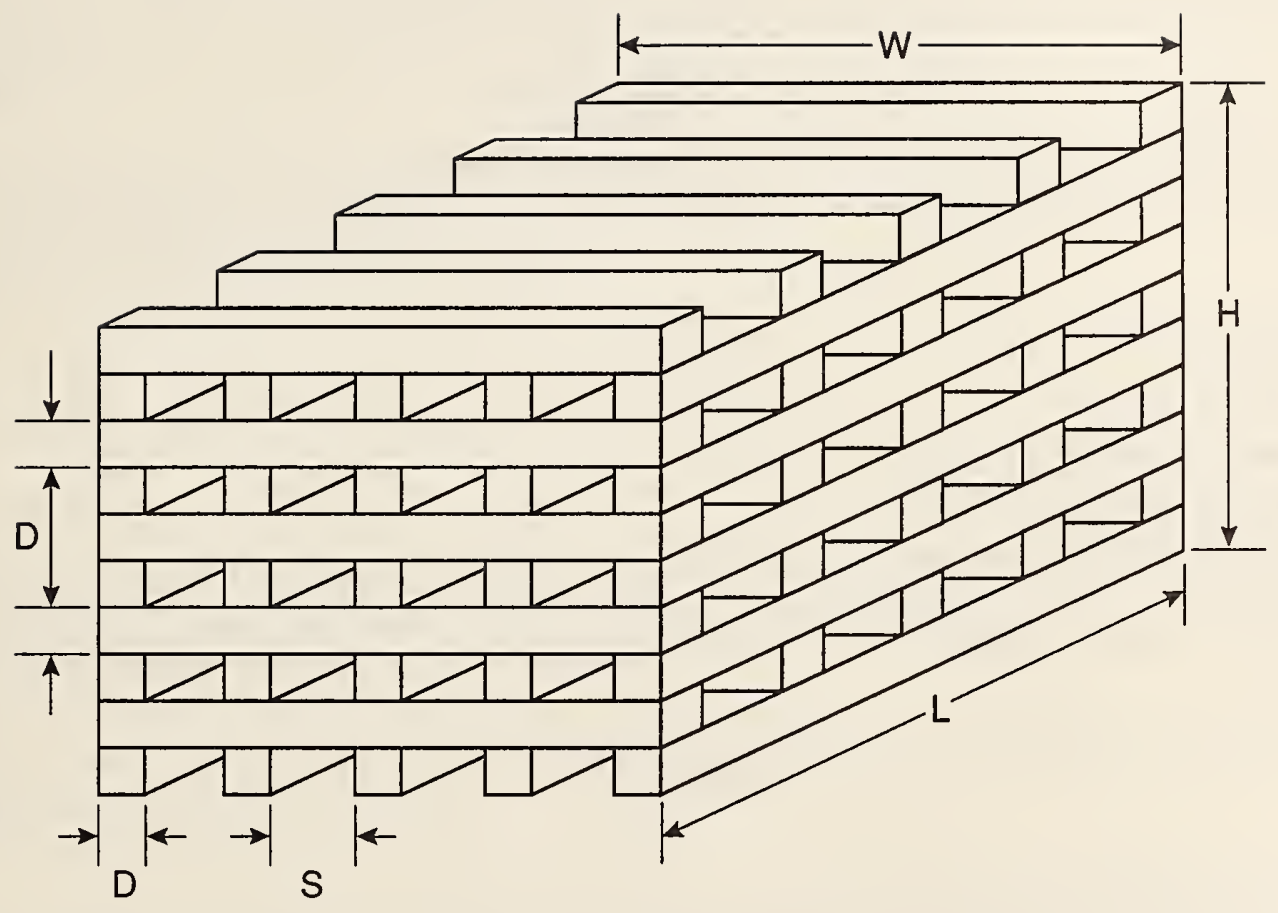

Figure 8. Construction of the test cribs 
The mass burning rate of a crib is a function of crib material, porosity, effective surface area, and stick dimension (thickness of a square stick).

Equations for predicting the burning rates of wood cribs are summarized in [32]. For freeburning cribs, the mass loss rate is the lesser of the rates given by eq. 2 or eq. 3 , below.

$$
\begin{aligned}
& \dot{m}_{f}=\frac{4}{D} m_{e} v_{p}\left(1-\frac{2 v_{p} t}{D}\right) \\
& \dot{m}_{f}=4.4 \times 10^{-4}\left(\frac{S}{H}\right)\left(\frac{m_{o}}{D}\right)
\end{aligned}
$$

where

D stick thickness $(m)$

$\mathrm{H}$ crib height $(\mathrm{m})$

$\mathrm{m}_{\mathrm{o}}$ initial crib mass $(\mathrm{kg})$

$\mathrm{S}$ clear spacing between sticks $(\mathrm{m})$

$t$ time since ignition (s)

$v_{p}$ fuel surface regression velocity $(\mathrm{m} / \mathrm{s})$.

The velocity of fuel surface regression, in turn, is given by:

$$
v_{p}=2.2 \times 10^{-6} D^{-0.6} \text {. }
$$

Equation (3) refers to a burning regime where the rate of mass loss is restricted due to tight packing of sticks; we will not be using cribs burning in this regime in the present study.

The peak mass loss rate, according to this model, occurs right after ignition and is obtained by setting $\mathrm{t}=0$ in eq 2 .

The primary source of data available on the burning of RPU cribs is from [33]. The density of the cribs studied there was about seven times that of the present specimens; thus, applicability of these equations is not clear. Nonetheless, the following equations were used:

$$
\dot{m}_{f}^{\prime \prime}=c D^{-0.5}
$$

and 


$$
\dot{m}_{f}=\dot{m}_{f}^{\prime \prime} \times 4 D \operatorname{LnN}
$$

where

$$
\begin{array}{ll}
\mathrm{L} & \text { length of stick (m) } \\
\mathbf{n} & \text { number of sticks per layer } \\
\mathrm{N} & \text { number of layers }
\end{array}
$$

and $\mathrm{c}\left(\mathrm{kg} \cdot \mathrm{m}^{-1.5} \cdot \mathrm{s}^{-1}\right)$ is characteristic of the material. For the rigid polyurethane studied in [33], a value of $c=1.2 \times 10^{-3}$ was seen. The equation is used to describe a 'steady-state', rather than peak, burning rate of the crib. For the same time comparison with wood data, a value of $c=0.88 \times 10^{-3}$ was suggested.

Delichatsios [34] studied the parameters controlling the fire growth of wood cribs. He found that the time for the flames to spread from a small ignition source below the center of a wood crib to the outer edge of a crib could be described by

$$
t_{0}=\frac{n}{\xi \sqrt{2}}
$$

where $\xi$ is a material dependent parameter. Equation (7) was taken as the time to reach 'steadystate' burning. From the work of Delichatsios, $\xi$ was taken as $0.045 \mathrm{~s}^{-1}$ for wood. For rigid polyurethane foam, $\xi$ was estimated from [33] as $0.03 \mathrm{~s}^{-1}$.

The duration of 'steady-state,' $t_{\mathrm{B}}$, was based on the mass loss between $5 \%$ weight loss and $55 \%$ weight loss and the mass burning rate of a crib such that

$$
t_{B}=\frac{\left(m_{55}-m_{5}\right)}{\dot{m}_{f}}
$$

where

$\mathrm{m}_{55}$ sample mass at $55 \%$ of total mass

$\mathrm{m}_{5}$ sample mass at $5 \%$ of total mass.

Cribs were designed such that the $\dot{Q}$ of a single crib would not be sufficient to flashover the compartment, but would be sufficient to ignite the material lining the wall. The actual designs of the cribs chosen are given below. No data are available in the literature for PVC cribs; therefore, PVC cribs were made according to the dimensions of the RPU crib. 
WOOD CRIB:

Total Crib Size: $\quad 580 \times 580 \times 445 \mathrm{~mm}(\mathrm{~W} \times \mathrm{L} \times \mathrm{H})$

stick length: $\quad 580 \mathrm{~mm}$

square stick: $\quad 45 \mathrm{~mm}(\mathrm{D})$

stick space: $\quad 89 \mathrm{~mm}(\mathrm{~S})$

sticks/layer: $\quad 5$

layers/crib: $\quad 10$

crib mass: $\quad 23 \mathrm{~kg}$

Rigid PolyURETHANe CRIB:

Total Crib Size: $\quad 330 \times 330 \times 254 \mathrm{~mm}(\mathrm{~W} \times \mathrm{L} \times \mathrm{H})$

stick length: $\quad 330 \mathrm{~mm}$

square stick: $\quad 25 \mathrm{~mm}(\mathrm{D})$

stick space: $\quad 51 \mathrm{~mm}(\mathrm{~S})$

sticks/layer: $\quad 5$

layers/crib: $\quad 10$

crib mass: $\quad 1.0 \mathrm{~kg}$

POLYVINYL CHLORIDE CRIB:

Total Crib Size: $\quad 330 \times 330 \times 254 \mathrm{~mm}(\mathrm{~W} \times \mathrm{L} \times \mathrm{H})$

stick length: $\quad 330 \mathrm{~mm}$

square stick: $\quad 25 \mathrm{~mm}(\mathrm{D})$ [formed by two pieces of $12.7 \mathrm{~mm}$ sticks]

stick space: $\quad 51 \mathrm{~mm}(\mathrm{~S})$

sticks/layer: $\quad 5$

layers/crib: $\quad 10$

crib mass: $\quad 16 \mathrm{~kg}$

The cribs were constructed as shown in Figure 8 and were held together with nails. The cribs were sized so that the wall materials would be sufficiently well ignited to lead to room flashover, but that flashover would not be so soon after ignition that pre-flashover measurements would be made difficult.

\section{Real-Scale tests}

\section{Tests conducted}

For each of the materials, a preliminary real-scale test was conducted with no test animals. The purpose of this test was to obtain gas data to ascertain whether suitable conditions for exposing the animals existed. The animal testing sequence consisted of at least two real-scale tests for each 
material. This allowed animal exposures to be made at slightly different times and, thus, better approximate an $\mathrm{LC}_{50}$.

\section{Test arrangement}

The real-scale test facility comprised a collinear burn room/corridor/target room arrangement, similar, although not identical, to that used in a previous study [7]. Figure 9 shows the layout. The burn room was lined with the test material on the end wall. The ignition source was, typically, one of the cribs described in the previous sections (but this varied according to the specific test; see Results). The measurements were taken primarily in the target room. The dimensions were:

\section{The test rooms}

\section{ROOM SIZES:}

Burn Room: $2.4 \mathrm{~m}$ wide $\times 3.7 \mathrm{~m}$ long $\times 2.4 \mathrm{~m}$ high

Corridor: $2.4 \mathrm{~m}$ wide $\times 4.6 \mathrm{~m}$ long $\times 2.4 \mathrm{~m}$ high

Target Room: $2.4 \mathrm{~m}$ wide $\times 3.7 \mathrm{~m}$ long $\times 2.4 \mathrm{~m}$ high

\section{DOORWAY OPENINGS:}

Burn Room/Corridor Opening: $2.03 \mathrm{~m}$ high $\times 0.76 \mathrm{~m}$ wide

Target Room/Corridor Opening: $2.03 \mathrm{~m}$ high $\times 0.76 \mathrm{~m}$ wide

Target Room/Atmosphere Opening: $1.75 \mathrm{~m}$ high $\times 0.95 \mathrm{~m}$ wide

The openings were chosen so as to provide for a well-ventilated fire during crib burning, but so as to be under-ventilated after the onset of flashover [35].

Walls and ceilings were made of $12.7 \mathrm{~mm}$-thick gypsum wallboard, covered by $12.7 \mathrm{~mm}$-thick Marinite. Floors were of reinforced concrete.

\section{Measurements taken}

Measurements were taken in three basic locations:
(1) Burn room.
(2) Target room.
(3) Collection hood.

The burn room instrumentation included:

- Thermocouple trees, to determine vertical temperature distribution and the average upper gas layer temperature. One tree located in the doorway opening, second tree in a room corner away from fire source.

- Static pressure probe, located $0.075 \mathrm{~m}$ above floor level, to assist in determining doorway flow rates.

- A video camera with a wide angle lens for video taping of each test. 


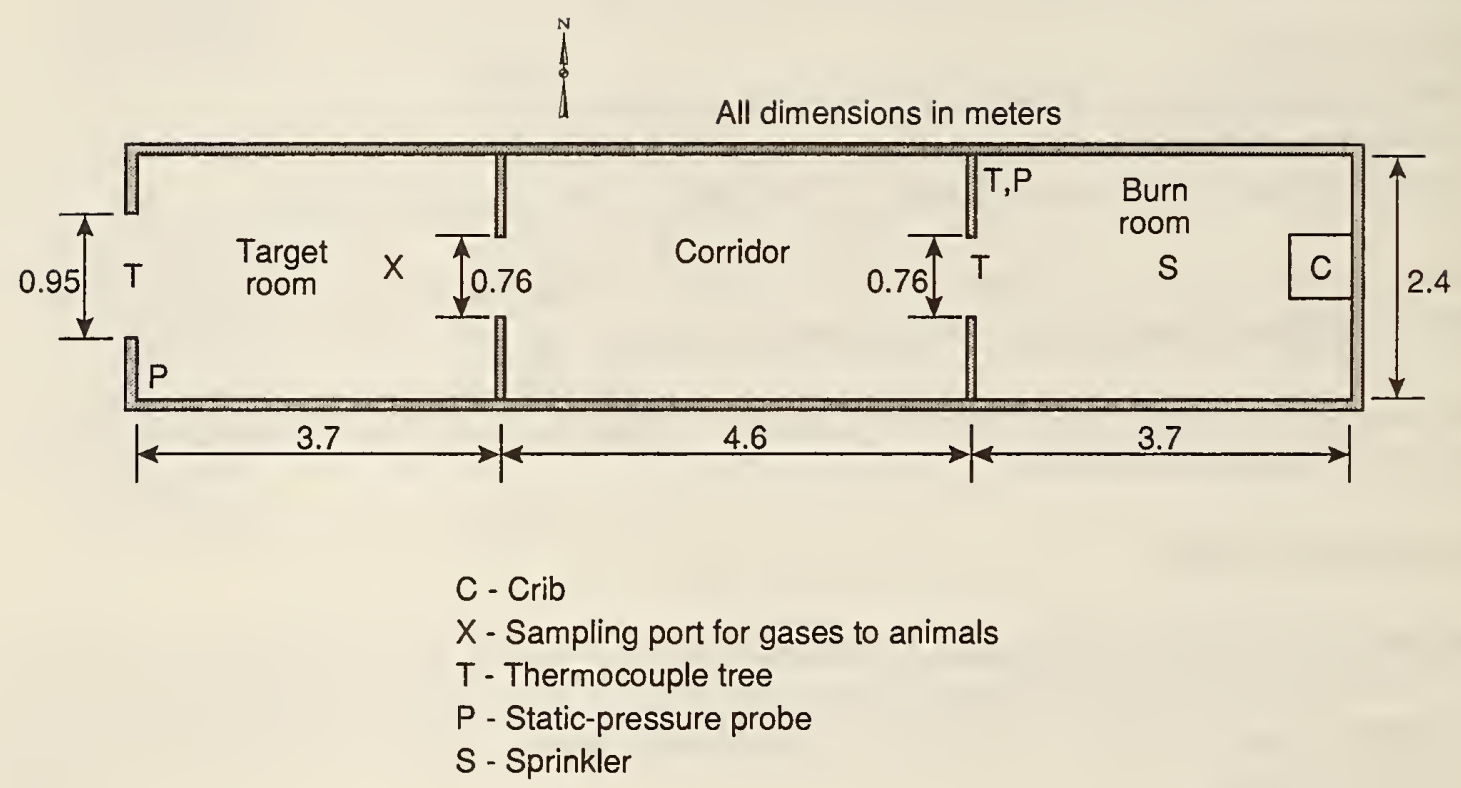

Figure 9. Layout of the burn room/corridor/target room used for real-scale tests 
The target room instrumentation included:

- Animal exposures to upper layer gas concentration.

- Measurements of $\mathrm{O}_{2}, \mathrm{CO}, \mathrm{CO}_{2}$, and $\mathrm{HCN}$ at the bypass line ahead of the animal exposure chambers.

- Gas temperature at animal sampling probe location.

- Measurements of $\mathrm{O}_{2}, \mathrm{CO}, \mathrm{CO}_{2}, \mathrm{HCN}$ and $\mathrm{NO}_{\mathrm{x}}$ in the animal exposure chambers.

- Gas temperature in the animal exposure chambers.

- Thermocouple tree at exit doorway.

- Static pressure probe at exit doorway.

The collection hood instrumentation included:

- Total exhaust gas flow rate

- Concentrations of $\mathrm{O}_{2}, \mathrm{CO}$, and $\mathrm{CO}_{2}$.

- Measurement of smoke obscuration.

ANIMAL EXPOSURES Animal measurements were made by sampling the atmosphere near the ceiling of the target room. These target room gases were pumped to and through a set of three animal exposure boxes, located in an adjacent room. Six Fischer 344 male rats, of identical specification as described for the NBS Cup Furnace test, were exposed in each chamber in a head-only mode.

The boxes were set up to have a flow of combustion products through them from the start of the test. At the start, all animal exposure chambers contained only ambient air. As the test progressed and the exposure chambers began to fill with combustion products, it was possible to replace different amounts of the ambient air by closing the sampling valve at a predetermined time or $\mathrm{CO}$ concentration.

The sampling port was located $25 \mathrm{~mm}$ below the ceiling level of the target room, situated in the center of the room. A blower motor was installed to draw a constant flow of combustion products through the sampling port, past the take-off valves feeding three animal exposure chambers (details of the animal test chambers are shown in Figure 10), and then back into the target room. The rate of sampling from the target room for the first two tests was 10.1 and $9.7 \ell / s$. However, this sampling rate was found to be too fast and the blower motor was changed to a smaller capacity $(2.0-2.9 \mathrm{l} / \mathrm{s})$ for the remaining tests.

The sampling line from the target room to the exposure boxes was $5.1 \mathrm{~m}$ in length; the first $1.4 \mathrm{~m}$ of the sampling line was $0.047 \mathrm{~m}$ inside diameter stainless steel tubing, the remaining $3.7 \mathrm{~m}$ was 0.051 $\mathrm{m}$ inside diameter glass tubing. Orifice plates were placed into the lines supplying each exposure chamber and the bypass line so that the flow of gases into each box was approximately one fourth that of the total flow from the target room. The constant flow geometry minimized the delay times between opening the valve to an animal chamber and actually filling it with combustion product. The target room discharge initially was located at one of the ceiling corners, but was moved to discharge into the hood. 


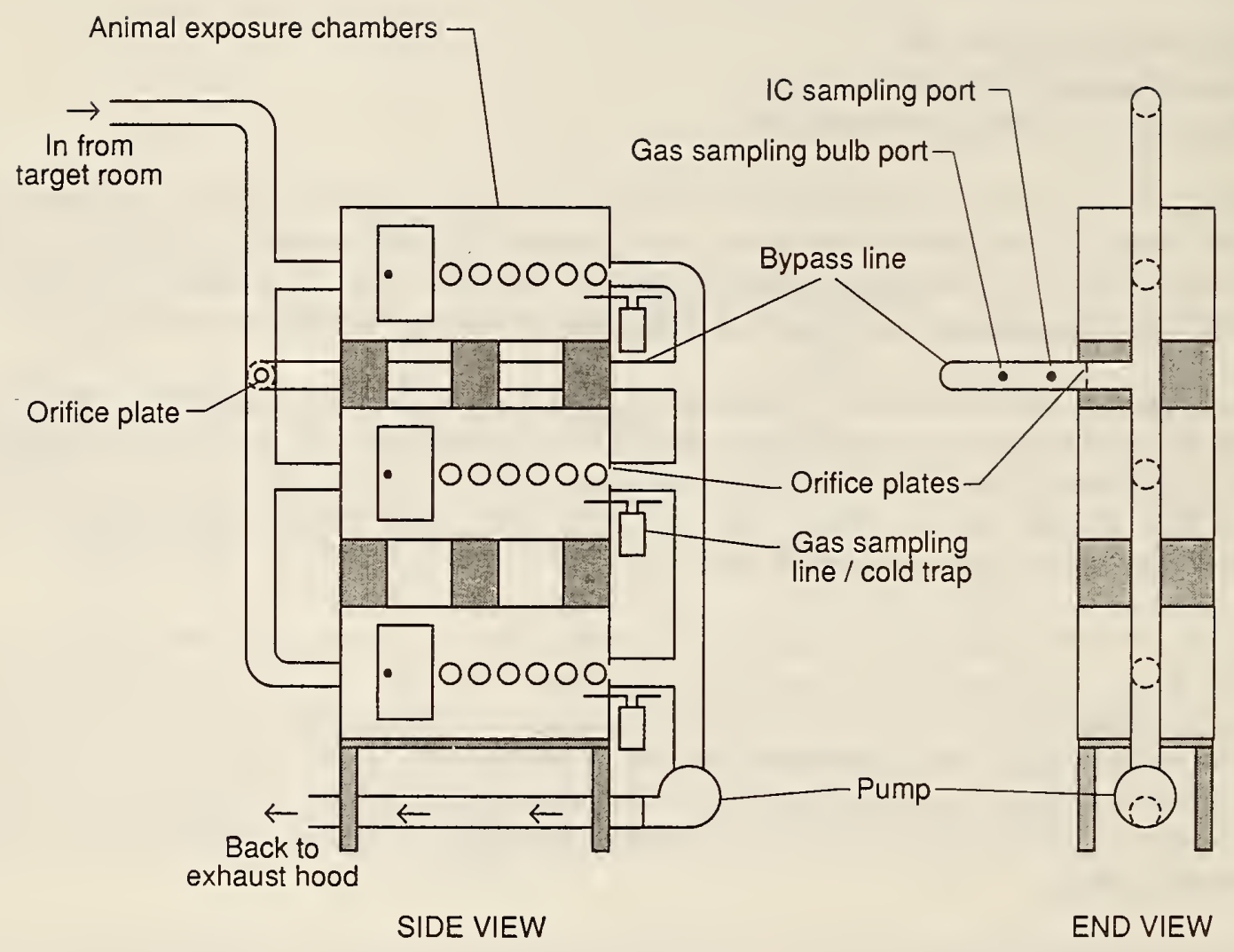

Figure 10. Installation of animal boxes in the real-scale tests 
GAS MEASUREMENTS The permanent gases, $\mathrm{O}_{2}, \mathrm{CO}_{2}$ and $\mathrm{CO}$, in each of the animal exposure chambers were measured continuously. Oxygen concentrations were measured with paramagnetic analyzers and $\mathrm{CO}_{2}$ and $\mathrm{CO}$ were monitored with infrared analyzers.

Impinger sampling for IC analysis of the acid gases $\mathrm{HCl}, \mathrm{HBr}$, and $\mathrm{HCN}$ generated in the target room was done with an apparatus similar to that shown in Figure 3. To detect the presence of $\mathrm{NO}_{\mathrm{x}}$, measurements of $\mathrm{HNO}_{3}$, and $\mathrm{HNO}_{2}$ were also made. A sampling rate of $0.9 \mathrm{l} /$ min was used, with the gases being drawn from a sampling port in the bypass line shown in Figure 10. The impingers contained dilute $\mathrm{KOH}$ solution $(5-20 \mathrm{mM})$. Gas samples were collected for 5-min intervals.

Combustion products were also collected in evacuated gas sampling bulbs from a sampling port in the bypass line shown in Figure 10 and from ports located on the side of each animal exposure chamber. The combustion products were analyzed for $\mathrm{HCN}$ by GC [23] and for $\mathrm{HCN}$ and other acid gases by IC. For the IC analyses, the previously described techniques were used.

IGNITION CRIBS Ignition was with cribs made of the same material as the test wall material. The dimensions and construction were as described above. 


\section{Results}

\section{Elemental analysis results}

A sample of each of the materials tested was submitted to a commercial laboratory for determining the elemental composition of the specimens. The results are given in Table 1. Note that the presence of $\mathrm{Cl}$ in the wood is not a measurement error. Presence of $\mathrm{Cl}$ was also noted in ion chromatography analysis during the real-scale tests. The source of this small amount of impurity in the test specimens has not been identified; it may be a residue from storage adjacent to other materials at the suppliers.

Based on the elemental analysis results, it is possible to compute what we shall term the 'notional' values of yields. These will be computed assuming that:

all $\mathrm{N}$ goes to $\mathrm{HCN}$

all $\mathrm{Cl}$ goes to $\mathrm{HCl}$

all $\mathrm{C}$ that did not go to $\mathrm{HCN}$ goes to $\mathrm{CO}_{2}$

all $\mathrm{H}$ that did not go to $\mathrm{HCN}$ or $\mathrm{HCl}$ goes to $\mathrm{H}_{2} \mathrm{O}$.

Thus, in the latter two cases, the yield of $\mathrm{CO}_{2}$ is computed as

$$
f_{\mathrm{CO}_{2}}=3.67\left[C-\frac{12}{14} N\right]
$$

and the yield of $\mathrm{H}_{2} \mathrm{O}$ as

$$
f_{H_{2} \mathrm{O}}=18\left[H-\frac{1}{14} N-\frac{1}{35.5} C l\right]
$$


Table 1. Elemental analysis of the materials in the study

\begin{tabular}{|c|c|c|c|c|c|c|c|c|}
\hline \multirow[b]{2}{*}{ Material } & \multicolumn{7}{|c|}{ Element } & \multirow{2}{*}{$\begin{array}{l}\text { Sum for } \\
\text { element } \\
\text { analyzed } \\
\text { (\%) }\end{array}$} \\
\hline & $\begin{array}{c}C \\
(\%)\end{array}$ & $\begin{array}{l}\mathrm{H} \\
(\%)\end{array}$ & $\begin{array}{l}0 \\
(\%)\end{array}$ & $\begin{array}{c}\mathrm{N} \\
(\%)\end{array}$ & $\begin{array}{l}\mathrm{Cl} \\
(\%)\end{array}$ & $\begin{array}{c}\mathrm{Br} \\
(p p m)\end{array}$ & $\begin{array}{l}P \\
(\%)\end{array}$ & \\
\hline DF & 48.06 & 6.23 & 45.26 & $0.040^{\mathrm{a}}$ & $52^{\mathrm{b}}$ & $<58$ & 0.0021 & 100 \\
\hline RPU & 64.75 & 6.61 & 21.53 & 6.36 & 1.37 & $<92$ & 0.12 & $>99$ \\
\hline PVC & 38.05 & 4.93 & 3.69 & $0.004^{\mathrm{a}}$ & 43.08 & $<62$ & $<0.08$ & 89.7 \\
\hline $\begin{array}{l}\text { a. } \\
\text { b. }\end{array}$ & sen b & & & & & & & \\
\hline
\end{tabular}

\begin{tabular}{|l|c|c|c|c|}
\hline \multirow{2}{*}{ Material } & \multicolumn{4}{|c|}{ Notional yields for complete combustion } \\
\cline { 2 - 5 } & $\begin{array}{l}\text { Yield } \\
\mathrm{CO}_{2} \\
(\mathrm{~g} / \mathrm{g})\end{array}$ & $\begin{array}{l}\text { Yield } \\
\mathrm{H}_{2} \mathrm{O} \\
(\mathrm{g} / \mathrm{g})\end{array}$ & $\begin{array}{c}\text { Yield } \\
\mathrm{HCN} \\
(\mathrm{g} / \mathrm{g})\end{array}$ & $\begin{array}{c}\text { Yield } \\
\mathrm{HCl} \\
(\mathrm{g} / \mathrm{g})\end{array}$ \\
\hline $\mathrm{DF}$ & 1.76 & 1.12 & 0.077 & 0.00005 \\
\hline RPU & 2.17 & 1.10 & 0.123 & 0.014 \\
\hline PVC & 1.40 & 0.67 & 0.008 & 0.443 \\
\hline
\end{tabular}

where $\mathrm{C}, \mathrm{N}, \mathrm{H}$, and $\mathrm{Cl}$ denote the mass fractions in the fuel of carbon, nitrogen, hydrogen, and chlorine, respectively. It is not, of course, expected that actual yields measured in any of the tests should correspond to these notional yields listed in Table 1; nonetheless, they are useful as indicators.

A significant amount of chlorine was found in the RPU upon analysis. This strongly suggests that while the material may not be claimed as FR by its manufacturer, for the purposes of understanding its fire behavior it may be more appropriate to consider it as being FR-treated.

\section{Bench-Scale results}

\section{NBS Cup Furnace Method}

The results are given in Tables $2-7$. Note that the respiration rates of the animals were not monitored, thus, the yields of $\mathrm{CO}_{2}$ are not corrected for the (relatively small) contribution due to respiratory expiration from the animals. 
Table 2. Chemical results for DF using the NBS Cup Furnace method

\begin{tabular}{|c|c|c|c|c|c|c|c|c|}
\hline \multicolumn{2}{|c|}{ Mass/chamber vol: } & \multirow{2}{*}{$\begin{array}{l}\text { Initial } \\
\text { temp. of } \\
\text { furnace } \\
\left({ }^{\circ} \mathrm{C}\right)\end{array}$} & \multicolumn{6}{|c|}{ Average gas concentration ${ }^{\mathbf{a}}$} \\
\hline $\begin{array}{c}\text { Loaded } \\
(m g / \ell)\end{array}$ & $\begin{array}{l}\text { Consumed } \\
(m g / \ell)\end{array}$ & & $\begin{array}{l}\mathrm{O}_{2} \\
(\%)\end{array}$ & $\begin{array}{c}\mathrm{CO} \\
(p p m)\end{array}$ & $\begin{array}{c}\mathrm{CO}_{2} \\
(p p m)\end{array}$ & $\begin{array}{l}\mathrm{HCN} \\
(\text { ppm })\end{array}$ & $\begin{array}{c}\mathrm{HCl} \\
(p p m)\end{array}$ & $\underset{(p p m)}{\mathrm{NO}_{\mathrm{x}}}$ \\
\hline 40 & 40 & 524 & 17.9 & 3400 & 27000 & NM & ND & NM \\
\hline $44^{\mathrm{c}}$ & NM & 527 & 17.8 & 3700 & 28000 & NM & 61 & 5 \\
\hline 45 & 45 & 527 & 17.5 & 3800 & 32000 & NM & NM & NM \\
\hline $46^{\mathrm{c}}$ & 46 & 524 & 17.6 & 3800 & 27000 & NM & 340 & 9 \\
\hline 47 & 47 & 526 & 17.6 & 3800 & 30000 & NM & NM & NM \\
\hline 50 & 50 & 524 & 17.7 & 4000 & 29000 & NM & NM & NM \\
\hline \multicolumn{9}{|c|}{ Average for the 30 min period. } \\
\hline \multicolumn{9}{|c|}{$\begin{array}{l}\text { The autoignition temperature was } 510^{\circ} \mathrm{C} \text {. Flaming was initiated with a sparker and started between } \\
0.5 \text { and } 2.5 \mathrm{~min} \text { and continued for } 4.8 \text { to } 6.3 \mathrm{~min} \text {. }\end{array}$} \\
\hline c. & \multicolumn{8}{|c|}{ Analytical test, no animals. } \\
\hline ND & \multicolumn{8}{|c|}{ Not detected. } \\
\hline NM & \multicolumn{8}{|c|}{ Not measured. } \\
\hline
\end{tabular}

\begin{tabular}{|c|c|c|c|c|c|}
\hline \multicolumn{2}{|c|}{ Mass/chamber vol. } & \multicolumn{2}{c|}{ Maximum gas concentration } & \multicolumn{2}{c|}{ Yields } \\
\hline $\begin{array}{c}\text { Loaded } \\
(\mathrm{mg} / \mathrm{l})\end{array}$ & $\begin{array}{c}\text { Consumed } \\
(\mathrm{mg} / \mathrm{l})\end{array}$ & $\begin{array}{c}\mathrm{CO} \\
(\mathrm{ppm})\end{array}$ & $\begin{array}{c}\mathrm{CO}_{2} \\
(\mathrm{ppm})\end{array}$ & $\begin{array}{c}\mathrm{CO} \\
(\mathrm{g} / \mathrm{g})\end{array}$ & $\begin{array}{c}\mathrm{CO}_{2} \text { e } \\
(\mathrm{g} / \mathrm{g})\end{array}$ \\
\hline 40 & 40 & 5900 & 33000 & 0.17 & 1.5 \\
44 & $44^{\mathrm{d}}$ & 7200 & 33000 & 0.19 & 1.3 \\
45 & 45 & 6800 & 38000 & 0.18 & 1.5 \\
46 & 46 & 7500 & 33000 & 0.19 & 1.3 \\
47 & 47 & 7700 & 37000 & 0.19 & 1.4 \\
50 & 50 & 8300 & 38000 & 0.19 & 1.4 \\
\hline d. $\quad$ Estimated \\
e. $\mathrm{CO}_{2}$ values not corrected for respiration of the animals \\
\hline
\end{tabular}

Autoignition TEMPERATURES: The autoignition temperatures of Douglas fir, the rigid polyurethane foam, and the PVC were found to be 510,550 , and $600{ }^{\circ} \mathrm{C}$, respectively. Since these tests were performed in the flaming mode, the temperature of the furnace was set 15 to $25^{\circ} \mathrm{C}$ above the predetermined autoignition temperature.

Chemical AND Toxicological Results: In the Tables, the average gas concentrations are obtained from the integrated areas under the instrument response curves for the 30 -min animal 
Table 3. Toxicological results for DF using the NBS Cup

Furnace method

\begin{tabular}{|c|c|c|c|c|c|c|}
\hline \multicolumn{2}{|c|}{ Mass/chamber vol. } & \multicolumn{2}{|c|}{$\mathrm{FED}^{\mathrm{a}}$} & \multicolumn{2}{|c|}{ No. died/ no. tested } & \multirow{2}{*}{$\begin{array}{l}\text { Latest day } \\
\text { of death }\end{array}$} \\
\hline $\begin{array}{l}\text { Loaded } \\
(m g / l)\end{array}$ & $\begin{array}{c}\text { Consumed } \\
(m g / l)\end{array}$ & WE & $\begin{array}{r}\text { WE } \\
+ \\
\mathrm{PE}\end{array}$ & WE & $\begin{array}{l}\text { WE } \\
+ \\
P E\end{array}$ & \\
\hline 40 & 40 & 0.86 & NA & $0 / 6$ & $0 / 6$ & - \\
\hline 45 & 45 & 1.00 & NA & $3 / 6$ & $3 / 6$ & 0 \\
\hline 47 & 47 & 0.98 & NA & $3 / 6$ & $3 / 6$ & 0 \\
\hline 50 & 50 & 1.00 & NA & $4 / 6$ & $4 / 6$ & 0 \\
\hline $\begin{array}{l}\text { a. } \\
\text { NA } \\
\text { PE } \\
\text { WE }\end{array}$ & $\begin{array}{l}\text { FED values wer } \\
\text { Not applicable } \\
\text { Post-exposure } \\
\text { Within exposure }\end{array}$ & culat & do & $\mathrm{CO}_{2}$ & & \\
\hline
\end{tabular}

exposure period divided by 30 minutes (i.e., ppm-min/30 min). Figure 11 illustrates the specific results from one particular test (RPU at $12 \mathrm{mg} / \ell$ ) to give an indication of how closely average values represent the time-varying actual measurements.

Based on the data given, $\mathrm{LC}_{50}$ (mass consumed) values were computed as follows, with the $95 \%$ confidence interval given in parentheses:

$\begin{array}{lcc}\text { Material } & \begin{array}{c}\text { Within exposure } \\ (\mathrm{mg} / \ell)\end{array} & \begin{array}{c}\text { Within exposure }+\mathbf{1 4} \text { days } \\ (\mathrm{mg} / \ell)\end{array} \\ \mathrm{DF} & 46(41-51) & 46(41-51) \\ \text { RPU } & 13(12-14) & 11(10-13) \\ \text { PVC } & >20 & 20(18-22)\end{array}$

The N-Gas Model was used to analyze the results. This model is based on studies of the toxicological interactions of up to five gases - $\mathrm{CO}, \mathrm{CO}_{2}, \mathrm{HCN}, \mathrm{HCl}$, and reduced $\mathrm{O}_{2}$ - and has been developed at NIST [15],[36],[8]. It is based on the observation that the probability of animal lethality should become $50 \%$ when the sum of the terms contributing to an effective exposure dose is close to 1.0. This summation is sometimes termed the 'Fractional Effective exposure Dose,' or FED [37]. The following equation used in this series of experiments was empirically derived to predict the death of $50 \%$ of the animals either within the 30 -min exposures or within the $30 \mathrm{~min}$ plus post-exposure period. 
Table 4. Chemical results for RPU using the NBS Cup Furnace method

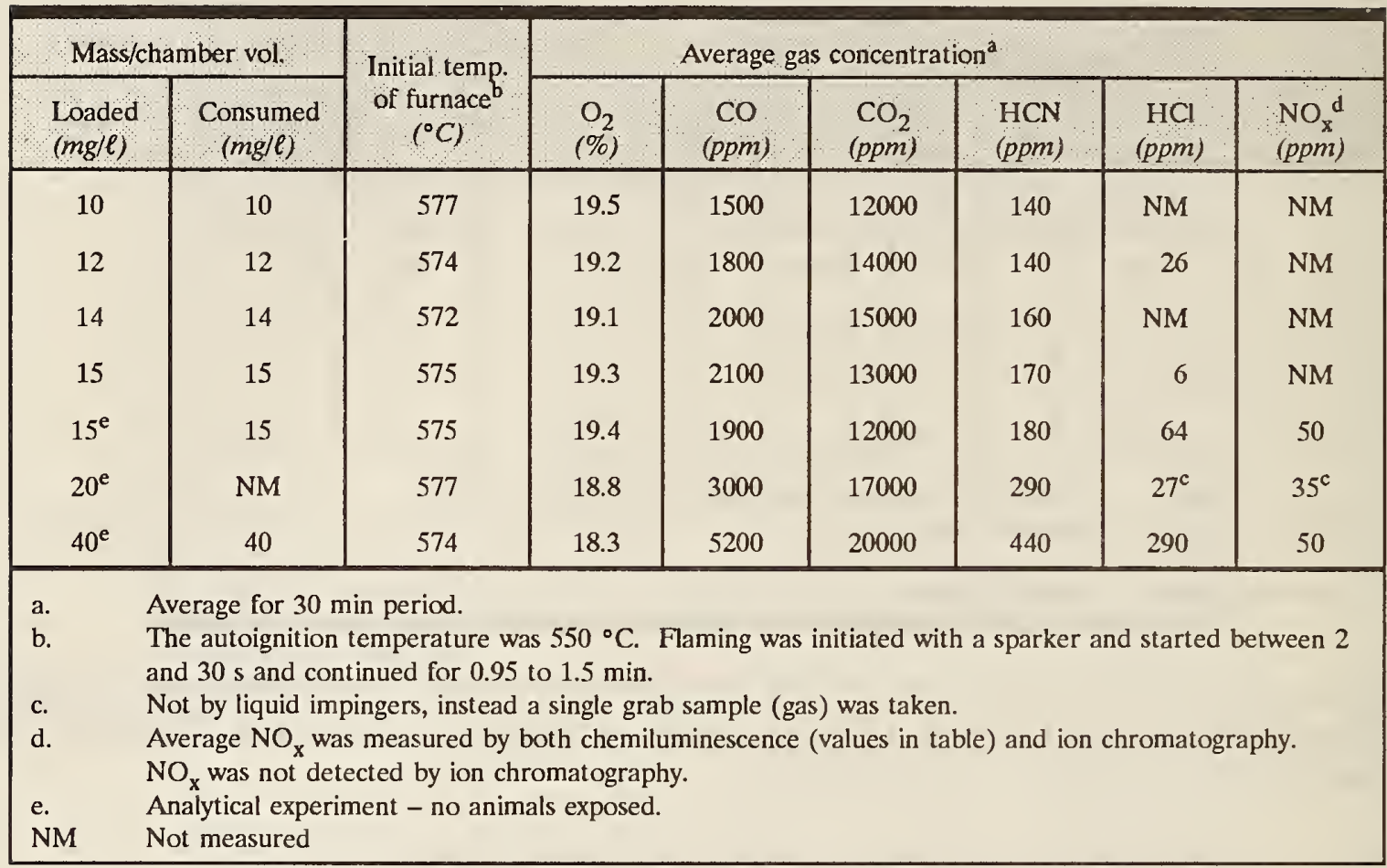

\begin{tabular}{|c|c|c|c|c|c|c|c|c|c|}
\hline \multicolumn{2}{|c|}{ Mass/chamber vol. } & \multicolumn{4}{|c|}{ Maximum gas concentration } & \multicolumn{4}{|c|}{ Yields } \\
\hline $\begin{array}{l}\text { Loaded } \\
\text { (mg/l) }\end{array}$ & $\begin{array}{c}\text { Consumed } \\
(m g / l)\end{array}$ & $\begin{array}{c}\mathrm{CO} \\
(p p m)\end{array}$ & $\underset{(p p m)}{\mathrm{CO}_{2}}$ & $\begin{array}{l}\mathrm{HCN} \\
(p p m)\end{array}$ & $\begin{array}{c}\mathrm{Hcl} \\
(p p m)\end{array}$ & $\begin{array}{l}\mathrm{CO} \\
(\mathrm{g} / \mathrm{g})\end{array}$ & $\underset{(\mathrm{g} / \mathrm{g})}{\mathrm{CO}_{2} \mathrm{~g}}$ & $\begin{array}{l}\mathrm{HCN} \\
(g / g)\end{array}$ & $\begin{array}{l}\mathrm{Hcl} \\
(\mathrm{g} / \mathrm{g})\end{array}$ \\
\hline 10 & 10 & 1810 & 14000 & 170 & NM & 0.21 & 2.6 & 0.019 & $\mathrm{NM}$ \\
\hline 12 & 12 & 2070 & 16000 & 180 & 26 & 0.20 & 2.3 & 0.017 & 0.003 \\
\hline 14 & 14 & 2480 & 17000 & 210 & NM & 0.20 & 2.2 & 0.017 & NM \\
\hline 15 & 15 & 2580 & 15000 & 230 & 6 & 0.20 & 1.9 & 0.017 & 0.001 \\
\hline 15 & 15 & 2350 & 13000 & 220 & 64 & 0.18 & 1.6 & 0.016 & 0.006 \\
\hline 20 & $20^{\mathrm{h}}$ & 3570 & 18000 & 370 & 27 & 0.21 & 1.6 & 0.020 & 0.002 \\
\hline 40 & 40 & 6720 & 22000 & 640 & 290 & 0.20 & 1.0 & 0.018 & 0.011 \\
\hline $\begin{array}{l}\text { f. } \\
\text { g. } \\
\text { h. } \\
\text { NM }\end{array}$ & $\begin{array}{l}\text { es are an a } \\
\text { es not corr } \\
\text { ured }\end{array}$ & $\begin{array}{l}\text { for } 30 \\
\text { or resp }\end{array}$ & ion of th & nimals & & & & & \\
\hline
\end{tabular}


Table 5. Toxicological results for RPU using the NBS Cup Furnace method

\begin{tabular}{|c|c|c|c|c|c|c|}
\hline \multicolumn{2}{|c|}{ Mass/chamber vol. } & \multicolumn{2}{|c|}{$\mathrm{FED}^{\mathrm{a}}$} & \multicolumn{2}{|c|}{ No. died/ no. tested } & \multirow{2}{*}{$\begin{array}{l}\text { Lates } \\
\text { day o } \\
\text { death }\end{array}$} \\
\hline $\begin{array}{l}\text { Loaded } \\
(m g / l)\end{array}$ & $\begin{array}{l}\text { Consumed } \\
(m g / \ell)\end{array}$ & WE & $\begin{array}{c}\text { WE } \\
+ \\
\text { PE }\end{array}$ & WE & $\begin{array}{l}\text { WE } \\
+ \\
P E\end{array}$ & \\
\hline 10 & 10 & 1.0 & 1.3 & $0 / 6$ & $2 / 6$ & 1 \\
\hline 12 & 12 & 1.1 & 1.4 & $3 / 6$ & $5 / 6$ & 1 \\
\hline 14 & 14 & 1.3 & 1. 6 & $4 / 6$ & $5 / 6$ & 1 \\
\hline 15 & 15 & 1.3 & 1.6 & $5 / 6$ & $6 / 6$ & 1 \\
\hline $\begin{array}{l}\text { a. } \\
\text { PE } \\
\text { WE }\end{array}$ & $\begin{array}{l}\text { FED values we } \\
\text { Post-exposure } \\
\text { Within exposur }\end{array}$ & Iculat & $\mathrm{ed} \mathrm{c}$ & $\mathrm{CO}_{2}$ & ad $\mathrm{O}_{2}$ & \\
\hline
\end{tabular}

$$
F E D=\frac{m[\mathrm{CO}]}{\left[\mathrm{CO}_{2}\right]-b}+\frac{[\mathrm{HCN}]}{L C_{50} H C N}+\frac{[\mathrm{HCl}]}{L C_{50} \mathrm{HCl}}+\frac{21-\left[\mathrm{O}_{2}\right]}{21-L C_{50} \mathrm{O}_{2}}
$$

where the numbers in the brackets indicate the actual concentration of the gases in ppm $\left(\mathrm{CO}, \mathrm{CO}_{2}\right.$, $\mathrm{HCN}, \mathrm{HCl})$ or percent $\left(\mathrm{O}_{2}\right)$. FED $\approx 1$ predicts that approximately $50 \%$ of the animals should die.

For the formula as presented above, experimental data indicate that the $50 \%$ probability of mortality occurs at $\mathrm{FED}=1.1$, with 1 -standard deviation error bars of \pm 0.2 .

The $\mathrm{LC}_{50}$ value of $\mathrm{HCN}$ is $200 \mathrm{ppm}$ for 30 -min exposures (WE) or $150 \mathrm{ppm}$ for 30 -min exposures plus post-exposure deaths (WE + PE). Animal lethalities for $\mathrm{HCl}$ exposures are not evaluated solely WE, since the effect is only manifested $\mathrm{PE}$; the $\mathrm{LC}_{50}$ for $\mathrm{HCl}(\mathrm{WE}+\mathrm{PE})$ is taken as $3700 \mathrm{ppm}$. The $\mathrm{LC}_{50}$ value for $\mathrm{O}_{2}$ is $5.4 \%$. The terms $\mathrm{m}$ and b equal -18 and 122000 , respectively, if the $\mathrm{CO}_{2}$ concentrations are $5 \%$ or less (where $1 \%$ is equivalent to $10,000 \mathrm{ppm}$ ). For $\mathrm{CO}_{2}$ concentrations $>5 \%$, these values become $\mathrm{m}=22.7$ and $\mathrm{b}=-39,000$.

For all materials, $\mathrm{CO}, \mathrm{CO}_{2}$, and $\mathrm{O}_{2}$ were included in the $\mathrm{FED}$ computation. $\mathrm{HCN}$ and $\mathrm{HCl}$ were added if they were produced by the material. The $\mathrm{HCl}$ term was only used in the prediction of the (WE + PE) effect.

The results were similar to those found previously in this laboratory for Douglas fir and for different samples of rigid polyurethane foam and PVC [9]. In the case of the Douglas fir, all deaths occurred during or immediately after the 30 -min exposures and the $\mathrm{LC}_{50}$ value was $46 \mathrm{mg} / \ell$. The FED value was based on the combined toxicity of $\mathrm{CO}, \mathrm{CO}_{2}$ and $\mathrm{O}_{2}$ and correctly predicted the deaths of the animals. In other words, when the FED value was 1.0, three or four out of the six exposed animals died. 


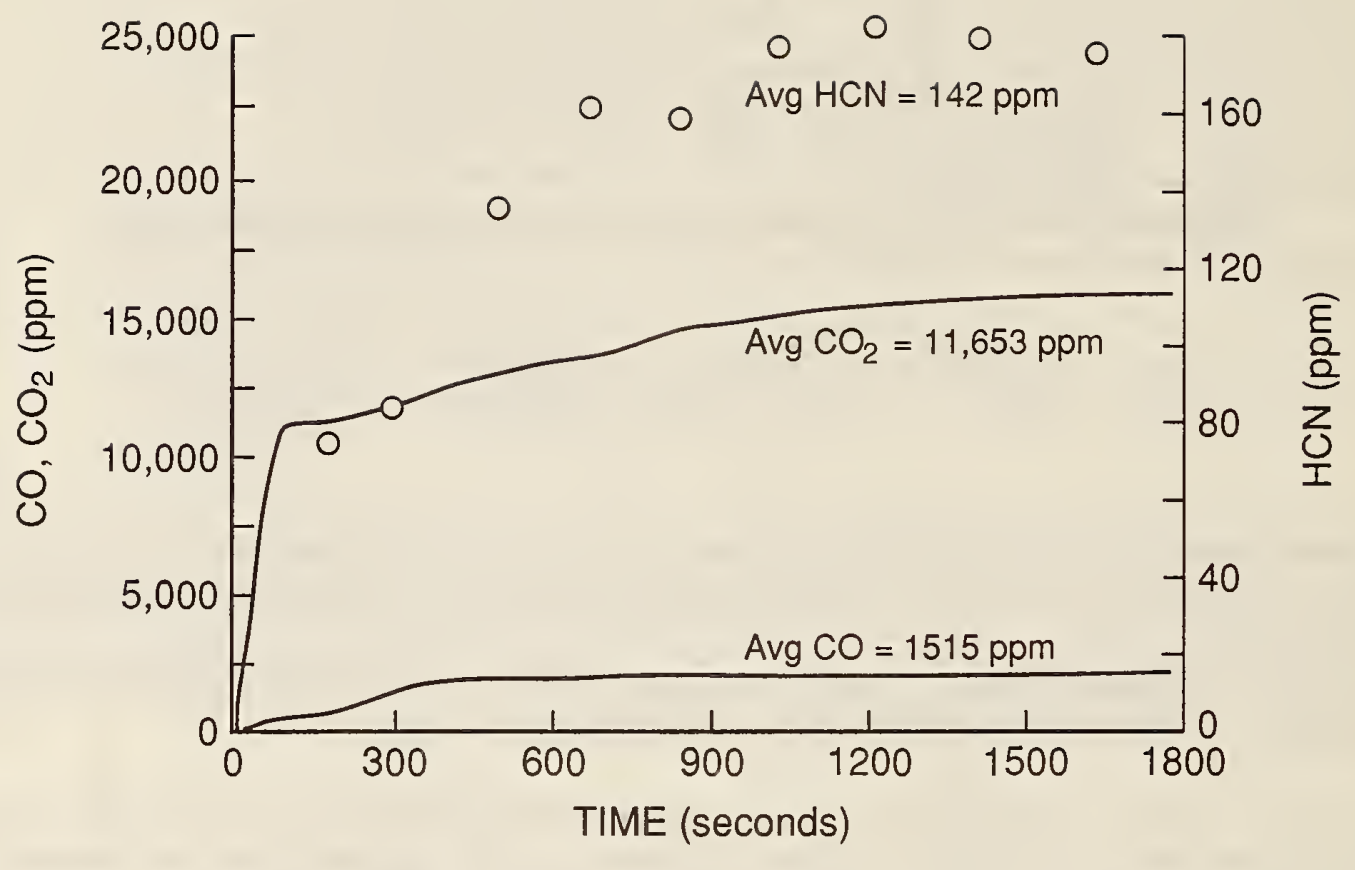

Figure 11. Typical time variation of gases within the $200 \ell$ animal box 
Table 6. Chemical results for PVC using the NBS Cup Furnace method

\begin{tabular}{|c|c|c|c|c|c|c|}
\hline \multicolumn{2}{|c|}{ Mass/chamber vol. } & \multirow{2}{*}{$\begin{array}{c}\text { Initial } \\
\text { temp. of } \\
\text { furnace } \\
\left({ }^{\circ} \mathrm{C}\right) \\
\end{array}$} & \multicolumn{4}{|c|}{ Average Gas Concentrations ${ }^{a}$} \\
\hline $\begin{array}{l}\text { Loaded } \\
(m g / \ell)\end{array}$ & $\begin{array}{c}\text { Consumed } \\
(\mathrm{mg} / \mathrm{l})\end{array}$ & & $\begin{array}{l}\mathrm{O}_{2} \\
(\%)\end{array}$ & $\begin{array}{c}\mathrm{CO} \\
\text { (ppm) }\end{array}$ & $\begin{array}{l}\mathrm{CO}_{2} \\
(\text { ppm })\end{array}$ & $\begin{array}{c}\mathrm{HCl} \\
(p p m)\end{array}$ \\
\hline $17^{\mathrm{d}}$ & 15 & 623 & 20.1 & 980 & 6900 & 2500 \\
\hline 17 & 16 & 623 & 19.8 & 1200 & 9300 & 2100 \\
\hline 18 & NM & 625 & 20.1 & 1000 & 6500 & 2800 \\
\hline $18^{\mathrm{d}}$ & 16 & 623 & 19.8 & 1300 & 9300 & 2800 \\
\hline $20^{\mathrm{d}}$ & 18 & 625 & 19.8 & 1400 & 9000 & $3700^{c}$ \\
\hline 20 & 18 & 623 & 19.9 & 1300 & 7900 & 3000 \\
\hline $\begin{array}{l}\text { a. } \\
\text { b. } \\
\text { c. }\end{array}$ & $\begin{array}{l}\text { ge for } 30 \text { - } \\
\text { utoignitior } \\
\text { d between } \\
\text { on bulbs }\end{array}$ & $\begin{array}{l}\text { riod. } \\
\text { erature } \\
\text { nd } 1.83 \\
\text { at } 10 \text { at }\end{array}$ & cor & $\begin{array}{l}\text { g wa } \\
\text { or } 0 .\end{array}$ & $\begin{array}{l}d \mathrm{wi} \\
07 \mathrm{~m}\end{array}$ & ker and \\
\hline & & pecimer & & & & \\
\hline
\end{tabular}

\begin{tabular}{|c|c|c|c|c|c|c|c|}
\hline \multicolumn{2}{|c|}{ Mass/chamber vol. } & \multicolumn{3}{|c|}{ Maximum gas concentration } & \multicolumn{3}{|c|}{ Yield } \\
\hline $\begin{array}{l}\text { Loaded } \\
(m g / \ell)\end{array}$ & $\begin{array}{c}\text { Consumed } \\
(m g / l)\end{array}$ & $\begin{array}{c}\mathrm{CO} \\
(p p m)\end{array}$ & $\begin{array}{c}\mathrm{CO}_{2} \\
(p p m)\end{array}$ & $\begin{array}{l}\mathrm{HCl}^{\mathrm{e}} \\
(p p m)\end{array}$ & $\begin{array}{c}\mathrm{CO} \\
(g / g)\end{array}$ & $\begin{array}{c}\mathrm{CO}_{2} \mathrm{f} \\
(\mathrm{g} / \mathrm{g})\end{array}$ & $\begin{array}{l}\mathrm{HC} \\
(g / g)\end{array}$ \\
\hline 17 & 15 & 1200 & 9100 & 2500 & 0.09 & 1.1 & 0.25 \\
\hline 17 & 16 & 1500 & 13000 & 2100 & 0.11 & 1.5 & 0.20 \\
\hline 18 & 16 & 1600 & 12000 & 2800 & 0.11 & 1.4 & 0.26 \\
\hline 20 & 18 & 1700 & 12000 & 3700 & 0.11 & 1.2 & 0.30 \\
\hline 20 & 18 & 1600 & 11000 & 3000 & 0.10 & 1.1 & 0.25 \\
\hline $\begin{array}{l}\text { e. } \\
\text { f. }\end{array}$ & $\begin{array}{l}\text { values } \\
\text { values }\end{array}$ & $\begin{array}{l}\text { rag } \\
\text { cted }\end{array}$ & $\begin{array}{l}\text { in. } \\
\text { ation }\end{array}$ & nimals. & & & \\
\hline
\end{tabular}

In the case of the rigid polyurethane foam, all deaths occurred during the 30-min exposures or within the first $24 \mathrm{~h}$ following the exposures. The within-exposure $\mathrm{LC}_{50}$ value was $13 \mathrm{mg} / \ell$; whereas, the within- plus post- exposure $\mathrm{LC}_{50}$ value was $11 \mathrm{mg} / \ell$. The FED values based on $\mathrm{CO}, \mathrm{CO}_{2}, \mathrm{HCN}$ and $\mathrm{O}_{2}$, appear to be somewhat high, compared to actual observed lethalities. In other words, some percentage of the animals died within-exposure at N-Gas values of 1.1 to 1.3 and within- plus postexposure at FED values of 1.3 to 1.6. The later value would suggest that an antagonistic effect may be occurring. 
No deaths occurred during the 30-min exposures to PVC smoke; all deaths occurred during the first 2 days of the post-exposure observation period. The $\mathrm{LC}_{50}$ value was $20 \mathrm{mg} / \ell$. The FED values successfully predict the post-exposure deaths and the absence of within exposure fatalities (Table 7). Note in Table 6 that some additional tests were performed on the PVC samples which included a coating of glue, since glue was used for mounting in some of the real-scale tests, as described subsequently.

The yields were computed on the basis of a nominal 200-L exposure chamber volume and a nominal room temperature. No correction was made for any (small) amount of box leakage.

$$
\begin{gathered}
f_{C O}=\frac{[\mathrm{CO} \text { ppm }] \times 0.23}{1000 \times[\text { mass sample consumed }(\mathrm{g})]} \\
f_{\mathrm{CO}_{2}}=\frac{\left[\mathrm{CO}_{2} \%\right] \times 3.9}{[\text { mass sample consumed }(\mathrm{g})]} \\
f_{H C N}=\frac{[\mathrm{HCN} \text { ppm }] \times 0.22}{1000 \times[\text { mass sample consumed }(\mathrm{g})]} \\
f_{H C l}=\frac{[\mathrm{HCl} \text { ppm }] \times 0.29}{1000 \times[\text { mass sample consumed }(\mathrm{g})]}
\end{gathered}
$$

\section{SwRI/NIST apparatus}

The results for the SwRI/NIST tests are given in Tables $8-10$. The time-varying behavior of the gases in the $200 \ell$ animal exposure box used in this test showed a very similar pattern as did the NBS Cup Furnace behavior, illustrated in Figure 11.

The scope of the investigation did not include an exact determination of the $\mathrm{LC}_{50}$. Instead, approximate values (reported to one significant figure) were obtained as follows: 
Table 7. Toxicological results for PVC using the

NBS Cup Furnace method

\begin{tabular}{|c|c|c|c|c|c|c|}
\hline \multicolumn{2}{|c|}{ Mass/chamber vol. } & \multicolumn{2}{|c|}{$\begin{array}{l}\text { FED } \\
\text { Value }^{\mathrm{a}}\end{array}$} & \multicolumn{2}{|c|}{ No. died/no. tested } & \multirow{2}{*}{$\begin{array}{l}\text { Latest } \\
\text { day of } \\
\text { death }\end{array}$} \\
\hline $\begin{array}{c}\text { Loaded } \\
(\mathrm{mg} / \mathrm{l})\end{array}$ & $\begin{array}{c}\text { Consumed } \\
(m g / l)\end{array}$ & WE & $\begin{array}{c}\text { WE } \\
+ \\
P E\end{array}$ & WE & $\begin{array}{c}\text { WE } \\
+ \\
\mathrm{PE}\end{array}$ & \\
\hline 17 & 15 & 0.21 & 0.90 & $0 / 5$ & $1 / 5$ & 1 \\
\hline 17 & 16 & 0.28 & 0.84 & $0 / 6$ & $1 / 6$ & 0 \\
\hline 18 & NM & 0.22 & 0.99 & $0 / 6$ & $3 / 6$ & 2 \\
\hline 18 & 16 & 0.29 & 1.0 & $0 / 6$ & $2 / 6$ & 1 \\
\hline 20 & 18 & 0.31 & 1.3 & $0 / 6$ & $4 / 6$ & 1 \\
\hline 20.1 & 18 & 0.29 & 1.1 & $0 / 6$ & $3 / 6$ & 1 \\
\hline
\end{tabular}

a. FED values based on $\mathrm{CO}, \mathrm{CO}_{2}$, and $\mathrm{O}_{2}$ for $\mathrm{WE}$ and $\mathrm{CO}, \mathrm{CO}_{2}$,

$\mathrm{O}_{2}$, and $\mathrm{HCl}$ for WE plus PE.

NM Not measured

PE Post-exposure

WE Within-exposure

$\begin{array}{lcc}\text { Material } & \begin{array}{c}\text { Within exposure } \\ (\mathrm{mg} / \ell)\end{array} & \begin{array}{c}\text { Within exposure } \\ (\mathrm{mg} / \ell)\end{array} \\ \text { DF } & 100-200 & 100-200 \\ \text { RPU } & 20-30 & 20-30 \\ \text { PVC } & >30 & 20-30\end{array}$

The analysis of FED values and of the gas yields was done in an identical manner for this test as for the NBS Cup Furnace method. The FED calculations for predicted lethalities were based on the formula given in the preceding section, which was derived on NBS Cup Furnace studies; thus any apparatus-dependence specific to the SwRI/NIST method are not taken into account. Same as for the NBS Cup Furnace method, a nominal $200 \ell$ box volume was assumed.

Only plain PVC samples were tested in the SwRI/NIST method, unlike the NBS Cup Furnace tests, where some PVC + glue samples were included.

For DF and RPU, all animal deaths occurred during the exposure. For PVC, there were no animal deaths within the exposure, all of the deaths occurring post-exposure. 
Table 8. Chemical and toxicological results for DF using the SwRI/NIST Toxicity method

\begin{tabular}{|c|c|c|c|c|c|c|c|c|c|c|c|}
\hline \multirow[b]{2}{*}{ Test } & \multirow{2}{*}{$\begin{array}{l}\text { Irrad. } \\
\text { Time } \\
\text { (min.) }\end{array}$} & \multirow{2}{*}{$\begin{array}{l}\text { Spec. } \\
\text { Area } \\
\left(\mathrm{cm}^{2}\right)\end{array}$} & \multirow{2}{*}{$\begin{array}{l}\text { Init. } \\
\text { Mass } \\
\text { (g) }\end{array}$} & & \multicolumn{2}{|c|}{ Mass loss } & \multirow{2}{*}{$\begin{array}{c}\text { Time } \\
\text { to ign. } \\
(s)\end{array}$} & \multirow{2}{*}{$\begin{array}{c}\text { Flame } \\
\text { Out } \\
(s)\end{array}$} & \multicolumn{3}{|c|}{ At end of test } \\
\hline & & & & \multicolumn{2}{|r|}{ (g) } & $(\%)$ & & & $\begin{array}{l}\mathrm{CO}_{2} \\
(\%)\end{array}$ & $\begin{array}{c}\mathrm{CO} \\
(p p m)\end{array}$ & $\begin{array}{l}\mathrm{O}_{2} \\
(\%)\end{array}$ \\
\hline DF-A & 16 & 12 & - & \multicolumn{2}{|r|}{7.5} & 93 & $53^{\mathrm{a}}$ & 442 & 3.2 & 1500 & $18.6^{b}$ \\
\hline DF-A3 & 20 & 38 & 23.87 & \multicolumn{2}{|r|}{21.4} & 90 & 65 & 493 & 10.6 & 4700 & 13.7 \\
\hline$D F-A 4$ & 15 & 37 & \multicolumn{2}{|c|}{23.74} & 20.6 & 87 & 70 & 503 & 10.3 & 2800 & 16.3 \\
\hline DF-A5 & 15 & 58 & \multicolumn{2}{|c|}{31.42} & 27.9 & 89 & 70 & 420 & 5.1 & 1000 & $12.0^{b}$ \\
\hline DF-A6 & 15 & 58 & 35.1 & & 31.5 & 90 & 64 & 464 & 11.6 & 5500 & 18.5 \\
\hline DF-ML1 & 15 & 92 & 57.6 & & - & & 55 & 488 & - & & 21.0 \\
\hline DF-ML2 & 15 & 92 & 65.5 & & - & & $13^{d}$ & 540 & - & & 21.0 \\
\hline DF-1 & 15.5 & 86 & 48.0 & & 41.7 & 87 & 71 & 570 & 11.6 & 7400 & 14.8 \\
\hline DF-2 & 17 & 70 & 48.0 & & 42.5 & 90 & 81 & 549 & 4.3 & 5700 & 17.8 \\
\hline DF-3 & 15 & 36 & 22.4 & & 20.2 & 90 & 57 & 639 & 6.7 & 2800 & 19.5 \\
\hline $\begin{array}{l}\text { a. } \\
\text { b. } \\
\text { c. } \\
\text { d. }\end{array}$ & $\begin{array}{l}\text { Out at } 86 \\
\text { No oxygen } \\
\text { Includes } 0 . \\
\text { Blackened }\end{array}$ & $\begin{array}{l}\text { s, re-ignite } \\
\text { added. } \\
38 \text { g lampl } \\
\text { surface. }\end{array}$ & $\begin{array}{l}\text { s at } 240 \\
\text { olack. }\end{array}$ & & & & & & & & \\
\hline & $\begin{array}{l}\text { Smoke } \\
\text { Concic }\end{array}$ & & Animal & ethality & & & $\begin{array}{l}\text { FED } \\
\text { Value }\end{array}$ & $\begin{array}{c}\mathrm{CO} \\
30-\min \end{array}$ & $\begin{array}{l}\mathrm{HCN} \\
30-\mathrm{min}\end{array}$ & & \\
\hline Test & $(m g / l)$ & $\begin{array}{l}\text { Expo- } \\
\text { sure }\end{array}$ & $\begin{array}{c}\text { Same } \\
\text { Day }\end{array}$ & $\begin{array}{l}\text { Post } \\
\text { Expo- } \\
\text { sure }\end{array}$ & $\begin{array}{l}\text { Total } \\
\text { Dead }\end{array}$ & WE & $\begin{array}{c}\text { WE } \\
+ \\
P E\end{array}$ & $\begin{array}{l}(p p m- \\
\text { min })\end{array}$ & $\begin{array}{l}\text { (ppm- } \\
\mathrm{min})\end{array}$ & $\begin{array}{l}\mathrm{CO} \\
(\mathrm{g} / \mathrm{g})\end{array}$ & $\begin{array}{l}\mathrm{CO}_{2} \\
(\mathrm{~g} / \mathrm{g})\end{array}$ \\
\hline DF-A & & & & & & & & & & 0.045 & 1.6 \\
\hline DF-A3 & & & & & & & & & & 0.053 & 1.9 \\
\hline DF-A4 & & & & & & & & & & 0.031 & 1.8 \\
\hline DF-A.5 & & & & & & & & & & 0.088 & 0.66 \\
\hline DF-A6 & & & & & & & & & & 0.040 & 1.3 \\
\hline DF-1 & 210 & 6 & - & - & 6 & 1.1 & 1.1 & 130,000 & - & 0.041 & 1.0 \\
\hline DF-2 & 217 & 5 & - & - & 5 & 1.1 & 1.1 & 120,000 & - & 0.031 & 0.36 \\
\hline DF-3 & 101 & 0 & 0 & 0 & 0 & 0.47 & 0.47 & 52,000 & - & 0.032 & 1.2 \\
\hline
\end{tabular}


Table 9. Chemical and toxicological results for RPU using the SwRI/NIST Toxicity method

\begin{tabular}{|c|c|c|c|c|c|c|c|c|c|c|c|}
\hline \multirow[b]{2}{*}{ Test } & \multirow{2}{*}{$\begin{array}{l}\text { Irrad. } \\
\text { Time } \\
\text { (min.) }\end{array}$} & \multirow{2}{*}{$\begin{array}{l}\text { Spec. } \\
\text { Area } \\
\left(\mathrm{cm}^{2}\right)\end{array}$} & \multirow{2}{*}{$\begin{array}{l}\text { Init: } \\
\text { Mass } \\
(g)\end{array}$} & \multicolumn{2}{|c|}{ Mass Loss } & \multirow{2}{*}{$\begin{array}{l}\text { Time } \\
\text { to } \\
\text { ign. } \\
(s)\end{array}$} & \multirow{2}{*}{$\begin{array}{c}\text { Flame } \\
\text { Out } \\
\text { (s) }\end{array}$} & \multicolumn{4}{|c|}{ At end of test } \\
\hline & & & & (g) & (\%) & & & $\begin{array}{l}\mathrm{CO}_{2} \\
(\%)\end{array}$ & $\begin{array}{c}\mathrm{CO} \\
(\mathrm{ppm})\end{array}$ & $\begin{array}{l}\mathrm{O}_{2} \\
(\%)\end{array}$ & $\begin{array}{l}\mathrm{HCN}^{\mathrm{d}} \\
(\mathrm{ppm})\end{array}$ \\
\hline RPU-A & 12 & 97 & 24.06 & 20.57 & 85 & 21 & 277 & 8.9 & 7100 & $12.0^{\mathrm{a}}$ & - \\
\hline RPU-1 & 15 & 58 & 13.75 & 12.97 & 94 & 23 & 318 & 2.9 & 4800 & 14.8 & 100 \\
\hline RPU-2 & 15 & 29 & 7.00 & 6.66 & 95 & 25 & 270 & 1.5 & 3500 & 18.8 & 120 \\
\hline RPU-3 & 15 & 16 & 4.00 & 3.87 & 97 & 26 & 230 & 0.7 & 1700 & 19.6 & 60 \\
\hline ML-1 & 15 & 97 & $22.47^{b}$ & 21.4 & 95 & $4^{c}$ & 383 & - & - & 21.0 & - \\
\hline $\begin{array}{l}\text { a. } \\
\text { b. } \\
\text { c. } \\
\text { d. }\end{array}$ & $\begin{array}{l}\text { No oxygen a } \\
\text { Mass include } \\
\text { Surface black } \\
\text { Does not sho }\end{array}$ & $\begin{array}{l}\text { g lamp } \\
\text { ady stat }\end{array}$ & & & & & & & & & \\
\hline
\end{tabular}

\begin{tabular}{|c|c|c|c|c|c|c|c|c|c|c|c|c|}
\hline \multirow[b]{2}{*}{ Test } & \multirow[b]{2}{*}{$\begin{array}{c}\text { Smoke } \\
\text { Conc. } \\
\text { (mg/l) }\end{array}$} & \multicolumn{4}{|c|}{ Animal lethality } & \multicolumn{2}{|c|}{$\begin{array}{l}\text { FED } \\
\text { Value }\end{array}$} & \multirow{2}{*}{$\begin{array}{c}\mathrm{CO} \\
30-\mathrm{min} \\
\mathrm{CT} \\
(p p m- \\
\text { min. }\end{array}$} & \multirow{2}{*}{$\begin{array}{l}\mathrm{HCN} \\
30-\mathrm{min} \\
\mathrm{CT} \\
(p p m- \\
\text { min.) }\end{array}$} & \multirow{2}{*}{$\begin{array}{c}\text { Yield } \\
\text { CO } \\
(g / g)\end{array}$} & \multirow{2}{*}{$\begin{array}{l}\text { Yield } \\
\mathrm{CO}_{2} \\
(g / g)\end{array}$} & \multirow{2}{*}{$\begin{array}{l}\text { Yield } \\
\mathrm{HCN} \\
(\mathrm{g} / \mathrm{g})\end{array}$} \\
\hline & & $\begin{array}{l}\text { Expo- } \\
\text { sure }\end{array}$ & $\begin{array}{c}\text { Same } \\
\text { day }\end{array}$ & $\begin{array}{l}\text { Post } \\
\text { Expo- } \\
\text { sure }\end{array}$ & $\begin{array}{l}\text { Total } \\
\text { Dead }\end{array}$ & WE & $\begin{array}{c}\text { WE } \\
+ \\
\text { PE }\end{array}$ & & & & & \\
\hline RPU-A & & & & & & & & & & 0.080 & 1.6 & \\
\hline RPU-1 & 65 & 6 & 0 & 0 & 6 & 1.7 & 1.9 & 130,000 & 3000 & 0.087 & 0.82 & 0.0019 \\
\hline RPU-2 & 33 & 6 & 0 & 0 & 6 & 1.1 & 1.3 & 85,000 & 2900 & 0.12 & 0.83 & 0.0044 \\
\hline RPU-3 & 19 & 0 & 0 & 0 & 0 & 0.57 & 0.65 & 43,000 & 1500 & 0.10 & 0.64 & 0.0034 \\
\hline
\end{tabular}

\section{Cone Calorimeter}

The data obtained in the Cone Calorimeter are summarized in Table 11. The values are averages of, typically, three runs each. The within-laboratory variability (repeatability, $r$ ) and the variability between laboratories (reproducibility, $R$ ) have been established for this method [29] and are given, for the case of the peak heat release rate, $\dot{\mathrm{q}}_{\max }^{\prime \prime}$, as: 
Table 10. Chemical and toxicological results for PVC using the SwRI/NIST Toxicity method

\begin{tabular}{|c|c|c|c|c|c|c|c|c|c|c|c|}
\hline \multirow[b]{2}{*}{ Test } & \multirow{2}{*}{$\begin{array}{l}\text { Irrad. } \\
\text { Time } \\
\text { (min.) }\end{array}$} & \multirow{2}{*}{$\begin{array}{l}\text { Spec } \\
\text { Area } \\
\left(\mathrm{cm}^{2}\right)\end{array}$} & \multirow{2}{*}{$\begin{array}{c}\text { Init. } \\
\text { Mass } \\
\text { (g) }\end{array}$} & \multicolumn{2}{|c|}{ Mass Loss } & \multirow{2}{*}{$\begin{array}{l}\text { Time } \\
\text { to } \\
\text { ign. } \\
(s)\end{array}$} & \multirow{2}{*}{$\begin{array}{c}\text { Flame } \\
\text { Out } \\
\text { (s) }\end{array}$} & \multicolumn{4}{|c|}{ At end of test } \\
\hline & & & & (g) & (\%) & & & $\begin{array}{l}\mathrm{CO}_{2} \\
(\%)\end{array}$ & $\underset{(p p m)}{\mathrm{CO}}$ & $\begin{array}{l}\mathrm{O}_{2} \\
(\%)\end{array}$ & $\begin{array}{l}\mathrm{HCl}^{\mathrm{a}} \\
(\mathrm{ppm})\end{array}$ \\
\hline FS-1 & 10 & 4.0 & 3.96 & 3.62 & 91 & 56 & 250 & 2.0 & 1400 & 19.1 & 3100 \\
\hline FS-2 & 10 & 4.8 & 4.23 & 4.23 & 85 & 45 & 270 & 1.9 & 1600 & 18.8 & 3800 \\
\hline FS-3 & 10 & 7.0 & 5.62 & 5.62 & 89 & 49 & 295 & 2.2 & 2100 & 18.8 & 4000 \\
\hline FS-4 & 10 & 8.7 & 6.75 & 6.75 & 85 & 57 & 296 & 2.6 & 2700 & 18.2 & 5700 \\
\hline
\end{tabular}

\begin{tabular}{|c|c|c|c|c|c|c|c|c|c|c|c|c|}
\hline \multirow[b]{2}{*}{ Test } & \multirow[b]{2}{*}{$\begin{array}{l}\text { Smoke } \\
\text { Conc. } \\
\text { (mg/e) }\end{array}$} & \multicolumn{4}{|c|}{ Animal lethality } & \multicolumn{2}{|c|}{$\begin{array}{l}\text { FED } \\
\text { Value }\end{array}$} & \multirow{2}{*}{$\begin{array}{c}\mathrm{CO} \\
30-\mathrm{min} \\
\mathrm{CT} \\
(\text { ppm- } \\
\text { min. })\end{array}$} & \multirow{2}{*}{$\begin{array}{c}\mathrm{HCl} \\
30-\mathrm{min} \\
\mathrm{CT} \\
(p p m- \\
\text { min.) }\end{array}$} & \multirow[b]{2}{*}{$\begin{array}{c}\text { Yield } \\
\mathrm{CO} \\
(\mathrm{g} / \mathrm{g})\end{array}$} & \multirow[b]{2}{*}{$\begin{array}{l}\text { Yield } \\
\mathrm{CO}_{2} \\
(\mathrm{~g} / \mathrm{g})\end{array}$} & \multirow[b]{2}{*}{$\begin{array}{l}\text { Yield } \\
\mathrm{HCl} \\
(\mathrm{g} / \mathrm{g})\end{array}$} \\
\hline & & $\begin{array}{l}\text { Expo- } \\
\text { sure }\end{array}$ & $\begin{array}{l}\text { Same } \\
\text { day }\end{array}$ & $\begin{array}{l}\text { Post } \\
\text { Expo- } \\
\text { sure }\end{array}$ & $\begin{array}{l}\text { Total } \\
\text { Dead }\end{array}$ & WE & $\begin{array}{c}\text { WE } \\
+ \\
\text { PE }\end{array}$ & & & & & \\
\hline FS-1 & 18 & 0 & 0 & 0 & 0 & 0.32 & 0.64 & 33,000 & 36,000 & 0.086 & 2.0 & 0.25 \\
\hline FS-2 & 21 & 0 & 0 & 3 & 3 & 0.38 & 0.86 & 40,000 & 53,000 & 0.089 & 1.6 & 0.26 \\
\hline FS-3 & 28 & 0 & 0 & 1 & 1 & 0.47 & 0.87 & 53,000 & 45,000 & 0.087 & 1.4 & 0.21 \\
\hline FS- 4 & 34 & 0 & 0 & 6 & 6 & 0.59 & 1.3 & 66,000 & 76,000 & 0.090 & 1.4 & 0.24 \\
\hline
\end{tabular}

$$
\begin{aligned}
& r=13.3+0.131 \dot{q}_{\max }^{\prime \prime} \\
& R=60.4+0.141 \dot{q}_{\max }^{\prime \prime}
\end{aligned}
$$

where $r$ and $R$ are computed for the $95 \%$ probability level and are in the same units $\left(\mathrm{kW} / \mathrm{m}^{2}\right)$ as is $\dot{q}_{\max }^{\prime \prime}$ Uncertainty ranges for other variables derived in the test are generally similar and may be found in [29].

Figures 12 through 14 show the rate of heat release curves obtained. Note that the values reported in Table 11, being averages of several runs, may not agree exactly with the curves shown in the corresponding Figures, which illustrate only a single run each. The variable 'MLR' shown in Table 11 is the mass loss rate over 90 - 10 period, that is, over the period starting when $90 \%$ of the mass burned still remains, and stopping when $10 \%$ remains. Note that the effective heat of combustion for RPU is similar to a handbook value of 22.7 [38], whereas the value for PVC is about half of the handbook value of 16.9 for pure material. 
Table 11. Cone Calorimeter data summary

\begin{tabular}{|c|c|c|c|c|c|c|c|c|c|}
\hline Material & $\begin{array}{c}\text { Flux } \\
\left(\mathrm{kW/m^{2 } )}\right.\end{array}$ & $\begin{array}{c}\text { Mass } \\
(g)\end{array}$ & $\begin{array}{c}\text { Mass } \\
\text { Burned } \\
(\%)\end{array}$ & $\underset{\left(g / m^{2} s\right)}{\text { MLR }}$ & $\begin{array}{l}\text { Ignition } \\
\text { Time } \\
\text { (s) }\end{array}$ & $\begin{array}{c}\text { Peak } \\
\dot{\mathrm{q}}^{\mathrm{n}} \\
\left(\mathrm{kW} / \mathrm{m}^{2}\right)\end{array}$ & $\begin{array}{c}\text { Peak } \\
\text { Time } \\
(s)\end{array}$ & $\begin{array}{c}\text { Total } \\
\mathrm{q}^{n} \\
\left(M J / m^{2}\right)\end{array}$ & $\begin{array}{c}\text { Eff. } \\
\Delta \mathrm{H}_{\mathrm{c}} \\
(M J / \mathrm{kg})\end{array}$ \\
\hline \multirow{3}{*}{ DF } & 35 & 209.5 & 77.6 & 5.6 & 39.8 & 175 & 60 & 217 & 11.8 \\
\hline & 50 & 209.3 & 81.1 & 6.1 & 14.0 & 184 & 35 & 227 & 11.8 \\
\hline & 75 & 181.9 & 83.5 & 6.8 & 3.7 & 283 & 23 & 208 & 12.1 \\
\hline \multirow{3}{*}{ RPU } & 35 & 24.9 & 78.3 & 4.7 & 3.4 & 160 & 25 & 43 & 19.7 \\
\hline & 50 & 25.0 & 87.7 & 4.8 & 3.0 & 191 & 20 & 52 & 21.1 \\
\hline & 75 & 24.6 & 82.9 & 8.5 & 2.7 & 234 & 215 & 47 & 18.9 \\
\hline \multirow{3}{*}{ PVC } & 35 & 91.5 & 78.2 & 12.8 & 69.8 & 147 & 530 & 77 & 9.5 \\
\hline & 50 & 90.3 & 80.1 & 14.9 & 34.8 & 147 & 283 & 72 & 8.9 \\
\hline & 75 & 90.5 & 81.6 & 20.4 & 15.4 & 189 & 243 & 66 & 7.9 \\
\hline
\end{tabular}

\begin{tabular}{|c|c|c|c|c|c|c|c|}
\hline \multirow[b]{2}{*}{ Material } & \multirow{2}{*}{$\underset{\left(k W / m^{2}\right)}{\text { Flux }}$} & \multicolumn{6}{|c|}{ Yield } \\
\hline & & $\begin{array}{c}\mathrm{CO} \\
(\mathrm{kg} / \mathrm{kg})\end{array}$ & $\begin{array}{c}\mathrm{CO}_{2} \\
(\mathrm{~kg} / \mathrm{kg})\end{array}$ & $\begin{array}{c}\mathrm{HCl} \\
(\mathrm{kg} / \mathrm{kg})\end{array}$ & $\begin{array}{l}\mathrm{HCN} \\
(\mathrm{kg} / \mathrm{kg})\end{array}$ & $\begin{array}{l}\mathrm{TUH}^{\mathrm{a}} \\
(\mathrm{kg} / \mathrm{kg})\end{array}$ & $\begin{array}{l}\text { Smoke } \\
\left(m^{2} / \mathrm{kg}\right)\end{array}$ \\
\hline \multirow{3}{*}{ DF } & 35 & 0.005 & 0.85 & 0.004 & ND & 0.0012 & 16 \\
\hline & 50 & 0.003 & 0.98 & 0.005 & ND & 0.0008 & 22 \\
\hline & 75 & 0.003 & 1.01 & 0.006 & ND & 0.0006 & 38 \\
\hline \multirow{3}{*}{ RPU } & 35 & 0.060 & 1.06 & 0.030 & 0.005 & 0.014 & 840 \\
\hline & 50 & 0.080 & 1.16 & 0.013 & 0.005 & 0.012 & 820 \\
\hline & 75 & 0.042 & 1.20 & 0.027 & 0.004 & 0.014 & 990 \\
\hline \multirow{3}{*}{ PVC } & 35 & 0.075 & 0.41 & 0.30 & ND & 0.038 & 1000 \\
\hline & 50 & 0.076 & 0.37 & 0.32 & ND & 0.043 & 1100 \\
\hline & 75 & 0.066 & 0.29 & 0.30 & ND & 0.054 & 1200 \\
\hline $\begin{array}{l}\text { a. } \\
\text { ND }\end{array}$ & ed. & & & & & & \\
\hline
\end{tabular}

Since enough diagnostic measurements, including total unburned hydrocarbons, are available for the Cone Calorimeter, it is possible to check the results by the use of carbon balance. We shall assume that the unburned hydrocarbons are $\mathrm{CH}_{4}$, that all residual char is pure carbon, and that the yield of soot is given according to 


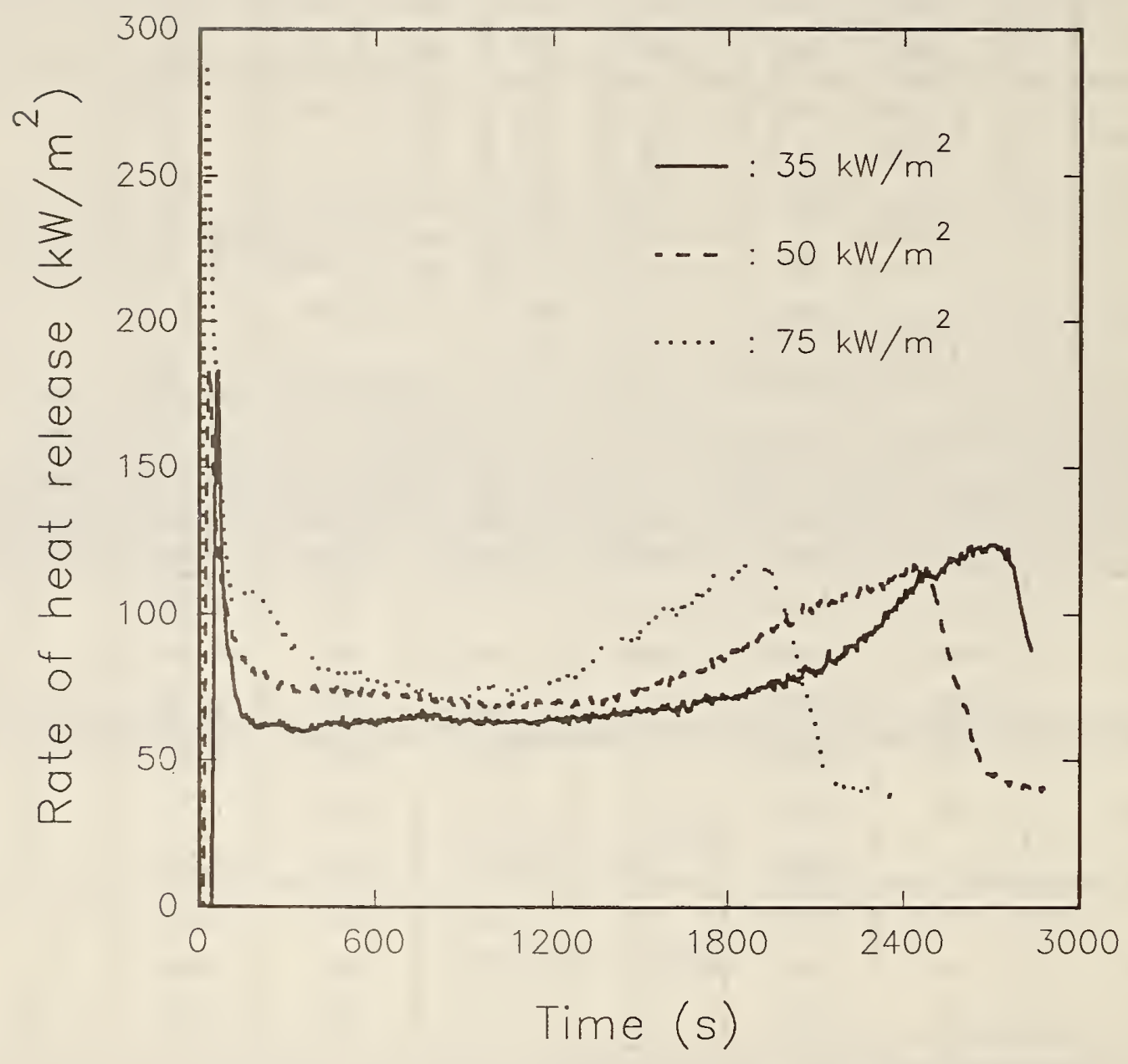

Figure 12. Heat release rates measured in the Cone Calorimeter for DF 


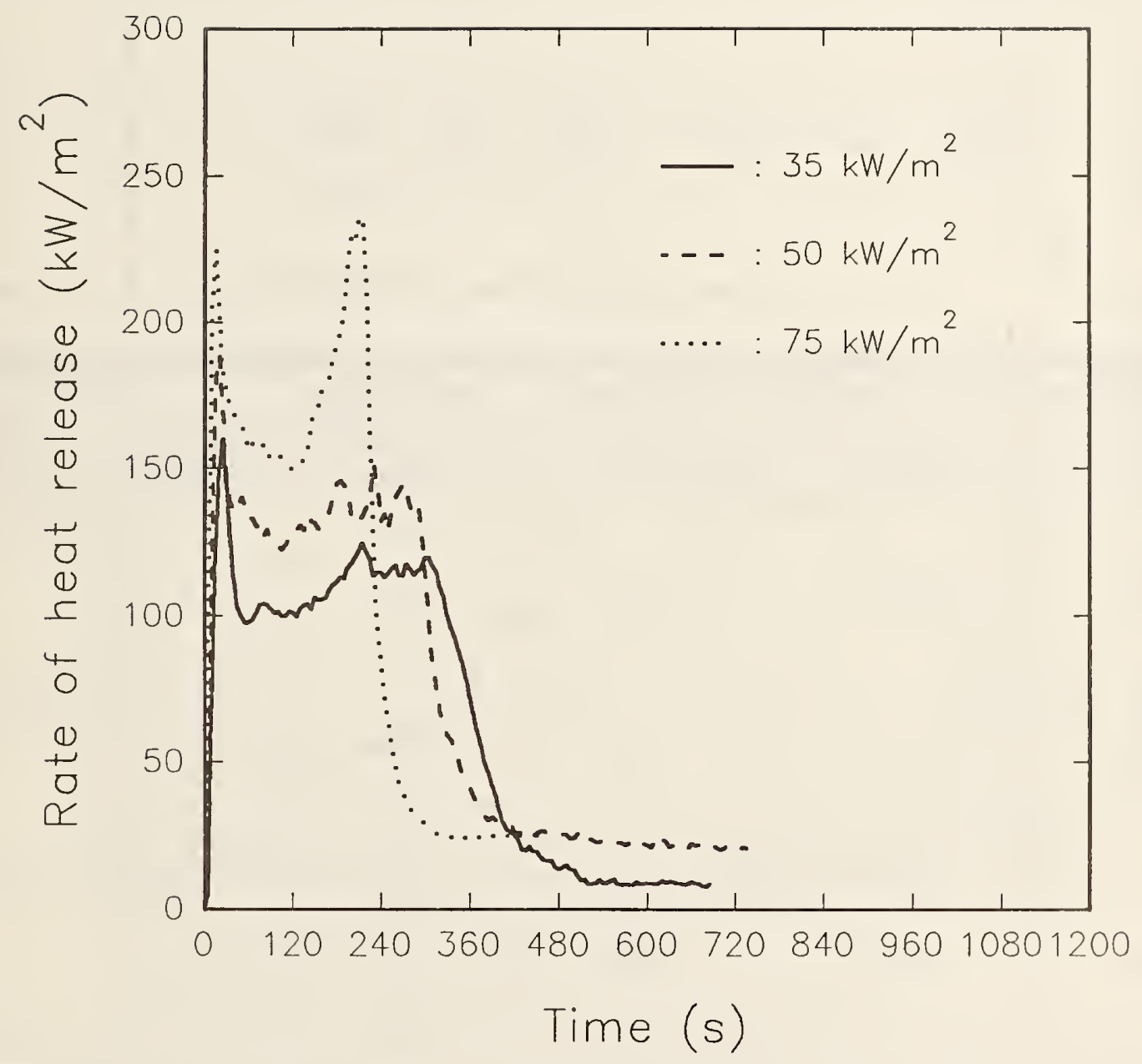

Figure 13. Heat release rates measured in the Cone Calorimeter for RPU 


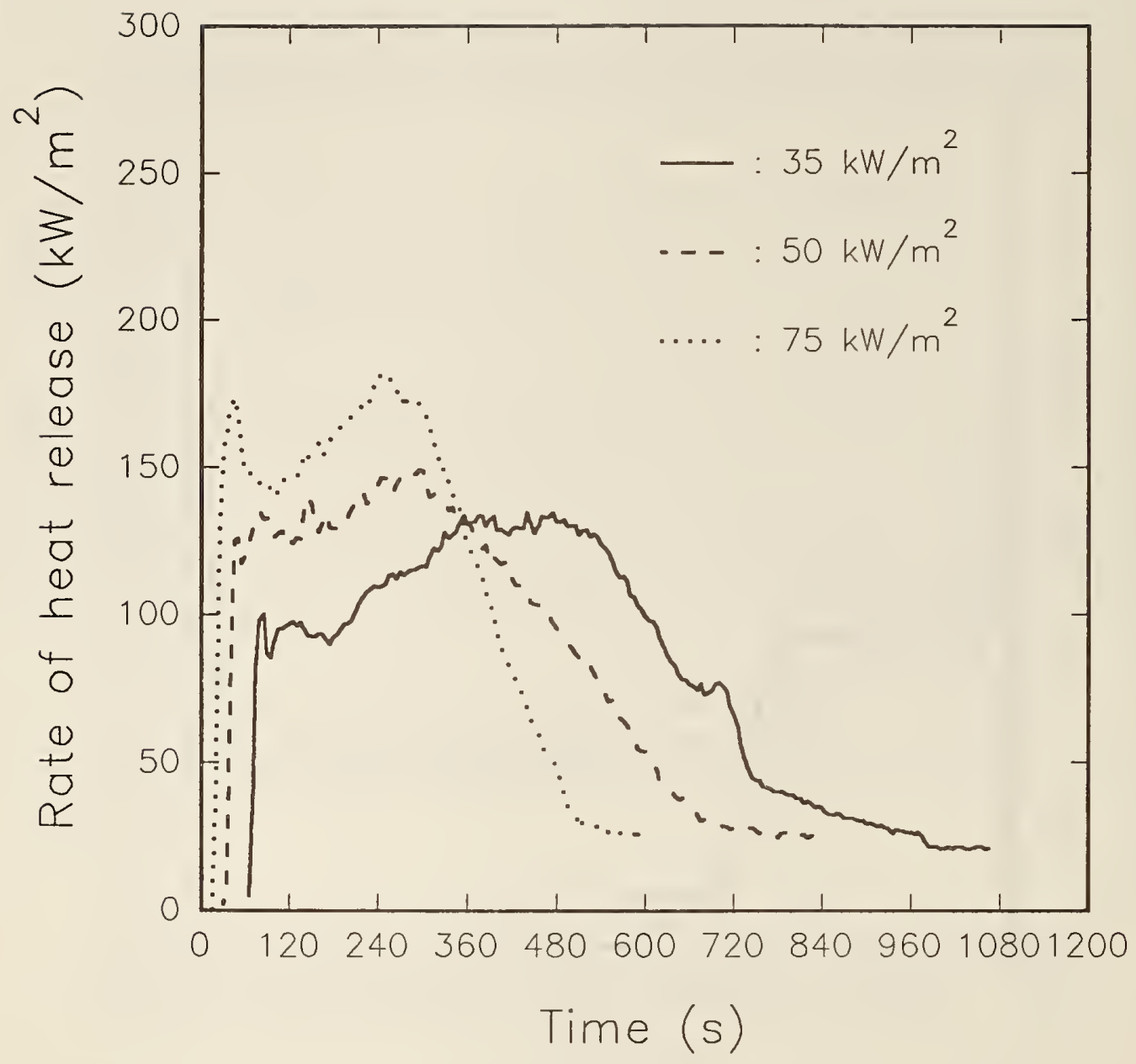

Figure 14. Heat release rates measured in the Cone Calorimeter for PVC 


$$
f_{\text {soot }}=\frac{\sigma_{f}}{12,000}
$$

where $\sigma_{\mathrm{f}}$ is the specific extinction area $\left(\mathrm{m}^{2} / \mathrm{kg}\right)$ and 12,000 is the assumed extinction area for pure graphitic carbon [39]. Then, the fraction of carbon recovered from the fuel is determined according to

$$
C=\frac{12}{44} f_{C O_{2}}+\frac{12}{28} f_{C O}+\frac{12}{29} f_{H C N}+\frac{12}{16} f_{T U H}+f_{\text {char }}+\frac{\sigma_{f}}{12,000}
$$

\begin{tabular}{|c|c|c|c|c|c|}
\hline Material & $\begin{array}{c}\text { Flux } \\
\left(\mathrm{kW} / \mathrm{m}^{2}\right)\end{array}$ & $\begin{array}{c}\text { Fraction of C } \\
\text { from carbon } \\
\text { balance }\end{array}$ & $\begin{array}{l}\text { Average for } \\
\text { the } 3 \text { fluxes }\end{array}$ & $\begin{array}{l}\text { Fraction of } C \\
\text { from elemental } \\
\text { analysis }\end{array}$ & $\begin{array}{c}\text { Percent } \\
\text { accounted for }\end{array}$ \\
\hline \multirow[t]{3}{*}{$\mathrm{DF}$} & 35 & 0.46 & \multirow{3}{*}{0.46} & \multirow{3}{*}{0.48} & \multirow{3}{*}{$95 \%$} \\
\hline & 50 & 0.46 & & & \\
\hline & 75 & 0.44 & & & \\
\hline \multirow[t]{3}{*}{ RPU } & 35 & 0.61 & \multirow{3}{*}{0.59} & \multirow{3}{*}{0.65} & \multirow{3}{*}{$91 \%$} \\
\hline & 50 & 0.55 & & & \\
\hline & 75 & 0.61 & & & \\
\hline \multirow[t]{3}{*}{ PVC } & 35 & 0.47 & \multirow{3}{*}{0.46} & \multirow{3}{*}{0.38} & \multirow{3}{*}{$119 \%^{\mathrm{a}}$} \\
\hline & 50 & 0.46 & & & \\
\hline & 75 & 0.44 & & & \\
\hline
\end{tabular}

Table 12. Carbon balance for Cone Calorimeter results

where the yield values of species $\mathrm{x}$ are denoted as ' $f_{\mathrm{x}}$ '. This comparison is made in Table 12. For DF and RPU, very reasonable recovery rates of $95 \%$ and $91 \%$ are seen. For PVC; the calculations indicate a C recovery of $119 \%$. Since this exceeds $100 \%$, it is obviously not correct. By referring to Table 1 , we can see that whereas the analyzed elements for the other materials constitute $\approx 100 \%$ of sample mass. from the PVC sample these accounted for only $90 \%$, consistent with the manufacturer's composition description given in Chapter 2. To get a second estimate, we can 
postulate that the remaining $10 \%$ of specimen mass constitutes inerts which will always remain in the char. Then, in the equation above we need to substitute $\left(f_{\text {char }}-0.10\right)$ for the $f_{\text {char }}$ term. With this adjustment, the average fraction of $\mathrm{C}$ from carbon balance becomes 0.35 for PVC, instead of 0.46 . The percent accounted for is then $92 \%$. Thus, it is now entirely plausible that the fraction of $\mathrm{C}$ recovered for PVC should be in the range $92 \%-119 \%$.

\section{Medium-Scale results}

Even though the medium-scale articles tested were ignition cribs, rather than actual end-use articles, the test data obtained in the Furniture Calorimeter should be indicative of performance to be expected in a medium scale. Thus, we will also examine the crib data from a toxicity point of view, in addition to verifying their behavior as ignition sources for room fires.

Table 13. Comparison of crib results to predicted values

\begin{tabular}{|l|c|c|c|c|}
\hline \multirow{2}{*}{} & \multicolumn{2}{|c|}{ DF } & \multicolumn{2}{c|}{ RPU } \\
\cline { 2 - 5 } & Predicted & Measured & Predicted & Measured \\
\hline Peak $\dot{\mathrm{q}}(\mathrm{kW})$ & 480 & 420 & - & 260 \\
\hline Steady-state $\dot{\mathrm{q}}(\mathrm{kW})$ & 315 & 330 & 275 & 212 \\
\hline Time to steady-state $(s)$ & 80 & 410 & 60 & 40 \\
\hline Duration of steady-state $(s)$ & 400 & 440 & 80 & 60 \\
\hline Total heat released $(M J)$ & - & 290 & - & 20 \\
\hline $\mathrm{CO}_{2}$ yield $(\mathrm{kg} / \mathrm{kg})$ & - & 1.6 & - & 2.5 \\
\hline $\mathrm{CO}$ yield $(\mathrm{kg} / \mathrm{kg})$ & - & 0.01 & - & 0.08 \\
\hline
\end{tabular}

The results of furniture calorimeter tests on the cribs are summarized in Table 13. For use of the cribs as ignition sources, the table compares the predicted and the measured values of heat release. The actual heat release rates for DF and RPU are shown in Figure 15. Once the ignition fuel was consumed, the PVC crib did not burn. While no real steady-state heat release rate was observed in any furniture calorimeter tests, an approximation of the average heat release rate was determined by averaging the heat release rate values during the period between $5 \%$ weight loss and $55 \%$ weight loss. This is comparable to the average heat release rate values reported by Quintiere and McCaffrey [33].

For DF, the actual time to achieve this 'steady-state' burning was longer than predicted, $410 \mathrm{~s}$ versus $80 \mathrm{~s}$. This was due to the differences in the ignition source. In the studies on which the predictions were based, the ignition source surface area was greater than the crib plane area, while in this work the ignition source area was much smaller than the crib plane area. It, therefore, took longer to achieve total crib involvement in the present work as compared to the previous work. 


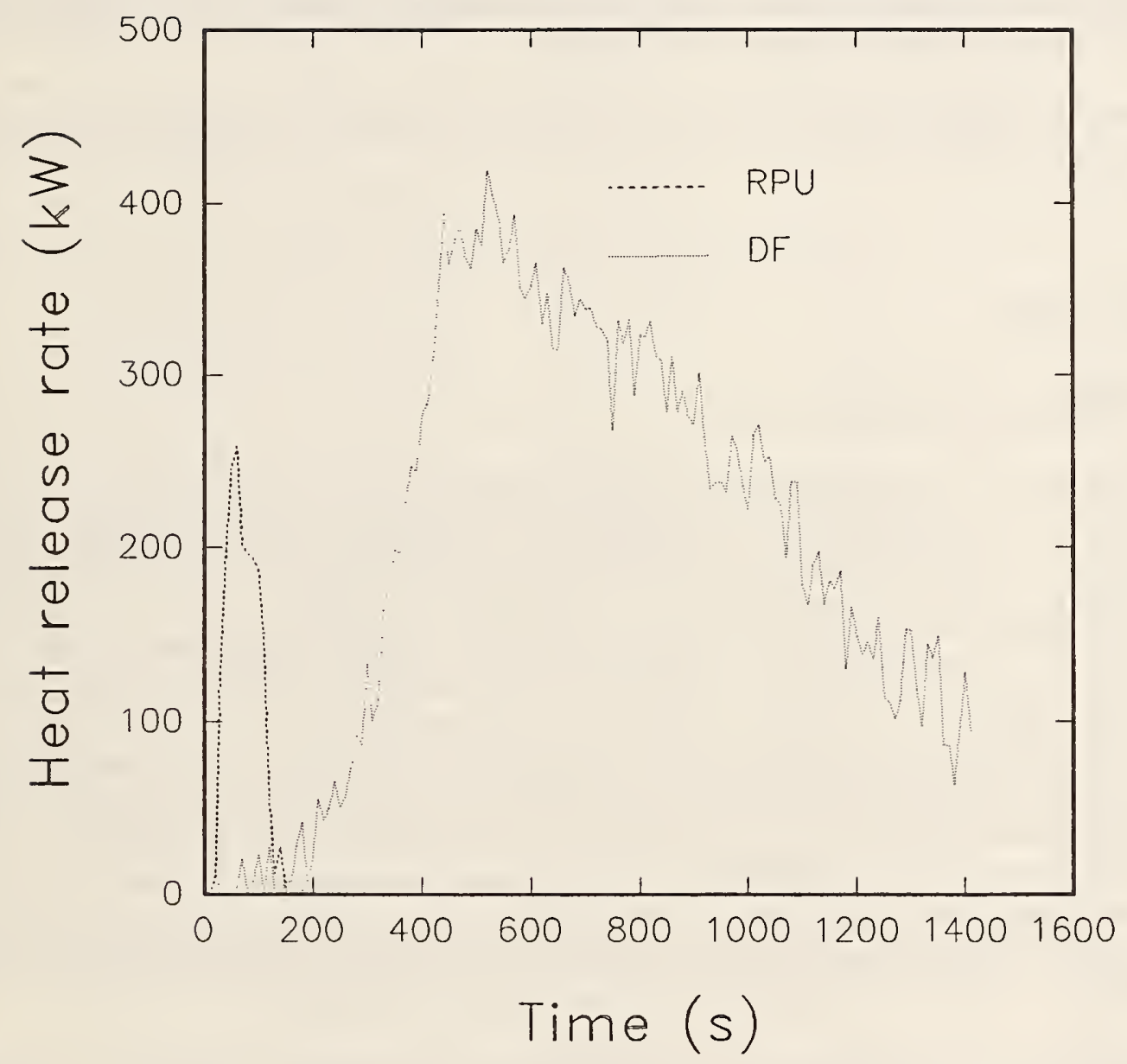

Figure 15. Heat release rates measured in the Furniture Calorimeter for cribs 
The comparison for the RPU shows a comparably good correlation between the predicted and measured values for the time to, the duration of, and the intensity of the 'steady-state' heat release rate. The duration of 'steady-state' burning was the same, $60 \mathrm{~s}$. The RPU crib developed 'steadystate' burning in only $40 \mathrm{~s}$. This was more rapid than the predicted $60 \mathrm{~s}$.

Thus, the DF and RPU cribs, as designed and tested, were seen to be appropriate as ignition sources. The PVC crib was not appropriate, since it did not show sustained burning. Thus, a different source - a gas burner - was required for tests of PVC walls.

For comparison with other results on the same test materials, Table 13 also gives the yields of gas species that were measured.

\section{Real-Scale results}

\section{Details of tests conducted}

General There were 12 real-scale tests performed in the burn room-corridor-target room facility shown in Figure 9. With one exception, the test materials were mounted on the back wall of the test room. In the case of the Douglas fir, the planks, once nailed to the wall, were monitored for moisture content. Actual testing was not started until the wood moisture dropped to below $10 \%$. Four tests were done for the Douglas fir, three for the rigid polyurethane foam, and five for the PVC. At least one test for each material was analytical (no animals used), the remaining tests being with animals. A summary of the tests is in Table 14. The ignition source for the Douglas fir and rigid polyurethane was cribs ignited with $100 \mathrm{~m} \ell$ of heptane contained in a pan centered under the crib. Since furniture calorimeter testing showed that a PVC crib would not burn enough to ignite a wall, the ignition source for the PVC tests was a line burner located on the floor and in the center of the test wall; burner output was $450 \mathrm{~kW}$. The latter value was chosen to be similar to the peak values obtained from cribs of the other materials and also to be sufficient to ignite the PVC wall material. For safety reasons, the gas supply to the burner was to be shut off when, in the judgement of the test operator, a flame no longer existed in the vicinity of the burner.

The main features of the real-scale tests conducted are summarized in Table 14. Narrative descriptions are given below, while a test log for each test is contained in Appendix A.

FS Analytical DF 1: This analytical test consisted of an end wall and a side wall of the ASTM room paneled with $2.4 \mathrm{~m}$ lengths of the boards, each approximately $20-\mathrm{mm}$ thick by $250-\mathrm{mm}$ wide. The boards were mounted vertically on 20 -mm furring strips which were nailed on top of a layer of calcium silicate board. Each board was attached by screw-gunning with 75 -mm long screws, using four screws per board. Wall moisture was measured at $8.5 \%$ to $10 \%$ before the test. A crib was placed into the corner and ignited. The combustion products were pumped from the target room at a rate of $7.0 \mathrm{l} / \mathrm{s}$ and into the animal exposure chambers shown in Figure 10. This test provided excessive combustion rates, due to too much fuel being liberated. It was decided to proceed with the remaining 
Table 14. Summary of real-scale tests

\begin{tabular}{|c|c|c|c|c|c|}
\hline Test & Identification & Date & Type & Crib Location & Comments \\
\hline 1 & FS Analytical DF 1 & $9-27-89$ & Analytical & Corner & $\begin{array}{l}\text { Two walls; } \\
\text { too much fuel }\end{array}$ \\
\hline 2 & FS Analytical DF 2 & $10-24-89$ & Analytical & $\begin{array}{l}\text { center of wall, } \\
1 \mathrm{~m} \text { above floor }\end{array}$ & One wall \\
\hline 3 & FS Animal DF 1 & $11-2-89$ & Animal & $\begin{array}{l}\text { Center of wall, } \\
1 \mathrm{~m} \text { above floor }\end{array}$ & One wall \\
\hline 4 & FS Animal DF 2 & $11-9-89$ & Animal & $\begin{array}{l}\text { Center of wall, } \\
\text { on floor }\end{array}$ & One wall \\
\hline 5 & FS Analytical RPU & $11-14-89$ & Analytical & $\begin{array}{l}\text { Center of wall, } \\
\text { on floor }\end{array}$ & One wall \\
\hline 6 & FS Animal RPU 1 & $11-16-89$ & Animal & $\begin{array}{l}\text { Center of wall, } \\
\text { on floor }\end{array}$ & $\begin{array}{l}\text { One wall, } \\
\text { Two cribs }\end{array}$ \\
\hline 7 & FS Animal RPU 2 & $11-20-89$ & Animal & $\begin{array}{l}\text { Center of wall, } \\
\text { on floor }\end{array}$ & $\begin{array}{l}\text { One wall, } \\
\text { Two cribs }\end{array}$ \\
\hline 8 & FS Analytical PVC 1 & $11-28-89$ & Analytical & No crib used & $\begin{array}{l}\text { One wall, } \\
\text { Line burner, } \\
\text { Wall collapsed }\end{array}$ \\
\hline 9 & FS Analytical PVC 2 & $12-1-89$ & Analytical & No crib used & $\begin{array}{l}\text { One wall, } \\
\text { Line burner, } \\
\text { Burner turned } \\
\text { off }\end{array}$ \\
\hline 10 & FS Animal PVC 1 & $12-5-89$ & Animal & No crib used & $\begin{array}{l}\text { One wall, } \\
\text { Line burner, } \\
\text { Burner } \\
\text { turned off }\end{array}$ \\
\hline 11 & FS Animal PVC 2 & $12-7-89$ & Animal & No crib used & $\begin{array}{l}\text { One wall, } \\
\text { Line burner, } \\
\text { Burner } \\
\text { turned off }\end{array}$ \\
\hline 12 & FS Animal PVC 3 & $12-11-89$ & Animal & No crib used & $\begin{array}{l}\text { One wall, } \\
\text { Line burner, } \\
\text { Burner } \\
\text { turned off }\end{array}$ \\
\hline
\end{tabular}

tests with only the back $2.4 \times 2.4$ m wall paneled. No data from this first test will be presented in this report.

FS Analytical DF 2: This was an analytical test. Only the end wall was covered with wood, the boards being, in this case, mounted horizontally. The boards were attached by screw-gunning with 
75-mm long screws. Eight screws were used in each board. No furring strips were used for mounting the test materials in this test nor in any of the subsequent tests. Wall moisture was measured to be $7.5 \%$ to $9 \%$ prior to this test. A crib was placed $1.4-\mathrm{m}$ above the floor on a stand and in the center of the wall. The combustion products were pumped from the target room at a rate of $10.1 \mathrm{l} / \mathrm{s}$.

FS Animal DF 1: This was an animal test done with the same wall and crib configuration as the previous test. Wall moisture was $7 \%$ to $8 \%$ prior to this test. Gases from the target room were pumped at a rate of $9.7 \mathrm{l} / \mathrm{s}$ to the animal exposure chambers. A recorder was connected to the $\mathrm{CO}$ analyzer of the top animal exposure chamber to monitor the $\mathrm{CO}$ concentration with time. The assumption was made that the $\mathrm{CO}$ concentration in all of the animal exposure chambers would approximate the concentration in the top animal exposure chamber. Decisions as to when to close the animal exposure chambers were made based on this $\mathrm{CO}$ concentration. This $\mathrm{CO}$ monitor was used in the remaining tests. The bottom, middle, and top animal exposure chambers were closed at 515,515 , and $720 \mathrm{~s}$, respectively. Animals were placed in the filled exposure chambers shortly after the chambers were closed. The middle exposure chamber leaked; no animals were exposed in this chamber. The wall and crib configuration used in this test did not result in flashover.

FS Animal DF 2: Since the previous test did not reach flashover, it was desired to obtain a test history where flashover was reached. This was done by using the same wall configuration, but placing the crib on the floor in the center of the wall. During the previous test it had been noted that the animal boxes filled too rapidly. Thus, for this and subsequent tests, a smaller pump was put in its place, with the gases being pumped from the target room at a rate of $2.9 \mathrm{e} / \mathrm{s}$. The bottom, middle, and top boxes were closed at 805, 930, and $1785 \mathrm{~s}$, respectively. Animals were placed in the bottom, middle, and top exposure chambers at 1000,1310 , and $1830 \mathrm{~s}$, respectively.

FS Analytical RPU: This was an analytical test with rigid polyurethane foam. The wall was constructed with two $1.2 \times 2.4$-m panels mounted vertically. The test panels were attached to the calcium silicate substrate by use of screws and washers. A total of 24 screws per panel were used. A crib was placed on the floor raised slightly by single bricks and in the center of the wall. Combustion products were pumped from the target room at a rate of $2.6 \mathrm{e} / \mathrm{s}$.

FS Animal RPU 1: This was an animal test with rigid polyurethane foam. During the previous test, the fire did not reach flashover, nearly died out, then picked up again and did reach flashover. Such erratic course of a fire was considered undesirable for obtaining representative gas samples, thus it was decided to increase the ignition source to two cribs. The wall was constructed in the same manner as the previous test, but two cribs sitting on the floor side by side and elevated with single bricks served as the ignition source. Combustion products were pumped from the target room at a rate of $2.5 \mathrm{e} / \mathrm{s}$. The bottom, middle, and top animal exposure chambers were closed at 180,460 , and $780 \mathrm{~s}$, respectively. Animals were placed in the bottom, middle, and top exposure chambers at 240, 480 , and $810 \mathrm{~s}$, respectively.

FS Animal RPU 2: This was an animal test conducted in the same manner as the previous test. Combustion products were pumped from the target room at a rate of $2.4 \mathrm{l} / \mathrm{second}$. Combustion products from the bypass line were collected in impingers and gas sampling bulbs and analyzed as previously described. The bottom, middle, and top animal exposure chambers were closed at 240, 360 , and $480 \mathrm{~s}$, respectively. Animals were placed into the bottom, middle, and top animal exposure chambers at 770,520, and $990 \mathrm{~s}$, respectively. 
FS Analytical PVC 1: This was an analytical test with PVC. The wall was constructed with two 1.2 $\times 2.4 \mathrm{~m}$ panels mounted vertically, and attached with screws to the calcium silicate substrate. Since a crib failed to provide adequate ignition, the aforementioned line burner was used as the ignition source. A separate test was performed in the burn room to calibrate the output from the burner. Combustion products were pumped from the target room at a rate of $2.4 \mathrm{l} / \mathrm{s}$. Shortly after ignition $(<180 \mathrm{~s}$ ), the panels collapsed onto the line burner and put the flame out; the gas to the line burner was turned off at $210 \mathrm{~s}$. This essentially ended the test even though dark smoke continued to billow through the rooms for some time. Only $3.2 \mathrm{~kg}$ of material, as determined by weight difference, was consumed in this test. This test arrangement failed the project objective of not collapsing during test.

FS Analytical PVC 2: This was a repeat analytical PVC test. To prevent the collapse of the test material, the panels were erected by first gluing the PVC sheets onto $13 \mathrm{~mm}$ thick gypsum wallboard panels, using $3 \mathrm{M}$ Fastbond 30, nonflammable, contact cement. The composite PVC/wallboard assembly was then screw-gunned onto the calcium silicate substrate with the same arrangement of screws as were the RPU specimens. Also, a thermocouple was placed over the line burner to indicate if the flame went out. This safety feature allowed for the gas to be turned off before an explosion could occur from the raw gas supplied to the burner. The flame went out after approximately 3 min and the gas was turned off. The material consumed in this test was $10.9 \mathrm{~kg}$, as determined by weight difference. The combustion products were pumped from the target room to the animal exposure chambers at a rate of $2.3 \mathrm{l} / \mathrm{s}$. During this test, in addition to the impinger samples normally collected from the bypass line ahead of the animal chambers, gases were also collected in gas sampling bulbs from a short, heated stainless steel line (about $1.5-\mathrm{m}$ length) drawing from a point $0.3-\mathrm{m}$ below the ceiling of the target room. These samples were collected to ascertain whether the $\mathrm{HCl}$ concentration was decreasing as a result of the longer distance from the target room to the animal exposure chambers. Results of these tests indicated that the $\mathrm{HCl}$ concentration in the upper layer as determined with the gas sampling bulbs was 31,000 and $23,000 \mathrm{ppm}$ after 120 and $240 \mathrm{~s}$, respectively; whereas the $\mathrm{HCl}$ concentration at the bypass line (measured during a 5-min sampling interval which included both the $120 \mathrm{~s}$ and the $240 \mathrm{~s}$ events) was $4000 \mathrm{ppm}$. This indicates that a significant amount of $\mathrm{HCl}$ was being lost in the feed line to the animal chambers. Since it was not possible to increase the diameter of the already-large tubing, nor to find any better substitute for glass, the sampling system was not changed.

FS Animal PVC 1: This was an animal test with PVC done with the same room construction as the previous analytical test. Gases were pumped from the target room at a rate of $2.4 \mathrm{l} / \mathrm{s}$. The line burner flame extinguished in about $450 \mathrm{~s}$, and the gas was turned off shortly thereafter. The bottom, middle, and top animal exposure chambers were closed at 180,300, and 420 s, respectively; animals were placed into the bottom, middle, and top exposure chambers at 210,330 , and $440 \mathrm{~s}$, respectively.

FS Animal PVC 2: This was an animal test done similarly to the previous test. Gases were pumped from the target room to the animal exposure chambers at a rate of $2.2 \mathrm{\ell} / \mathrm{s}$. The bottom, middle, and top exposure chambers were closed at 135,180 , and $235 \mathrm{~s}$, respectively; animals were placed in the bottom, middle, and top exposure chambers at 160, 210, and $280 \mathrm{~s}$, respectively. The burner extinguished in about $500 \mathrm{~s}$, and the gas was turned off.

FS Animal PVC 3: This was an animal test done similarly to the previous test. Gases were pumped from the target room to the animal exposure chambers at a rate of $2.0 \mathrm{l} / \mathrm{s}$. The bottom, middle, and 
top exposure chambers were closed at 155,210 , and $460 \mathrm{~s}$, respectively; animals were placed in the bottom, middle, and top exposure chambers at 180,240 , and $495 \mathrm{~s}$, respectively. As in the previous test, the burner went out and the gas was turned off after about $500 \mathrm{~s}$.

\section{Analysis of results}

The main results of heat, gas, and smoke measurements are given in Table 15. Toxicological results and additional chemical measurement data are given in Tables $16-18$.

Specimen mass loss rate computations Most of the data given are obtained by straightforward means from the measuring instruments. The test room, due to practical difficulties, could not be equipped with weighing devices to monitor specimen mass. Thus, a computational procedure had to be derived whereby approximate mass loss rates could be derived from stack measurements. Appendix B describes the algorithms used for this computation.

Since heat release rates are considered the most crucial data in describing room fires, the complete heat release rate curves are given for all tests (Figures $16-18$ ). Since the burn room used corresponded to the ASTM standard room [40], it is known that flashover occurs at slightly over $1000 \mathrm{~kW}$. For this work we will assume that flashover occurs exactly at the time that the $1000 \mathrm{~kW}$ rate is reached.

Yields of gas species The yields of $\mathrm{CO}, \mathrm{CO}_{2}$, and smoke could be obtained directly from measurements made in the exhaust stack. Exhaust stack instrumentation was not available for determining the yields of $\mathrm{HCl}$ and $\mathrm{HCN}$. Thus, the values reported in Table 15 are estimates based on measurements of $\mathrm{CO}_{2}$ and $\mathrm{HCl}$ or $\mathrm{HCN}$ in the bypass line ahead of the animal boxes. The $\mathrm{HCl}$ and $\mathrm{HCN}$ yields were computed as

$$
\begin{gathered}
f_{\mathrm{HCl}}=\frac{[\mathrm{HCl}]_{\text {bypass }}}{\left[\mathrm{CO}_{2}\right]_{\text {bypass }}} \times \frac{36.5}{44} \times f_{\mathrm{CO}_{2 \text { seack }}} \\
f_{\mathrm{HCN}}=\frac{[\mathrm{HCN}]_{\text {bypass }}}{\left[\mathrm{CO}_{2}\right]_{\text {bypass }}} \times \frac{27}{44} \times f_{\mathrm{CO}_{2 \text { sack }}}
\end{gathered}
$$

where $\mathrm{f}_{\mathrm{CO}_{2}}$ stack is the yield of $\mathrm{CO}_{2}$ as measured in the exhaust stack. This value is then multiplied by a $\mathrm{HCl} / \mathrm{CO}_{2}$ (or $\mathrm{HCN} / \mathrm{CO}_{2}$ ) ratio to arrive at the desired yield. This ratio requires measuring of $\mathrm{HCl}$ or $\mathrm{HCN}$. These $\mathrm{HCl}$ and $\mathrm{HCN}$ measurements were based on 5-min average impinger samples, taken at the bypass line ahead of the animal boxes. The comparable $\mathrm{CO}_{2}$ concentration, for the same time and location, was then also needed. This was taken as the value measured in the target room, near the point where the sampling line to the animal boxes started out.

For all the gas species, only test-average values of the yields have been computed. It was not possible to separate out the contributions of the pre-flashover and the post-flashover periods. Such separation 
Table 15. Release rates, yields, and related quantities measured in the real-scale tests

\begin{tabular}{|l|c|c|c|c|c|c|c|c|}
\hline \multicolumn{1}{|c|}{ Test } & $\begin{array}{c}\text { Peak } \\
\text { heat } \\
\text { release } \\
\text { rate } \\
(\mathrm{kW})\end{array}$ & $\begin{array}{c}\text { Total } \\
\text { heat } \\
\text { released } \\
(\mathrm{MJ})\end{array}$ & $\begin{array}{c}\text { Time } \\
\text { to } \\
\text { fashover } \\
(\mathrm{s})\end{array}$ & $\begin{array}{c}\text { Total } \\
\text { mass } \\
\text { lost } \\
(\mathrm{kg})\end{array}$ & $\begin{array}{c}\text { Approx. } \\
\text { fraction } \\
\text { mass } \\
\text { lost } \\
(\%)\end{array}$ & $\begin{array}{c}\text { Total } \\
\mathrm{CO} \\
(\mathrm{kg})\end{array}$ & $\begin{array}{c}\text { Total } \\
\mathrm{CO} 2 \\
(\mathrm{~kg})\end{array}$ & $\begin{array}{c}\text { Total } \\
\text { smoke } \\
\left(\mathrm{m}^{2}\right)\end{array}$ \\
\hline FS analytical DF2 & 860 & 748 & - & 40 & 28 & 3.6 & 47 & 1300 \\
FS animal DF1 & 860 & 788 & - & 42 & 29 & 3.0 & 50 & 1900 \\
FS animal DF2 & 1570 & 1670 & 657 & 49 & 34 & 5.7 & 86 & 2900 \\
\hline FS analytical RPU & 1550 & 422 & 387 & 10 & 63 & 1.4 & 22 & 3700 \\
FS animal RPU 1 & 1400 & 397 & 177 & 16 & 94 & 2.0 & 25 & 3300 \\
FS animal RPU 2 & 1440 & 504 & 137 & 13 & 76 & 1.3 & 28 & 3500 \\
\hline FS analytical PVC 1 & 730 & 134 & - & $3.2^{\mathrm{b}}$ & 6 & 0.78 & 3.1 & 1500 \\
FS analytical PVC 2 & 1390 & 204 & 147 & $11^{\mathrm{b}}$ & 20 & 2.0 & 7.3 & 4100 \\
FS animal PVC 1 & 1510 & 813 & 189 & 15 & 28 & 6.5 & 16 & 12000 \\
FS animal PVC 2 & 1570 & 799 & 158 & 19 & 35 & 5.4 & 14 & 11000 \\
FS animal PVC 3 & 1310 & 298 & 158 & 5.4 & 10 & 2.5 & 1.7 & 5200 \\
\hline
\end{tabular}

\begin{tabular}{|c|c|c|c|c|c|}
\hline \multirow[b]{2}{*}{ Test } & \multicolumn{5}{|c|}{ Yields } \\
\hline & $\begin{array}{c}\mathrm{CO} \\
(\mathrm{kg} / \mathrm{kg})\end{array}$ & $\begin{array}{c}\mathrm{CO}_{2} \\
(\mathrm{~kg} / \mathrm{kg})\end{array}$ & $\underset{(\mathrm{kg} / \mathrm{kg})}{\mathrm{HCl}}$ & $\begin{array}{l}\mathrm{HCN} \\
(\mathrm{kg} / \mathrm{kg})\end{array}$ & $\begin{array}{l}\text { Smoke } \\
\left(m^{2} / \mathrm{kg}\right.\end{array}$ \\
\hline FS analytical DF 2 & 0.091 & 1.2 & - & - & 33 \\
\hline FS animal DF 1 & 0.072 & 1.2 & - & - & 46 \\
\hline FS animal DF 2 & 0.12 & 1.8 & - & - & 59 \\
\hline FS analytical RPU & 0.14 & 2.2 & - & 0.009 & 360 \\
\hline FS animal RPU 1 & 0.12 & 1.5 & - & 0.005 & 200 \\
\hline FS animal RPU 2 & 0.10 & 2.2 & - & 0.011 & 270 \\
\hline FS analytical PVC 1 & 0.25 & 0.96 & 0.12 & - & 480 \\
\hline FS analytical PVC 2 & 0.19 & 0.67 & 0.22 & - & 380 \\
\hline FS animal PVC 1 & 0.43 & 1.1 & 0.19 & - & 800 \\
\hline FS animal PVC 2 & 0.29 & 0.78 & 0.18 & - & 590 \\
\hline FS animal PVC 3 & 0.47 & 0.32 & 0.09 & - & 970 \\
\hline $\begin{array}{l}\text { Based on } \\
\text { Based on }\end{array}$ & $\begin{array}{l}\text { given i } \\
\text { of ma }\end{array}$ & $\begin{array}{l}B \text { un } \\
\text { to anc }\end{array}$ & $\begin{array}{l}\text { other } \\
\text { e test. }\end{array}$ & & \\
\hline
\end{tabular}


Table 16. Chemical and toxicological results for DF in real-scale tests

\begin{tabular}{|c|c|c|c|c|c|c|c|c|}
\hline \multirow[b]{2}{*}{ Test } & \multirow{2}{*}{$\begin{array}{l}\text { Animal } \\
\text { exposure } \\
\text { chamber }\end{array}$} & \multirow{2}{*}{$\begin{array}{c}\text { Time } \\
\text { chamber } \\
\text { closed } \\
(s)\end{array}$} & \multirow{2}{*}{$\begin{array}{c}\text { Time } \\
\text { animals } \\
\text { inserted } \\
(s)\end{array}$} & \multicolumn{5}{|c|}{ Average gas concentration } \\
\hline & & & & $\begin{array}{c}\mathrm{CO} \\
(p p m)\end{array}$ & $\begin{array}{c}\mathrm{CO}_{2} \\
(p p m)\end{array}$ & $\begin{array}{c}\mathrm{HCl} \\
(p p m)\end{array}$ & $\begin{array}{l}\mathrm{O}_{2} \\
(\%)\end{array}$ & $\begin{array}{c}\mathrm{NO}_{\mathrm{x}} \\
(p p m)\end{array}$ \\
\hline \multirow[t]{3}{*}{ FS Animal DF 1} & bottom & 515 & 695 & 6600 & 72000 & NM & 13.0 & NM \\
\hline & middle & \multicolumn{7}{|c|}{ chamber leaked - no data } \\
\hline & top & 720 & 1068 & 1500 & 34000 & NM & 17.3 & NM \\
\hline \multirow[t]{3}{*}{ FS Animal DF $2^{\mathrm{a}}$} & bottom & 805 & 1000 & 890 & 53000 & 50 & 15.8 & 12 \\
\hline & middle & 930 & 1310 & 930 & 63000 & 3 & 14.8 & ND \\
\hline & top & 1785 & 1830 & 2900 & 35000 & 16 & 17.2 & 11 \\
\hline
\end{tabular}

\begin{tabular}{|c|c|c|c|c|c|c|c|c|}
\hline \multirow{2}{*}{ Test } & \multirow{2}{*}{$\begin{array}{l}\text { Animal } \\
\text { exposure } \\
\text { chamber }\end{array}$} & \multirow{2}{*}{$\begin{array}{l}\text { Smoke } \\
\text { Conc. } \\
(\mathrm{mg} / \mathrm{l})\end{array}$} & \multirow[t]{2}{*}{ Time $^{b}$} & \multicolumn{2}{|c|}{$\mathrm{FED}^{\mathrm{c}}$} & \multicolumn{2}{|c|}{ No.died/no. tested } & \multirow{2}{*}{$\begin{array}{l}\text { Latest day } \\
\text { of PE death }\end{array}$} \\
\hline & & & & WE & $\begin{array}{c}\mathrm{WE}+ \\
\mathrm{PE}\end{array}$ & WE & $W E+P E$ & \\
\hline \multirow[t]{3}{*}{ FS Animal DF 1} & \multirow{3}{*}{$\begin{array}{l}\text { bottom } \\
\text { middle } \\
\text { top }\end{array}$} & 88 & PRE & 1.9 & NA & $6 / 6$ & $6 / 6$ & - \\
\hline & & \multicolumn{7}{|c|}{ chamber leaked - no data } \\
\hline & & 40 & PRE & 0.56 & NA & $0 / 6$ & $0 / 6$ & - \\
\hline \multirow[t]{3}{*}{ FS Animal DF 2} & bottom & 59 & PO & 0.57 & NA & $0 / 6$ & $0 / 6$ & - \\
\hline & middle & 72 & PO & 0.61 & NA & $0 / 6$ & $0 / 6$ & - \\
\hline & top & 42 & PO & 0.86 & NA & $0 / 6$ & $0 / 6$ & - \\
\hline
\end{tabular}

a. Pump was changed in this test to one with a lower flow rate $(2.9 \mathrm{l} / \mathrm{s})$.

b. $\quad \mathrm{PRE}=$ pre-flashover; $\mathrm{TR}=$ transition; $\mathrm{PO}=$ post-flashover

c. $\quad \mathrm{FED}$ values were calculated on $\mathrm{CO}, \mathrm{CO}_{2}, \mathrm{O}_{2}$.

NA Not applicable.

ND Not detected.

NM Not measured.

WE Within exposure

PE Post-exposure 
Table 17. Chemical and toxicological results for RPU in real-scale tests

\begin{tabular}{|c|c|c|c|c|c|c|c|c|c|}
\hline \multirow{2}{*}{ Test } & \multirow{2}{*}{$\begin{array}{l}\text { Animal } \\
\text { exposure } \\
\text { chamber }\end{array}$} & \multirow{2}{*}{$\begin{array}{l}\text { Time } \\
\text { chamber } \\
\text { closed } \\
(s)\end{array}$} & \multirow{2}{*}{$\begin{array}{l}\text { Time } \\
\text { animals } \\
\text { inserted } \\
(s)\end{array}$} & \multicolumn{6}{|c|}{ Average gas concentration } \\
\hline & & & & $\begin{array}{c}\mathrm{CO} \\
(\mathrm{ppm})\end{array}$ & $\begin{array}{c}\mathrm{CO}_{2} \\
(p p m)\end{array}$ & $\begin{array}{l}\mathrm{HCN} \\
(p p m)\end{array}$ & $\begin{array}{l}\mathrm{O}_{2} \\
\text { (\%) }\end{array}$ & $\begin{array}{c}\mathrm{NO}_{\mathrm{x}}^{\mathrm{a}} \\
(\text { ppm) }\end{array}$ & $\begin{array}{l}\mathrm{HCl}^{\mathrm{a}} \\
(\mathrm{ppm})\end{array}$ \\
\hline \multirow[t]{3}{*}{ FS Animal RPU 1} & bottom & 180 & 240 & 1300 & 32000 & 95 & 18.0 & ND & 60 \\
\hline & middle & 460 & 480 & 1700 & 48000 & 120 & 15.4 & 15 & 130 \\
\hline & top & 780 & 810 & 1200 & 25000 & 55 & 18.4 & 5 & 110 \\
\hline \multirow[t]{3}{*}{ FS Animal RPU 2} & bottom & 240 & 770 & 1300 & 40000 & 90 & 16.1 & 5 & 50 \\
\hline & middle & 360 & 520 & 1700 & 48000 & 120 & 15.3 & 15 & 60 \\
\hline & top & 480 & 990 & 1500 & 45000 & 110 & 15.5 & 10 & 40 \\
\hline
\end{tabular}

\begin{tabular}{|c|c|c|c|c|c|c|c|c|c|}
\hline & & & & & & & No.c & o. tested & \\
\hline & umber & $\begin{array}{l}\text { exposure } \\
\text { chamber }\end{array}$ & $\begin{array}{l}\text { conc. } \\
(\mathrm{mg} / \mathrm{l})\end{array}$ & ${ }_{b}^{1 m e}$ & WE & $\begin{array}{c}\text { WE }+ \\
P E\end{array}$ & WE & $\mathrm{WE}+\mathrm{PE}$ & PE death \\
\hline FS A & al RPU 1 & bottom & 30 & TR & 0.93 & 1.1 & $0 / 6$ & $1 / 6$ & 0 \\
\hline & & middle & 42 & PO & 1.4 & 1.6 & $1 / 6$ & $5 / 6$ & 4 \\
\hline & & top & 22 & PO & 0.67 & 0.79 & $0 / 6$ & $0 / 6$ & - \\
\hline FS A & al RPU 2 & bottom & 35 & PO & 1.0 & 1.2 & $1 / 6$ & $2 / 6$ & 2 \\
\hline & & middle & 42 & PO & 1.4 & 1.6 & $3 / 6$ & $3 / 6$ & - \\
\hline & & top & 39 & PO & 1.3 & 1.5 & $1 / 6$ & $6 / 6$ & 0 \\
\hline a. & 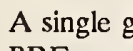 & nlk & & & & & & & \\
\hline b. & $\mathrm{PRE}=$ & over & 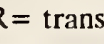 & ; $P$ & post- & hover & & & \\
\hline c. & $\begin{array}{l}\text { FED valu } \\
\text { for WE + }\end{array}$ & $\begin{array}{l}\text { were calcu } \\
\text { E. }\end{array}$ & ed on $C$ & $\mathrm{CO}_{2}$ & $\mathrm{ICN}$, & $\mathrm{d} \mathrm{O}_{2}$ for & and & $\mathrm{O}, \mathrm{CO}_{2}, \mathrm{H}$ & $\mathrm{J}, \mathrm{O}_{2}$, and $\mathrm{HCl}$ \\
\hline ND & Not detec & & & & & & & & \\
\hline WE & Within-ex & sure & & & & & & & \\
\hline PE & Post-expo & & & & & & & & \\
\hline
\end{tabular}


Table 18. Chemical and toxicological results for PVC in real-scale tests

\begin{tabular}{|c|c|c|c|c|c|c|c|c|c|c|}
\hline \multirow{2}{*}{\multicolumn{2}{|c|}{ Test }} & \multirow{2}{*}{$\begin{array}{l}\text { Animal } \\
\text { exposure } \\
\text { chamber }\end{array}$} & \multirow{2}{*}{\multicolumn{2}{|c|}{$\begin{array}{l}\text { Time } \\
\text { chamber } \\
\text { closed } \\
\text { (s) }\end{array}$}} & \multirow{2}{*}{$\begin{array}{l}\text { Time } \\
\text { animals } \\
\text { inserted } \\
\quad(s)\end{array}$} & \multicolumn{5}{|c|}{ Average gas concentration } \\
\hline & & & & & & $\begin{array}{c}\mathrm{CO} \\
(p p m)\end{array}$ & $\begin{array}{l}\mathrm{CO}_{2} \\
(p p m)\end{array}$ & $\begin{array}{l}\mathrm{HCN} \\
(p p m)\end{array}$ & $\begin{array}{l}\mathrm{O}_{2} \\
(\%)\end{array}$ & $\begin{array}{l}\mathrm{HCl}^{\mathrm{a}} \\
(p p m)\end{array}$ \\
\hline \multirow{3}{*}{\multicolumn{2}{|c|}{ FS Animal PVC 1}} & bottom & \multicolumn{2}{|l|}{180} & 210 & 4400 & 22000 & NM & 16.9 & 490 \\
\hline & & middle & \multicolumn{2}{|l|}{300} & 330 & 5600 & 27000 & NM & 16.4 & 1100 \\
\hline & & top & \multicolumn{2}{|l|}{420} & 440 & 8300 & $>52000^{\mathrm{b}}$ & NM & 13.0 & 1300 \\
\hline \multirow{3}{*}{\multicolumn{2}{|c|}{ FS Animal PVC 2}} & bottom & \multicolumn{2}{|l|}{135} & 160 & 2300 & 18000 & NM & 18.2 & 360 \\
\hline & & middle & \multicolumn{2}{|l|}{180} & 210 & 3700 & 17000 & NM & 18.0 & 820 \\
\hline & & top & \multicolumn{2}{|l|}{235} & 280 & 5500 & 34000 & NM & 15.3 & 1400 \\
\hline \multirow{3}{*}{\multicolumn{2}{|c|}{ FS Animal PVC 3}} & bottom & \multirow{3}{*}{\multicolumn{2}{|c|}{$\begin{array}{l}155 \\
215 \\
460\end{array}$}} & 175 & 2700 & 16000 & NM & 18.1 & 470 \\
\hline & & middle & & & 240 & 4100 & 20000 & NM & 17.6 & 750 \\
\hline & & top & & & 495 & 4400 & 28000 & NM & 17.1 & 480 \\
\hline \multirow{2}{*}{\multicolumn{2}{|c|}{ Test }} & \multirow{2}{*}{$\begin{array}{l}\text { Animal } \\
\text { exposure } \\
\text { chamber }\end{array}$} & \multirow{2}{*}{$\begin{array}{l}\text { Smoke } \\
\text { conc. } \\
(m g / l)\end{array}$} & \multirow{2}{*}{ Time } & \multicolumn{2}{|c|}{ FED $^{d}$} & \multicolumn{2}{|c|}{ No.died/no. tested } & \multirow{2}{*}{\multicolumn{2}{|c|}{$\begin{array}{l}\text { Latest day of } \\
\text { PE death }\end{array}$}} \\
\hline & & & & & WE & $\begin{array}{c}\text { WE + } \\
P E\end{array}$ & WE & $\begin{array}{c}\text { WE + } \\
P E\end{array}$ & & \\
\hline \multirow{3}{*}{\multicolumn{2}{|c|}{ FS Animal PVC 1}} & bottom & 37 & TR & 1.1 & 1.2 & $3 / 6$ & $3 / 6$ & & - \\
\hline & & middle & 46 & $\mathrm{PO}$ & 1.4 & 1.7 & $6 / 6$ & $6 / 6$ & & - \\
\hline & & top & NA & $\mathrm{PO}$ & 2.6 & 3.0 & $6 / 6$ & $6 / 6$ & & - \\
\hline \multirow{3}{*}{\multicolumn{2}{|c|}{ FS Animal PVC 2}} & bottom & 29 & PRE & 0.59 & 0.68 & $0 / 6$ & $0 / 6$ & & - \\
\hline & & middle & 29 & $\mathrm{PO}$ & 0.84 & 1.1 & $0 / 6$ & $0 / 6$ & & - \\
\hline & & & 56 & $\mathrm{PO}$ & 1.5 & 1.9 & $6 / 6$ & $6 / 6$ & & - \\
\hline \multirow{3}{*}{\multicolumn{2}{|c|}{ FS Animal PVC 3}} & bottom & 27 & TR & 0.65 & 0.78 & $0 / 6$ & $0 / 6$ & & - \\
\hline & & middle & 34 & $\mathrm{PO}$ & 0.95 & 1.2 & $0 / 6$ & $0 / 6$ & & - \\
\hline & & top & 46 & $\mathrm{PO}$ & 1.1 & 1.2 & $5 / 6$ & $5 / 6$ & & - \\
\hline \multicolumn{11}{|c|}{ a. $\quad$ Average of three bulb samples. } \\
\hline b. & \multirow{3}{*}{\multicolumn{10}{|c|}{$\begin{array}{l}\text { Average of three bulb samples. } \\
\text { Highest reading possible on instrument; actual average was higher. } \\
\mathrm{PRE}=\text { pre-flashover; } \mathrm{TR}=\text { transition; } \mathrm{PO}=\text { post-flashover. } \\
\text { FED values were calculated on } \mathrm{CO}, \mathrm{CO}_{2} \text {, and } \mathrm{O}_{2} \text { for } \mathrm{WE} \text { and on } \mathrm{CO}, \mathrm{CO}_{2}, \mathrm{O}_{2} \text {, and } \mathrm{HCl} \text { for } \mathrm{WE}+ \\
\mathrm{PE} \text {. }\end{array}$}} \\
\hline $\begin{array}{l}\text { c. } \\
\text { d. }\end{array}$ & & & & & & & & & & \\
\hline & & & & & & & & & & \\
\hline NA & \multicolumn{10}{|c|}{ Not available } \\
\hline NM & \multicolumn{10}{|c|}{ Not measured } \\
\hline WE & Within ex & osure & & & & & & & & \\
\hline PE & Post expo & & & & & & & & & \\
\hline
\end{tabular}




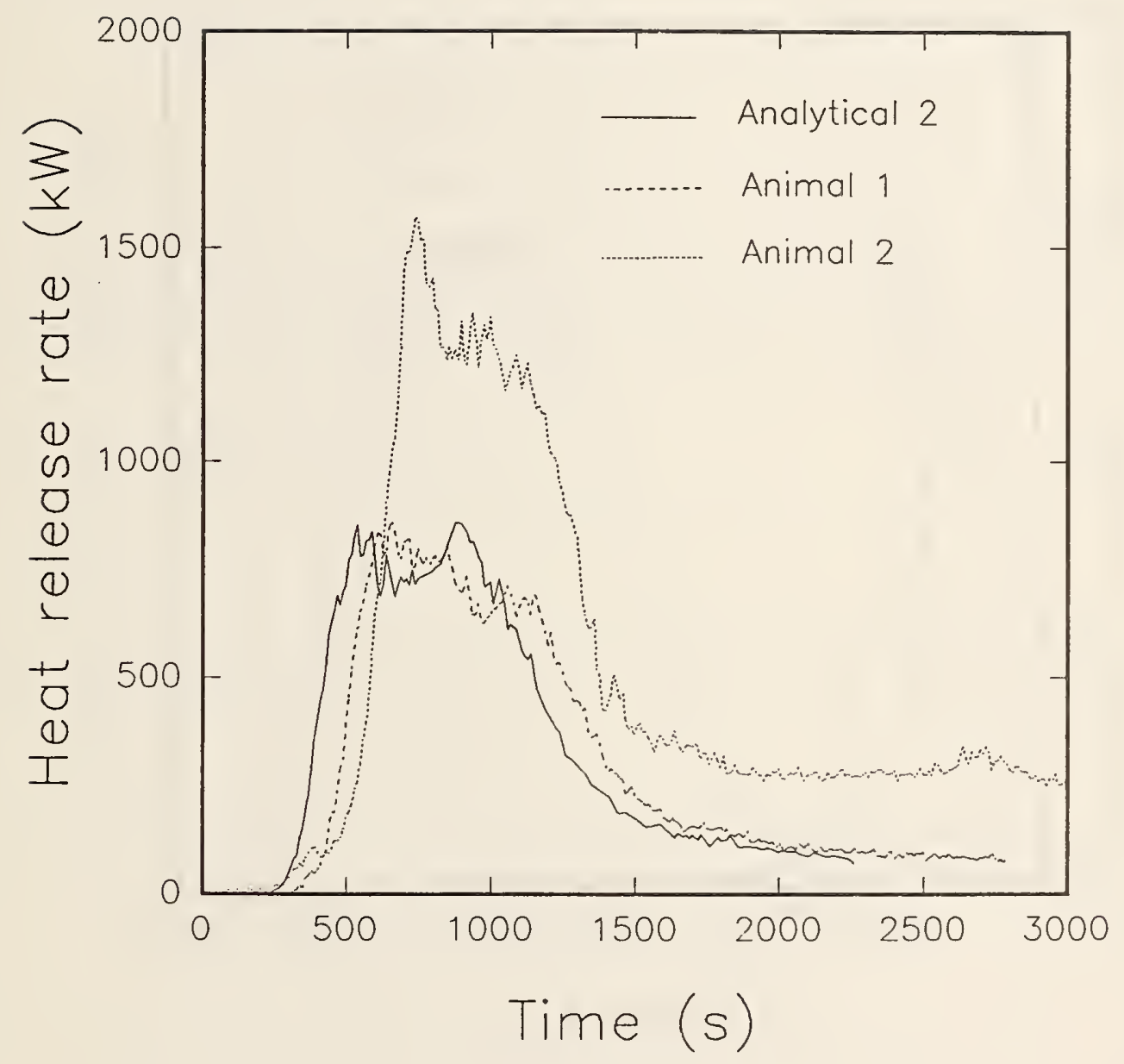

Figure 16. Heat release rates measured for DF in the real-scale tests 


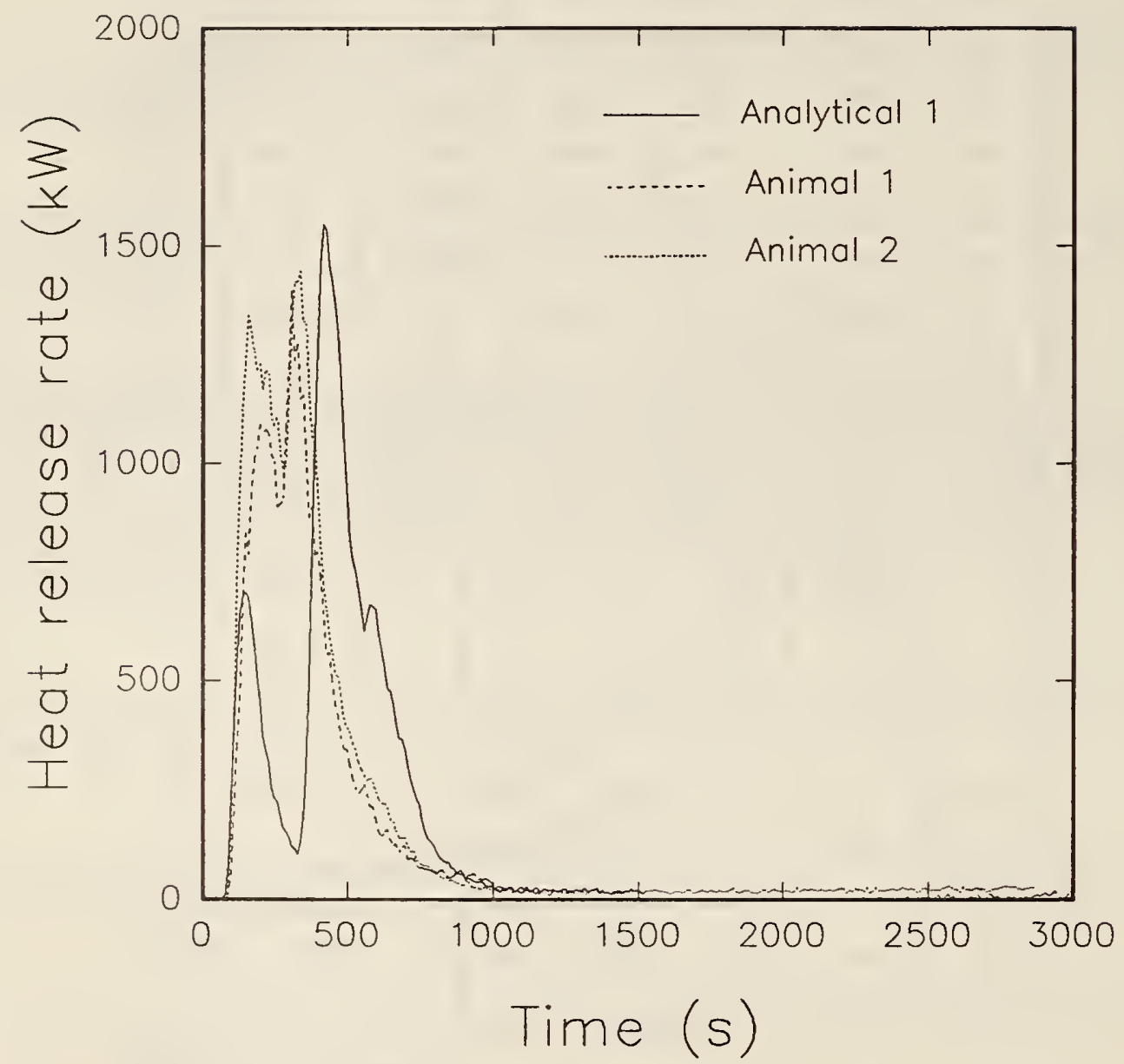

Figure 17. Heat release rates measured for RPU in the real-scale tests 


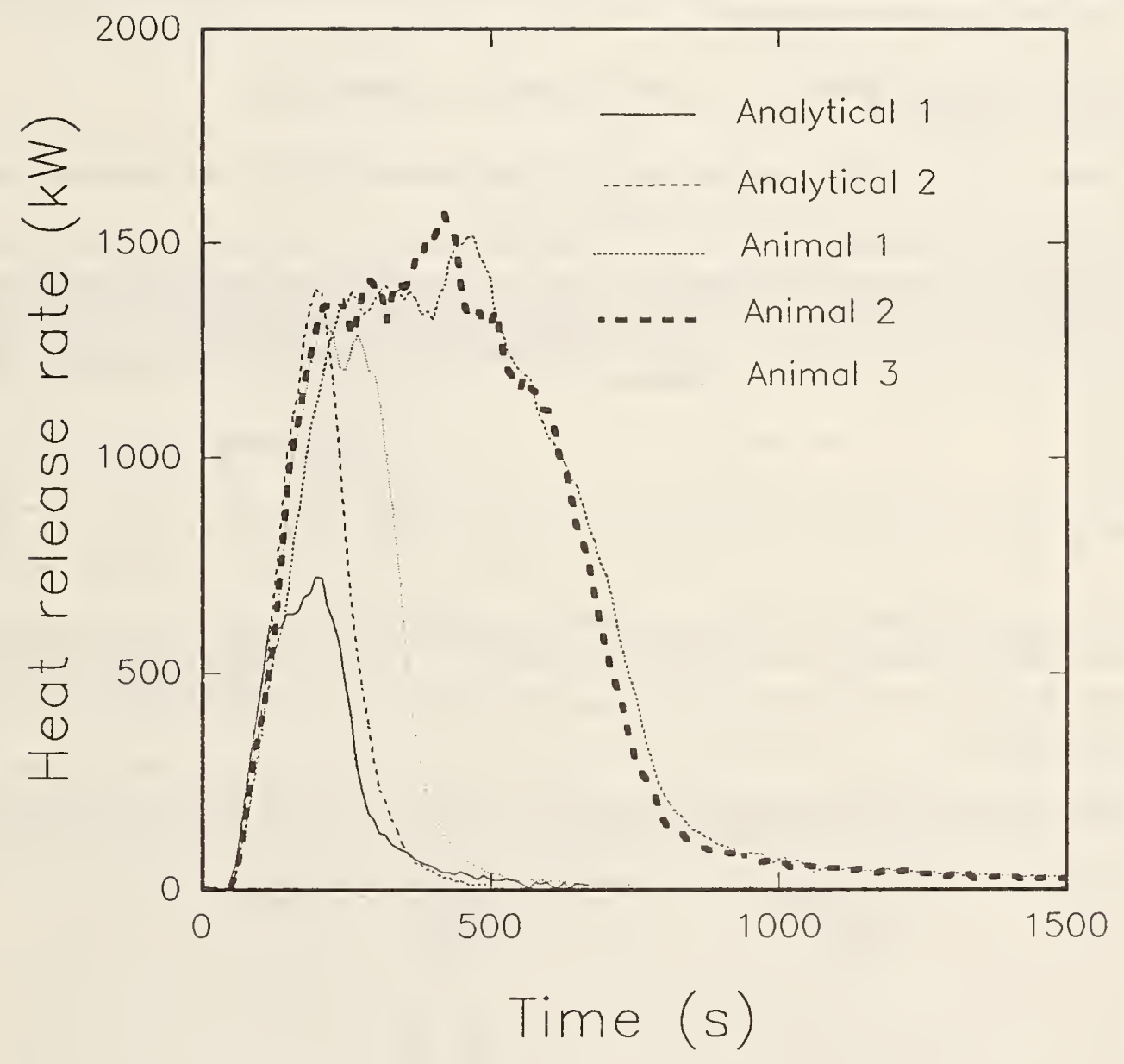

Figure 18. Heat release rates measured for PVC in the real-scale tests 
can be possible in other real-scale test arrangements where the specimen mass loss rate is monitored directly. In the present series, however, the mass loss had to be estimated from gas readings. While approximate values could be derived for the entire test period, computations made during the time when the (small) amount of mass is being lost pre-flashover could not be done with confidence.

Computation of $\mathrm{LC}_{50}$ values $\mathrm{A}$ direct measurement of the specimen mass which entered each animal box could not be made. To get an indirect estimate of the $\mathrm{LC}_{50}$ 's, we use the measured values of $\mathrm{CO}_{2}$ and $\mathrm{CO}$ in the animal boxes, along with the elemental analysis results for the materials. Taking a nominal $200 \ell$ box volume and a temperature of $298 \mathrm{~K}$, the relationship between grams of carbon in the box and the gas measurements is:

$$
\text { grams } C=9.78 \times 10^{-5}\left[\mathrm{ppm} \mathrm{CO}+\mathrm{ppm} \mathrm{CO}_{2}\right] \text {. }
$$

Using the values given in Table 1, and allowing for an additional $10 \%$ of fuel carbon which became species other than $\mathrm{CO}_{2}$ and $\mathrm{CO}$, it is now possible to give:

\begin{tabular}{|l|c|}
\hline Material & $\begin{array}{l}\text { To obtain fuel concentration in the box }(\mathrm{mg} / \ell), \\
\text { multiply }\left[\mathrm{ppm} \mathrm{CO}_{2}+\mathrm{ppm} \mathrm{CO}\right] \text { by }\end{array}$ \\
\hline DF & $1.12 \times 10^{-3}$ \\
\hline RPU & $0.84 \times 10^{-3}$ \\
\hline PVC & $1.42 \times 10^{-3}$ \\
\hline
\end{tabular}

The results are given in Tables 16 - 18, along with the notation as to whether the animal data were obtained pre-flashover, during (transition), or post-flashover. We will not consider further the preflashover data, and will consider the transition and the post-flashover data combined as denoting the post-flashover period.

From the above data, we can derive approximate values of the $\mathrm{LC}_{50}$ for the real-scale tests.

$\begin{array}{lcc}\text { Material } & \begin{array}{c}\text { Within exposure } \\ (\mathrm{mg} / \ell)\end{array} & \begin{array}{c}\text { Within exposure }+\mathbf{1 4} \text { days } \\ (\mathrm{mg} / \ell)\end{array} \\ \text { DF } & >70 & >70 \\ \text { RPU } & 40-50 & 30-40 \\ \text { PVC } & 35-45 & 35-45\end{array}$




\section{4}

\section{Discussion}

In Chapter 1 we postulated four promising validation hypotheses. We now must examine how well the bench-scale methods compare against them, based on the data collected in the pilot project. With this in hand, we will also be able to reflect on the utility or suitability of the proposed validation hypotheses themselves.

\section{The equal $\mathrm{LC}_{50}$ hypothesis}

$L C_{50}$ values, as measured in the bench-scale test and in the real-scale one, agree to within the acceptable uncertainty.

We will first compare the $\mathrm{LC}_{50}$ values of the two bench-scale methods, then compare bench-scale results to real-scale findings.

Comparison between bench-scale tests The values of $\mathrm{LC}_{50}$ obtained in the two bench-scale toxicity methods are compared in Table 19. These values are related to each other in roughly a similar proportion, but are different between the two test methods by factors of about 1.5 to 3 . Based on the postulated validation criterion of results agreeing to within a factor of two, successful agreement is seen for only some test materials, but not for others. To find out why that is so, we need to examine the yields of the gases in these tests. A comparison of yields is given in Tables 20-23. Looking at the yields of CO (Table 20), we can see for PVC the values in the NBS Cup Furnace method and the ones in the SwRI/NIST methods are roughly similar. For RPU, the values in the NBS Cup Furnace are about twice as high, while for DF they are auvut a factor of five to seven higher. Thus, such differences in $\mathrm{CO}$ yield are, not unexpectedly, showing up as differences in $\mathrm{LC}_{50}$ values.

It has already been pointed out that the generation of $\mathrm{CO}$ in fires is predominantly associated with ventilation and geometry effects in the actual real-scale environment [14]. Furthermore, available data indicate that $\mathrm{CO}$ yields in real-scale, post-flashover fires tend to a value of, very roughly, 0.2 $\mathrm{kg} / \mathrm{kg}$, with that value being largely independent of the material being burned. These are effects a bench-scale test cannot, reasonably, be asked to reproduce. The yield of $\mathrm{CO}$ produced in a specific bench-scale test will depend on the test in question; in general, however, these yields tend to be lower 
Table 19. Comparison of results for $\mathrm{LC}_{50}$

\begin{tabular}{|l|c|c|c|}
\hline \multirow{2}{*}{ Method } & \multicolumn{3}{|c|}{$\begin{array}{l}\text { LC }_{50}{ }^{\mathrm{a}} \\
(\mathrm{mg} / \ell)\end{array}$} \\
\cline { 2 - 4 } & DF & RPU & PVC \\
\hline NBS Cup Furnace & $41-51$ & $10-13$ & $18-22$ \\
\hline SwRI/NIST method & $100-200$ & $20-30$ & $20-30$ \\
\hline Real-scale & $>70$ & $30-40$ & $35-45$ \\
\hline
\end{tabular}

a. Values based on 30 min exposure +14 day post-exposure period; given as the $95 \%$ confidence interval for NBS Cup Furnace results, and as approximate ranges for SwRINIST results.

\begin{tabular}{|c|c|c|c|}
\hline Material & DF & RPU & PVC \\
\hline $\operatorname{MLR}\left(k g / m^{2} \cdot s\right)$ & $6.11 \times 10^{-3}$ & $4.84 \times 10^{-3}$ & $14.9 \times 10^{-3}$ \\
\hline $\mathrm{t}_{\mathrm{ig}}(s)$ & 14.0 & 3.0 & 34.8 \\
\hline \multicolumn{4}{|c|}{ NBS Cup Furnace data } \\
\hline $\mathrm{LC}_{50}(m g / \ell)$ & $41-51$ & $10-13$ & $18-22$ \\
\hline $\mathrm{LC}_{50}$ (corr) $(\mathrm{mg} / \mathrm{\ell})$ & $21-24$ & $9-12$ & $16-19$ \\
\hline $\mathrm{m}_{100}(\mathrm{~g})$ & 8.9 & 2.4 & 3.6 \\
\hline [CO] (ppm) & 3800 & 1800 & 1400 \\
\hline relative FED & 0.02 & $0.1-0.2$ & 0.03 \\
\hline \multicolumn{4}{|c|}{ SwRI/NIST data } \\
\hline $\mathrm{LC}_{50}(\mathrm{mg} / \mathrm{\ell})$ & $100-200$ & $20-30$ & $20-30$ \\
\hline $\mathrm{LC}_{50}($ corr $)(m g / \ell)$ & $21-23$ & $14-19$ & $13-17$ \\
\hline $\mathrm{m}_{100}(\mathrm{~g})$ & 31.3 & 5.3 & 4.2 \\
\hline $\mathrm{CO}(p p m)$ & 4000 & 2600 & 1600 \\
\hline relative FED & $0.01-0.02$ & 0.1 & $0.02-0.03$ \\
\hline
\end{tabular}

than $0.2 \mathrm{~kg} / \mathrm{kg}$. Appendix $\mathrm{C}$ gives details on how $\mathrm{LC}_{50}$ measurements made in bench-scale tests where $\mathrm{CO}$ yields are not equal to 0.2 can be computationally adjusted, using a relative FED concept, to correspond to $\mathrm{f}_{\mathrm{CO}}=0.2$. Such calculations have been performed and are given in Table 19. The necessary values of $\dot{m}$ " are taken as the MLR values from the Cone Calorimeter (Table 11) at a flux of $50 \mathrm{~kW} / \mathrm{m}^{2}$. The value of $\mathrm{A}$ is taken as $1 /$ (ignition time).

The result for these relative FED's are shown in Table 19. It can now be seen that, on this basis, the toxicity of DF and PVC are identical in the two methods to within their respective error bands. 
Table 20. Yields of CO

\begin{tabular}{|l|c|c|c|c|}
\hline \multicolumn{1}{|c|}{ Method } & $\begin{array}{c}\text { Test } \\
\text { conditions }\end{array}$ & DF & RPU & PVC \\
\hline $\begin{array}{l}\text { NBS } \\
\text { Cup Furnace }\end{array}$ & flaming & 0.2 & 0.2 & 0.1 \\
\hline SwRI/NIST & $\mathrm{a}$ & $0.03-0.04$ & $0.09-0.12$ & 0.09 \\
\hline $\begin{array}{l}\text { Cone } \\
\text { Calorimeter }\end{array}$ & $35 \mathrm{~kW} / \mathrm{m}^{2}$ & 0.005 & 0.06 & 0.08 \\
\cline { 2 - 5 } & $50 \mathrm{~kW} / \mathrm{m}^{2}$ & 0.003 & 0.08 & 0.08 \\
\cline { 2 - 5 } & $75 \mathrm{~kW} / \mathrm{m}^{2}$ & 0.003 & 0.04 & 0.07 \\
\hline $\begin{array}{l}\text { Furniture } \\
\text { Calorimeter }\end{array}$ & average & 0.013 & 0.08 & $\mathrm{~b}$ \\
\cline { 2 - 5 } & steady-state & 0.012 & 0.06 & $0.2-0.5$ \\
\hline Real-scale & $\begin{array}{c}\text { in exhaust } \\
\text { stack }\end{array}$ & $0.07-0.12$ & $0.10-0.14$ & \\
\hline a. Range for the following tests \\
DF: DF-A4, DF-A6, DF-1, DF-2, DF-3 \\
RPU: RPU-1, RPU-2, RPU-3 \\
PVC: FS-1, FS-2, FS-3, FS-4
\end{tabular}

The FED results for RPU are not within the respective error bands, but still are well within a factor of two. On the assumption that the treatment in Appendix $C$ is accurate for the present configuration, the above analysis confirms that the differences in the two methods are mostly due to differences in $\mathrm{CO}$ production.

For RPU, the remaining differences between the methods in FED value can be addressed on the basis of $\mathrm{HCN}$ yield. Table 4 shows that the yield of $\mathrm{HCN}$ in the NBS Cup Furnace method is about 0.017 , while Table 9 gives the comparable yield in the SwRI/NIST method as 0.004 . These differences are substantive. For the NBS Cup Furnace method, the fraction of FED accounted for by the HCN is $140 / 150=0.93$, while for the SwRI/NIST method it is approximately 90/150 $=0.60$. This difference in $\mathrm{HCN}$ yield can essentially explain the residual difference between the methods.

It is not surprising that the generation of $\mathrm{HCN}$, similarly as it is for $\mathrm{CO}$, should be different in a thermal-immersion test, such as the NBS Cup Furnace method, from the radiant heat combustion system of the SwRI/NIST apparatus. Which is 'right,' however, remains to be established.

On the basis of these concepts, it can also be convenient to consider a 'corrected $\mathrm{LC}_{50}$,' which is the $\mathrm{LC}_{50}$ that would have been measured, had the $\mathrm{CO}$ yield been exactly $=0.2$. These values are also 
Table 21. Yields of $\mathrm{CO}_{2}$

\begin{tabular}{|c|c|c|c|c|}
\hline Method & Test conditions & DF & RPU & PVC \\
\hline $\begin{array}{l}\text { Notional value } \\
\text { for complete } \\
\text { combustion }\end{array}$ & - & 1.76 & 2.17 & 1.40 \\
\hline $\begin{array}{l}\text { NBS } \\
\text { Cup Furnace }\end{array}$ & flaming & $1.3-1.5$ & $1.6-2.6^{\mathrm{a}}$ & $1.1-1.5$ \\
\hline SwRI/NIST & b & $1.0-1.8$ & $0.6-0.8$ & $1.4-2.0$ \\
\hline \multirow{3}{*}{$\begin{array}{l}\text { Cone } \\
\text { Calorimeter }\end{array}$} & $35 \mathrm{~kW} / \mathrm{m}^{2}$ & 0.9 & 1.1 & 0.4 \\
\hline & $50 \mathrm{~kW} / \mathrm{m}^{2}$ & 1.0 & 1.2 & 0.4 \\
\hline & $75 \mathrm{~kW} / \mathrm{m}^{2}$ & 1.0 & 1.2 & 0.3 \\
\hline \multirow{2}{*}{$\begin{array}{l}\text { Furniture } \\
\text { Calorimeter }\end{array}$} & average & 1.6 & 2.1 & $\mathrm{c}$ \\
\hline & steady-state & 1.6 & 1.4 & c \\
\hline Real-scale & $\begin{array}{c}\text { in exhaust } \\
\text { stack }\end{array}$ & $1.2-1.8$ & $1.5-2.2$ & $0.3-1.1$ \\
\hline \multicolumn{5}{|c|}{$\begin{array}{l}\text { a. Excludes results at the highest }(40 \mathrm{mg} / \ell) \text { loading. } \\
\text { b. } \\
\text { Range for the following tests } \\
\text { DF: DF-A4, DF-A6, DF-1, DF-3 } \\
\text { RPU: RPU-1, RPU-2, RPU-3 } \\
\text { PVC: FS-1, FS-2, FS-3, FS-4 } \\
\text { c. Not measurable, due to no sustained burning. }\end{array}$} \\
\hline
\end{tabular}

reported in Table 19. The agreement for DF between the two bench-scale methods on the basis of $\mathrm{LC}_{50}$ (corr) is spot-on, while for RPU and PVC it is still within a factor of two.

Thus, for the present data set, it can be concluded that the raw $\mathrm{LC}_{50}$ data from the two bench-scale methods, do not agree to within the factor of two, but do agree when adjusted for $\mathrm{CO}$.

Comparison of bench-scale to real-scale data Comparing now the bench-scale data to the real-scale, Table 19 shows that for the NBS Cup Furnace method the raw LC $_{50}$ RPU data do not agree with the real-scale results to within a factor of two, while the PVC data are marginally at about a factor of two discrepancy. An estimate of the real-scale DF $\mathrm{LC}_{50}$ could not be obtained. The data from the SwRI/NIST method agree comfortably to within a factor of two for both RPU and PVC. 
Table 22. Yields of $\mathrm{HCN}$

\begin{tabular}{|c|c|c|c|c|}
\hline Method & Test conditions & $\mathrm{DF}$ & RPU & PVC \\
\hline $\begin{array}{l}\text { Notional value } \\
\text { for complete } \\
\text { combustion }\end{array}$ & - & 0.077 & 0.123 & 0.008 \\
\hline $\begin{array}{l}\text { NBS } \\
\text { Cup Furnace }\end{array}$ & flaming & - & $0.016-0.020$ & - \\
\hline SwRI/NIST & $\mathrm{a}$ & - & $0.002-0.004$ & - \\
\hline \multirow{3}{*}{$\begin{array}{l}\text { Cone } \\
\text { Calorimeter }\end{array}$} & $35 \mathrm{~kW} / \mathrm{m}^{2}$ & - & 0.005 & - \\
\hline & $50 \mathrm{~kW} / \mathrm{m}^{2}$ & - & 0.005 & - \\
\hline & $75 \mathrm{~kW} / \mathrm{m}^{2}$ & - & 0.004 & - \\
\hline Real-scale & $\begin{array}{l}\text { in bypass line } \\
\text { ahead of the } \\
\text { animal boxes }\end{array}$ & - & $0.005-0.011$ & - \\
\hline \multicolumn{5}{|c|}{$\begin{array}{l}\text { a. Range for the following tests } \\
\text { RPU: RPU-1, RPU-2, RPU-3 }\end{array}$} \\
\hline
\end{tabular}

If the comparison is made in terms of the bench-scale $\mathrm{LC}_{50}$ values corrected for a $\mathrm{CO}$ yield of 0.2 , then Table 19 shows that RPU agreement is still not achieved for the NBS Cup Furnace and is, now, only marginally achieved to within a factor of two for the SwRI/NIST method. For PVC, the corrected $\mathrm{LC}_{50}$ data from the NBS Cup Furnace method remains marginally a factor of two away from the real-scale results, while the SwRI/NIST method values are about a factor of three apart.

Thus, in the present test series it is found, on the basis of raw bench-scale $\mathrm{LC}_{50}$ values, that agreement of the SwRI/NIST method to the real-scale results is within a factor of two, while for the NBS Cup Furnace method it is within a factor of three. On the basis of bench-scale $\mathrm{LC}_{50}$ values corrected to a $\mathrm{CO}$ yield of 0.2 , both bench-scale methods can only achieve agreement to the real-scale data to within a factor of three.

\section{The primary toxic gases hypothesis}

The bench-scale test shows the same primary toxic gases as the real-scale test.

A criterion which should be satisfied for successful validation is that the list of gases which contribute a statistically significant amount to the FED should be the same for a bench-scale test being validated 
Table 23. Yields of $\mathrm{HCl}$

\begin{tabular}{|l|c|c|c|c|}
\hline \multicolumn{1}{|c|}{ Method } & Test conditions & DF & RPU & PVC \\
\hline $\begin{array}{l}\text { Notional value } \\
\text { for complete } \\
\text { combustion }\end{array}$ & - & 0.00005 & 0.014 & 0.443 \\
\hline $\begin{array}{l}\text { NBS } \\
\text { Cup Furnace }\end{array}$ & flaming & - & - & $0.20-0.30$ \\
\hline SwRI & $\mathrm{a}$ & - & - & $0.21-0.26$ \\
\hline $\begin{array}{l}\text { Cone } \\
\text { Calorimeter }\end{array}$ & $35 \mathrm{~kW} / \mathrm{m}^{2}$ & - & - & 0.30 \\
\cline { 2 - 5 } & $50 \mathrm{~kW} / \mathrm{m}^{2}$ & - & - & 0.30 \\
\cline { 2 - 5 } & $75 \mathrm{~kW} / \mathrm{m}^{2}$ & - & - & $0.09-0.22$ \\
\hline \multirow{2}{*}{$\begin{array}{l}\text { Real-scale } \\
\text { in bypass line } \\
\text { ahead of the } \\
\text { animal boxes }\end{array}$} & - & - & \\
\hline \multirow{2}{*}{$\begin{array}{l}\text { Range for the following tests } \\
\text { DF: DF-A4, DF-A6, DF-1, DF-2, DF-3 } \\
\text { RPU: RPU-1, RPU-2, RPU-3 } \\
\text { PVC: FS-1, FS-2, FS-3, FS-4 }\end{array}$} & \\
\hline
\end{tabular}

as it is for the real-scale test. These we are calling primary gases. The criterion of significance might, ideally, be the $95 \%$ confidence interval for interlaboratory reproducibility. Interlaboratory data are not available at present. Instead, we will use a preliminary value for the repeatability confidence interval (i.e., obtained in only a single laboratory). Based on our studies of pure gases and gas mixtures, a value of 0.20 is used as the criterion of significance. This means that only those gases contributing 0.20 or more to the FED are listed. The comparative lists of primary gases are given in Table 27. Since $\mathrm{CO}$ and $\mathrm{CO}_{2}$ only occur in the FED formula as a combined entity, they are so handled here. Note that the lists in Table 27 are made up based on actual test measurements - the computational adjustment to $\mathrm{CO}$ data is not reflected in this tabulation. Table 27 clearly serves to illustrate the pilot nature of this project - the list of fuels studied is small, and so the list of primary gases that can be assembled is also limited.

On the whole, the primary-gas lists are the same, with a few exceptions: oxygen concentrations are clearly not well represented in bench-scale burning. This is not surprising, since the details of a fire's fuel/air history cannot reasonably be represented in a bench-scale device. The second difference, at first surprising, is that while $\mathrm{HCl}$ is on list for the two bench-scale tests, it is not for the real-scale PVC tests (the real-scale FED contribution is 0.13 , which is below the 0.20 statistically significant limit). This is because the wall losses to the sampling duct reduce the value of $\mathrm{HCl}$ available at the 
Table 24. Comparison of the lists of primary gases

\begin{tabular}{|c|l|l|l|}
\hline Material & \multicolumn{1}{|c|}{$\mathrm{NBS}^{2}$ Cup Furnace } & SwRINIST apparatus & \multicolumn{1}{c|}{ Real-scale tests } \\
\hline $\mathrm{DF}$ & $\mathrm{CO} / \mathrm{CO}_{2}, \mathrm{O}_{2}$ & $\mathrm{CO} / \mathrm{CO}_{2}$ & (not determined) \\
\hline $\mathrm{RPU}$ & $\mathrm{CO} / \mathrm{CO}_{2}, \mathrm{HCN}$ & $\mathrm{CO} / \mathrm{CO}_{2}, \mathrm{HCN}$ & $\mathrm{CO} / \mathrm{CO}_{2}, \mathrm{O}_{2}, \mathrm{HCN}$ \\
\hline $\mathrm{PVC}$ & $\mathrm{CO} / \mathrm{CO}_{2}, \mathrm{HCl}$ & $\mathrm{CO} / \mathrm{CO}_{2}, \mathrm{HCl}$ & $\mathrm{CO} / \mathrm{CO}_{2}, \mathrm{O}_{2}$ \\
\hline
\end{tabular}

a. Runs analyzed for each method correspond, as closely as possible, to one producing $50 \%$ animal lethalities. For the real-scale tests, pre-flashover data are excluded.

measuring point; indeed, the toxicity results for these FS tests show no PE deaths, contrary to what would be expected if $\mathrm{HCl}$ were a significant contributor. Thus, this is an anomaly in terms of the sampling procedure, but it is explainable.

Based on these investigations, then, is the primary-gases hypothesis viable? The hypothesis is viable, if two points are accepted.

- Combustion condition differences may result in substantially different levels of oxygen depletion. Thus, disagreement on whether oxygen depletion is or is not a primary gas may reflect merely the supply of oxygen to the apparatus and not an intrinsic toxicity characteristic of the test material.

- Species highly prone to losses by surface sorption may be lost enough in one test to fall below the cut-off value, while not falling as low in another.

In cases such as the above for $\mathrm{HCl}$, where losses in the bench-scale method are lower than in the real-scale test, it should be proper to retain them on the primary gases list, especially when, as for $\mathrm{HCl}$, methods for computing the losses [41], as well as using them in room fire hazard computation programs [42], are available.

The two bench-scale methods examined in the pilot project, then, do not show an unexplainable discrepancy when compared against the real-scale results for the three test materials used.

\section{The equal yields hypothesis}

The yields of the measured toxic gases are the same, to within the acceptable uncertainty, in the benchscale and in the real-scale tests.

The yields of gases are compared in Tables 20 - 23. As stated above, the values for the real-scale tests could only be derived as test-average numbers. It may be reasonably assumed, however, that for the post-flashover period, the $\mathrm{CO}$ yields are higher than the test average, while the $\mathrm{CO}_{2}$ yields 
are correspondingly lower. For the SwRI/NIST results, since the test runs covered a wide range of conditions, only those which capture the main thrust of the data were compared; the exact test identifications are given in each of the tables.

For PVC, the $\mathrm{CO}$ yields are very similar for all of the less-than-room-scale tests. For RPU, the CO yields in the SwRI/NIST apparatus, the Cone Calorimeter, and the Furniture Calorimeter are, essentially, similar; the value from the NBS Cup Furnace method, however, is about twice that of the remaining tests. For DF, the Cone Calorimeter gives the very low yields characteristic of materials without FR additives. The $\mathrm{CO}$ yield from the Furniture Calorimeter is a factor of four higher, while for the SwRI/NIST method it is a factor of three higher yet. Finally, for the NBS Cup Furnace method, the $\mathrm{CO}$ yield for DF is nearly an order of magnitude greater than for the Furniture Calorimeter.

For the real-scale tests, the CO yields for DF and RPU were both around 0.1. For the PVC tests, this range is $0.2-0.4$. Both sets of values are typical of results normally obtained in fully-involved room fires [43]. Whether the difference between 0.1 and $0.2-0.4$ is due to different fuel/air mixtures being represented in the respective samples, or whether this represents an actual, small fuel effect, cannot be stated at this time. Confirming the statements made earlier that bench-scale tests do not predict $\mathrm{CO}$ yields in real-scale, none of the bench-scale tests show the same trends as seen in the real scale.

The yields of $\mathrm{CO}_{2}$ are similar in the NBS Cup Furnace and in the Furniture Calorimeter. The results from the SwRI/NIST method are also within the same range, except for RPU, which shows about half the yield as do the two preceding methods. (We remind the reader here that for neither of the methods is the $\mathrm{CO}_{2}$ yield corrected for the respiration of the animals; this, however, is a small effect and would not likely be seen in the data scatter.) The Cone Calorimeter yields for all three materials are lower than for the other methods; this factor ranges from about two for DF and RPU to three for PVC. Such low values possibly reflect an instrumentation irregularity, since $\mathrm{CO}_{2}$ yields in the Cone Calorimeter are normally significantly closer to the notional yields for complete combustion.

Within a broad band, the real-scale test results reflect the trends noted in the bench-scale.

The yields of $\mathrm{HCN}$ in the SwRI/NIST apparatus are lower than in the real-scale by about a factor of three. The yields in the NBS Cup Furnace, by contrast, are high by about a factor of 2.5. The Cone Calorimeter yields agree with the real-scale to within about a factor of two.

The yields for $\mathrm{HCl}$ agree very closely in the NBS Cup Furnace method and in the SwRI/NIST apparatus. These values are about one-half of what would happen if all of $\mathrm{Cl}$ were recovered as $\mathrm{HCl}$. This difference is not at all difficult to understand, since there are losses both in the exposure chamber and in the sampling system. This effect has been documented by Galloway and associates [44]. The values for the Cone Calorimeter are also very similar to the values obtained in the toxicity tests.

For real-scale $\mathrm{HCl}$ yields, it was, as discussed above, impossible to sample in such a way as to not lose a significant portion. This is not unrealistic from the point of view of fire modeling - an individual with his face very close to the fire will suffer ill consequences way beyond $\mathrm{HCl}$ exposure. From the point of view of a simple comparison of yields, difficulties are presented. Thus, the data in Table 23 
on real-scale $\mathrm{HCl}$ yields are not directly comparable to values obtained in the bench-scale toxicity tests, which even though significant [44], are still not as large. With this in mind, the $0.1-0.2$ value from the real-scale tests is not too far apart from the $0.2-0.25$ seen in the bench-scale tests.

In summary, this hypothesis is not readily met. The yields in the bench-scale toxic potency tests are equal to those in the real-scale to within a factor of two only in some cases, the exceptions being:

- For $\mathrm{CO}$ the agreement is not critical, since it is already noted that bench-scale test conditions are not expected to simulate the real-scale ones.

- For HCN, the values with the SwRI/NIST method were about a factor of three lower than ones in the real scale, while the values in the NBS Cup Furnace were about a factor of 2.5 higher.

\section{The N-Gas hypothesis}

The real-scale and the bench-scale results agree, to within the acceptable uncertainty, with predictions based on measured gas concentrations and computations made according to the N-Gas Model.

The data needed to make these comparisons are given in Tables $25-27$. For the real-scale tests, we will only consider the post-flashover (including transition period) data. We will primarily focus here on the within-exposure + post-exposure results, although the results obtained solely in the WE period are also tabulated. For clarity, we state results here to only one decimal place. 
Table 25. Comparison of bench- and real-scale toxicity results for DF

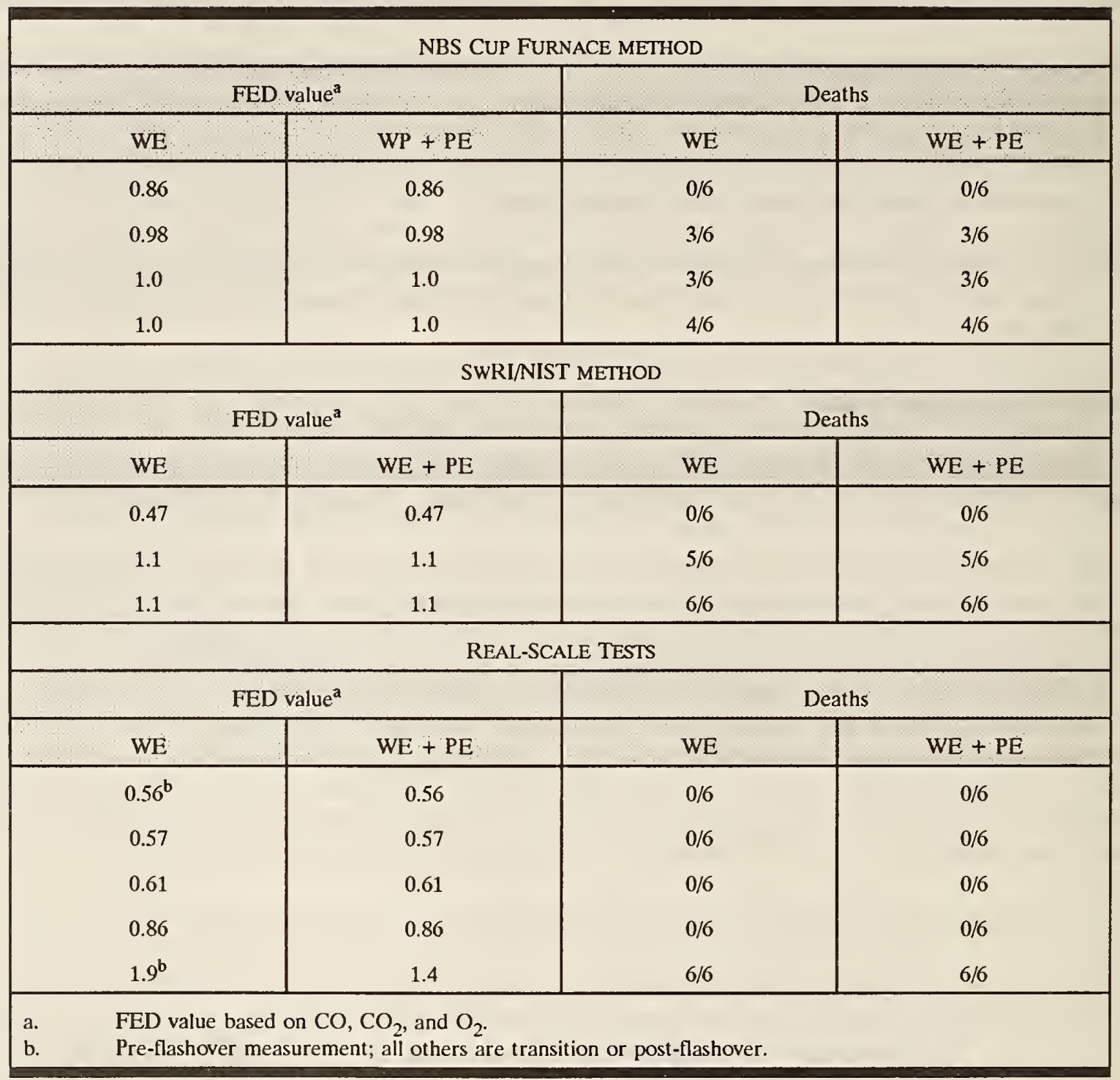


Table 26. Comparison of bench- and real-scale toxicity results for RPU

\begin{tabular}{|c|c|c|c|}
\hline \multicolumn{4}{|c|}{ NBS CUP FURNACE METHOD } \\
\hline \multicolumn{2}{|c|}{ FED value ${ }^{\mathrm{a}}$} & \multicolumn{2}{|c|}{ Deaths } \\
\hline WE & $W E+P E$ & WE & $\mathrm{WE}+\mathrm{PE}$ \\
\hline 1.0 & 1.3 & $0 / 6$ & $2 / 6$ \\
\hline 1.1 & 1.4 & $3 / 6$ & $5 / 6$ \\
\hline 1.3 & 1.6 & $4 / 6$ & $5 / 6$ \\
\hline 1.3 & 1.6 & $5 / 6$ & $6 / 6$ \\
\hline \multicolumn{4}{|c|}{ SWRI/NIST METHOD } \\
\hline \multicolumn{2}{|c|}{ FËD value ${ }^{\mathrm{a}}$} & \multicolumn{2}{|c|}{ Deaths } \\
\hline WE & $W E+P E$ & WE & $\mathrm{WE}+\mathrm{PE}$ \\
\hline 0.57 & 0.65 & $0 / 6$ & $0 / 6$ \\
\hline 1.1 & 1.3 & $6 / 6$ & $6 / 6$ \\
\hline 1.7 & 1.9 & $6 / 6$ & $6 / 6$ \\
\hline \multicolumn{4}{|c|}{ REAL-SCALE TESTS } \\
\hline \multicolumn{2}{|c|}{ FED value } & \multicolumn{2}{|c|}{ Deaths } \\
\hline WE & $W E+P E$ & WE & $\mathrm{WE}+\mathrm{PE}$ \\
\hline 0.67 & 0.79 & $0 / 6$ & $0 / 6$ \\
\hline 0.93 & 1.1 & $0 / 6$ & $1 / 6$ \\
\hline 1.0 & 1.2 & $1 / 6$ & $2 / 6$ \\
\hline 1.3 & 1.5 & $1 / 6$ & $6 / 6$ \\
\hline 1.4 & 1.6 & $1 / 6$ & $5 / 6$ \\
\hline 1.4 & 1.6 & $3 / 6$ & $3 / 6$ \\
\hline
\end{tabular}

For the NBS Cup Furnace method, 50\% animal lethalities occur at:

$\begin{array}{lc}\text { DF: } & 1.0 \\ \text { RPU: } & 1.3-1.4 \\ \text { PVC: } & 1.0-1.3\end{array}$

For the SwRI/NIST method, 50\% animal lethalities occur at:

DF: $\quad 0.5-1.1$

RPU: $0.7-1.3$

PVC: $0.9-1.3$ 
Table 27. Comparison of bench- and real-scale toxicity results for PVC

\begin{tabular}{|c|c|c|c|}
\hline \multicolumn{4}{|c|}{ NBS CUP FURNACE METHOD } \\
\hline \multicolumn{2}{|c|}{ FED value ${ }^{a}$} & \multicolumn{2}{|c|}{ Deaths } \\
\hline WE & $W E+P E$ & WE & $\mathrm{WE}+\mathrm{PE}$ \\
\hline 0.28 & 0.84 & $0 / 6$ & $1 / 6$ \\
\hline 0.21 & 0.90 & $0 / 5$ & $1 / 5$ \\
\hline 0.22 & 0.99 & $0 / 6$ & $3 / 6$ \\
\hline 0.29 & 1.0 & $0 / 6$ & $2 / 6$ \\
\hline 0.29 & 1.1 & $0 / 6$ & $3 / 6$ \\
\hline 0.31 & 1.3 & $0 / 6$ & $4 / 6$ \\
\hline \multicolumn{4}{|c|}{ SWRI/NIST METHOD } \\
\hline \multicolumn{2}{|c|}{ FED value ${ }^{a}$} & \multicolumn{2}{|c|}{ Deaths } \\
\hline WE & $W E+P E$ & WE & $\mathrm{WE}+\mathrm{PE}$ \\
\hline 0.32 & 0.64 & $0 / 6$ & $0 / 6$ \\
\hline 0.38 & 0.86 & $0 / 6$ & $3 / 6$ \\
\hline 0.47 & 0.87 & $0 / 6$ & $1 / 6$ \\
\hline 0.59 & 1.3 & $0 / 6$ & $6 / 6$ \\
\hline \multicolumn{4}{|c|}{ REAL-SCALE TESTS } \\
\hline \multicolumn{2}{|c|}{ FED value ${ }^{\mathrm{a}}$} & \multicolumn{2}{|c|}{ Deaths } \\
\hline WE & $W E+P E$ & WE & $W E+P E$ \\
\hline $0.59^{\mathrm{b}}$ & 0.68 & $0 / 6$ & $0 / 6$ \\
\hline 0.65 & 0.78 & $0 / 6$ & $0 / 6$ \\
\hline 0.84 & 1.1 & $0 / 6$ & $0 / 6$ \\
\hline 0.95 & 1.2 & $0 / 6$ & $0 / 6$ \\
\hline 1.1 & 1.2 & $3 / 6$ & $3 / 6$ \\
\hline 1.1 & 1.2 & $5 / 6$ & $5 / 6$ \\
\hline 1.4 & 1.7 & $6 / 6$ & $6 / 6$ \\
\hline 1.5 & 1.9 & $6 / 6$ & $6 / 6$ \\
\hline 2.6 & 3.0 & $6 / 6$ & $6 / 6$ \\
\hline
\end{tabular}


For the real-scale tests, $50 \%$ animal lethalities occur at:

DF: (not determined)

RPU: $1.2-1.6$

PVC: $\quad 1.2$

Since pure gas studies using the formulas for the FED already given show that the expected $\mathrm{LC}_{50}$ occurs at $1.1 \pm 0.2$, we would expect all of the above results to lie within the range 0.9 to 1.3 . For most of the data, the above results indeed do bear this out. The exceptions are: RPU in all tests, and the wide uncertainty intervals of the SwRI/NIST data. The wide uncertainty intervals of the SwRI/NIST method merely reflect the fact that the data were of an exploratory nature, and a sufficient number of tests was not run to narrow down to a small interval. The RPU results for the NBS Cup Furnace and for the real-scale tests are somewhat higher than the expected range. This has been noticed in previous studies [45] and indicates that lethalities observed when decomposing $\mathrm{HCN}$-producing materials are lower than when studying pure gas mixtures. This is considered to be an antagonism between $\mathrm{HCN}$ and $\mathrm{NO}_{2}$. It occurs since $\mathrm{NO}_{2}$ is emitted when $\mathrm{N}$-containing materials are burned, but not when gas mixtures with $\mathrm{HCN}$ (but no $\mathrm{NO}_{2}$ ) are used. Work is ongoing in our laboratories to quantify this effect and to incorporate it into the N-Gas Model. When the NGas Model is updated to include both $\mathrm{NO}_{2}$ and the interactions between $\mathrm{HCN}$ and $\mathrm{NO}_{2}$, this anomaly is expected to be resolved.

We conclude that the present 5-gas Model successfully predicts the results of present test series to within a factor of two in all cases and to within $30 \%$ in most cases.

\section{The type of death hypothesis}

The type of death (within-or post-exposure) is similar for the bench-scale and for the real-scale tests.

It is possible that test animals may die under similar exposure conditions in two different test methods. Such agreement may be fortuitous if the causes of death are notably different. In a basic analysis, we distinguish between narcotic gases, which cause lethalities during (or very shortly after) the exposure, and irritant gases, which typically cause lethalities several hours or days post-exposure. Thus, if in the case of one test method the lethalities are all within-exposure, and with a second method the lethalities occur post-exposure, then it is clear that the two test methods are not measuring the same behavior, even if numeric toxic potency values should agree. The purpose of the present validation hypothesis, then, is to assure ourselves that such a disparity is not ignored.

Details of the type of the deaths (within exposure or post-exposure) of the animals for the tests conducted are given in Table 28. Within-exposure deaths are defined as those that occur during the $30 \mathrm{~min}$ exposure or within $5 \mathrm{~min}$ following the exposure. Post-exposure deaths are defined as those that occur later. The normal period for post-exposure monitoring is 14 days. During this period animal weights are monitored daily. If the animal is still losing weight on day 14, the time is extended until the animal dies or recovers, as determined by three successive days of weight gain. For the real-scale tests, only the results in the post-flashover (including transition) period have been included. The type-of-death results can be summarized as: 
Table 28. Types of animal deaths

\begin{tabular}{|c|c|c|}
\hline Toxicity method & Within-exposure deaths ${ }^{a}$ & Post-exposure deaths ${ }^{b}$ \\
\hline \multicolumn{3}{|c|}{ DF } \\
\hline NBS Cup Furnace & $10 / 24$ & $0 / 14$ \\
\hline SwRI/NIST & $11 / 18$ & $0 / 7$ \\
\hline Real-scale ${ }^{c}$ & $0 / 18$ & $0 / 18$ \\
\hline \multicolumn{3}{|c|}{ RPU } \\
\hline NBS Cup Furnace & $12 / 24$ & $6 / 12$ \\
\hline SwRI/NIST & $12 / 18$ & $0 / 6$ \\
\hline Real-scale ${ }^{c}$ & $6 / 36$ & $11 / 30$ \\
\hline \multicolumn{3}{|c|}{ PVC } \\
\hline NBS Cup Furnace & $0 / 35$ & $14 / 35$ \\
\hline SwRI/NIST & $0 / 24$ & $10 / 24$ \\
\hline Real-scale ${ }^{c}$ & $26 / 48$ & $0 / 22$ \\
\hline \multicolumn{3}{|c|}{$\begin{array}{l}\text { Reported as: } \\
\quad \text { (no. died within exposure)/(total no. of animals exposed). } \\
\text { Reported as: } \\
\quad \text { (no. died after exposure)/(no. of animals remaining at start of post-exposure period). } \\
\text { Excluding tests where the gases were sampled in the pre-flashover period. }\end{array}$} \\
\hline
\end{tabular}

\begin{tabular}{|c|c|c|c|}
\hline \multirow{2}{*}{ Material } & \multicolumn{3}{|c|}{ Toxicity test method } \\
\cline { 2 - 4 } & NBS Cup Furnace & SwRI/NIST & Real-scale \\
\hline DF & within & within & (no deaths) \\
\hline RPU & within \& post & $\begin{array}{c}\text { within } \\
\text { (inconclusive) }\end{array}$ & within \& post \\
\hline PVC & post & post & within \\
\hline
\end{tabular}

The actual numbers in Table 28 should not be used to compare the different test procedures directly because the number of deaths are related to the amount of decomposed material and concentrations 
of toxic gases in the animal chambers and these concentrations differed in each experiment. Rather, these numbers are provided to indicate that a substantial number of animals were tested to determine whether animals are affected primarily within the exposures or post-exposure or both. However, if all the animals die within the exposure, it is not possible to see post-exposure effects.

The results on DF from both bench-scale methods indicate that deaths of the animals occurred only within exposure and not post-exposure. A statement about real-scale animal lethalities with DF cannot be made since post-flashover fire conditions did not result in any animal lethalities.

The results on RPU show that deaths of the animals occurred both within and post-exposure in the NBS Cup Furnace Method and in the real-scale tests. By contrast, only within-exposure deaths were observed with the SwRI/NIST test procedure. However, in the SwRI/NIST case, only three experiments were conducted. In two experiments, all the animals died during the 30-min exposure and in the other experiment, the concentration was too low to cause deaths within or post. Therefore, the experimental data do not, in fact, answer the question as to whether post-exposure deaths would be observed with RPU in the SwRI/NIST method had more animal data been available at concentrations in the vicinity of the $\mathrm{LC}_{50}$.

In the case of the PVC experiments, both the bench-scale tests agreed in that all the deaths were post-exposure. However, in the real-scale tests, no post-exposure deaths were observed following the 30 -min exposures. In these tests, there was sufficient concentrations of $\mathrm{CO}, \mathrm{CO}_{2}$, and low $\mathrm{O}_{2}$ to account for the within-exposure deaths. If $\mathrm{HCl}$ were additive at all concentrations, one would have expected to see some post-exposure deaths. However, it appears that there is a no observable effect level (NOEL) for $\mathrm{HCl}$ even in the presence of other toxic gases. The data generated in this series of experiments suggest that $820 \mathrm{ppm}$ of $\mathrm{HCl}$ is lower than the threshold lethal concentration and concentrations of this level or less do not provide any additive toxicity in combination with the other gases. However, there are data from SwRI [46] for pure gas mixtures containing $\mathrm{CO}$ and $\mathrm{HCl}$, where effects are observable at the $600 \mathrm{ppm}$ level, so this point deserves further exploration.

The type-of-death hypothesis appears to be sound and should be used. When considering gas species which are prone to wall losses (such as $\mathrm{HCl}$ ), the same caveat as for the equal-yields hypothesis should be added: type-of-death agreement may not be observed if a readily-losable species is a significant contributor to toxicity of the mixture, and if it undergoes much different losses in the two methods being compared.

The two bench-scale methods were successfully validatable under this hypothesis, with the following limitations:

- Sufficient data for RPU were not obtained with the SwRI/NIST method to state definitively if the validation hypotheses was or was not fulfilled for the method using this particular material.

- For both bench-scale methods, PVC did not agree with the real-scale results since the conditions of the caveat were not fulfilled - the losses of $\mathrm{HCl}$ were significantly higher in the real-scale test than in the bench-scale methods. 


\section{Alternative acceptable levels of agreement}

From the discussion above it can be seen that on several validation hypotheses the bench-scale methods had difficulty in providing data to within a factor of two agreement to the real scale. As mentioned at the beginning of this study (Assumption 4), the factor of two was selected as a reasonable target from the point of view of providing data with a wide usefulness of application. It becomes of interest now to consider if a somewhat relaxed assumption as to the needed agreement would enable the bench-scale tests being studied to be more successfully validated.

We can, then, briefly re-examine the results above from the point of view of seeking a factor-of-3 agreement.

- The equal- $\mathrm{LC}_{50}$ hypothesis is met, under such an assumption, by both the NBS Cup Furnace and the SwRI/NIST method.

- The primary toxic gases hypothesis continues to be met by both methods.

- The equal-yields hypothesis is met by both methods. While the present data, then, show agreement even for $\mathrm{CO}$, to within a factor of three, combustion considerations suggest that a proviso be maintained requiring expected $\mathrm{CO}$ yields to be obtained by means other than direct measurement within the bench-scale toxicity apparatus.

- The N-Gas hypothesis, which was well-met for both methods under the factor-of-2 assumption, of course, continues to be met.

- The conclusions for the type-of-death hypothesis are not affected by numerical considerations of the error margin. 


\section{Conclusions}

The present study has been a pilot study, intended to systematize methodologies and start providing indicative data. The task was made more complex by the fact that, simultaneously with this validation effort we have also been developing a new bench-scale test procedure (the SwRI/NIST method), the data from which form an integral part of the validation. Nonetheless, even with this brief exploration, it is possible to make some conclusions both about test methods and about the proper course for test validation. Viewed as another step in CFR's efforts in this area, by including more aspects of validation, more bench-scale tests, and more test materials, we extend and generalize previous conclusions [4].

We will first make the conclusions with respect to the validity of the validation hypotheses themselves, then reflect on the usability of the bench-scale test methods in representing post-flashover real-scale fires, and finally conclude with some general remarks.

\section{The validation hypotheses}

\section{The equal $L C_{50}$ hypothesis}

This hypothesis is fundamentally sound. In practice, it can be difficult to confirm, since it requires an $\mathrm{LC}_{50}$ determination in the real-scale tests. Under some scenarios, such as the present one, computations of the $\mathrm{LC}_{50}$ in real-scale tests require indirect computations and significant simplifications. Unless bench-scale toxic potency methods are developed wherein combustion conditions are specifically managed to replicate real-scale $\mathrm{CO}$ yields, the basis of comparison should involve bench-scale $\mathrm{LC}_{50}$ data computationally corrected to reflect expected real-scale $\mathrm{CO}$ generation.

\section{The primary toxic gases hypothesis}

This hypothesis is seen to be sound, with the following constraints: the oxygen levels and the amount of losses (of gas species prone to losses) must be similar for the bench-scale method and for the real- 
scale fire. This requirement may limit certain bench-scale tests to representing only certain types of fires.

\section{The equal yields hypothesis}

This hypothesis is sound. It is also one of the most stringent that we have available. It should not be applied to $\mathrm{CO}$, since numerical procedures for post-correcting test results are available.

\section{The N-Gas hypothesis}

This hypothesis is sound and is especially promising since it serves to unify biological measurements and analytical chemistry computations.

\section{The type of death hypothesis}

This hypothesis is reasonable and should be applied. Just as for the primary-toxic-gases hypothesis, similarity of losses of toxicologically significant species between the two methods being compared is required.

\section{Assumption as to the level of agreement}

The data collected during this study showed that for several of the validation hypotheses being considered, the two bench-scale methods had difficulties in achieving a factor-of-2 agreement with the real scale. In most of those cases, agreement was achieved when the allowable error band was expanded to be a factor-of-3. It is still reasonable to assume that bench-scale data which reflect realscale fires to within a factor-of- 3 will be useful for assessing fire hazards and risks. Thus, we will now make conclusions on the validation of the bench-scale methods by using a factor-of-3 criterion.

\section{The bench-scale toxicity methods}

\section{The NBS Cup Furnace method}

The previous study [4] has shown this method to be acceptable under the equal- $\mathrm{LC}_{50}$ hypothesis; the scenario and the materials tested in the present study corroborate this at the factor-of- 3 level.

The yield data in the present study for non-CO species show the method to be acceptable, using a factor-of-3 agreement criterion. (Real-scale $\mathrm{CO}$ yields should be computed by appropriate means and not by measurements taken in the bench scale.)

The N-Gas hypothesis is adequately proved out.

The primary toxic gases hypothesis is proved out, except for well-evident reasons stated in the caveat. 
For a very limited data set, the type of death hypothesis is also proved out, except for matching of $\mathrm{HCl}$ losses.

\section{The SwRI/NIST method}

This method was not included in the previous study; the equal- $\mathrm{LC}_{50}$ hypothesis is proved out in the present study.

The yield data in the present study for non-CO species show the method to be acceptable, using a factor-of-3 agreement criterion. (Real-scale $\mathrm{CO}$ yields should be computed by appropriate means and not by measurements taken in the bench scale.)

The N-Gas hypothesis is adequately proved out.

The primary toxic gases hypothesis is proved out, under the same caveat conditions as for the NBS Cup Furnace method.

General conclusions on the type of death hypothesis cannot be made due to lack of sufficient data.

\section{General remarks}

Bench-scale toxicity tests cannot be fully and adequately specified without knowing the real-scale fire types which they are to represent. When the real-scale fire characteristics are known, an attempt should be made to match oxygen depletion and loss (for gas species prone to being lost) conditions in the bench-scale test.

The bench-scale methods considered here were being examined solely for validity in representing flaming, post-flashover room fires. Their applicability to other, less common fire scenarios, has not been examined in this study.

We see bench-scale toxicity test methods as being the most promising when used in the context of the N-Gas Model. For such application, existing data indicate that both of the bench-scale methods studied are successful.

Since bench-scale oxygen/fuel ratio conditions, and therefore the $\mathrm{CO}$ generation, will rarely correspond to those in real-scale fires, the data should be treated in a context of a method, such as the one illustrated, which can correct the effects of this disparity.

The study does establish that bench-scale toxic potency methods can give useful data, to within a factor-of-3 agreement with real-scale.

All five validation hypotheses examined were found to be sound and generally applicable; certain ones required further constraints (such as matching of gas species losses) to be applicable in a particular situation. As a minimum, to prove validity of a bench-scale toxic potency method, it is necessary to examine the type-of-death hypothesis, plus one of the four remaining hypotheses. Which one of those four hypotheses is selected will depend on the application to which the test data is to be put. 
The N-Gas hypothesis and the primary toxic gases hypothesis are easier to meet than are the equal$\mathrm{LC}_{50}$ hypothesis and the equal-yields hypothesis. Design methods should be encouraged which rely on the easier-to-meet hypotheses.

The examination of the type-of-death hypothesis was seriously limited due to the small amount of data available; future studies in this area would be desirable.

Further validation with different materials and composites is desirable. To the extent that the toxicity test is to be used for searching for very rarely found species, however, validation by enumeration is not feasible.

Only homogeneous materials were examined in this study. The performance of bench-scale toxic potency tests in treating composite specimens must be assessed before actual test protocols are developed. Such capability may form an additional criterion in selecting an appropriate bench-scale test method.

The SwRI/NIST developmental method is promising for future use; its development continues after the end of the present pilot study. One of the development tasks will be to derive all of the crucial needed test information needed for toxic fire hazard assessment ( $\mathrm{LC}_{50}, \mathrm{MLR}$, and ignition time) in the same apparatus.

Finally, this study has not addressed other requirements, besides validity, which a successful benchscale method will have to meet so as to be able to provide sufficient data for the prediction of fire toxicity. Some of these considerations have been examined in an earlier study [47]. 
6

\section{Acknowledgments}

The portions of this work dealing with PVC were funded by BFGoodrich, with Dr. M. M. Hirschler as contract monitor. Dr. G. Smith of BFGoodrich provided valuable assistance during the real-scale tests with PVC. R. Peacock and P. Martin were of essential help in reducing real-scale test data. N. Eller, M. Navarro, and R. McCombs assisted with bio-assay studies and data analysis. R. Zile provided real-scale fire testing services. Dr. W. J. Parker developed the equations for estimating mass flows in the exhaust duct from gas analyzer and Cone Calorimeter data. The work done by Dr. A. F. Grand and co-workers at SwRI was essential in examining the performance of the SwRI/NIST test method. 


\section{References}

[1]. New York State Uniform Fire Prevention and Building Code, Article 15, Part 1120: Combustion Toxicity Testing (9 NYCRR 1120).

[2]. Kaplan, H.L., Grand, A.F., and Hartzell, G.E., Combustion Toxicology. Technomic Publishing, Lancaster, PA (1983).

[3]. Babrauskas, V., and Wickström, U.G., The Rational Development of Bench-Scale Fire Tests for Full-Scale Fire Prediction, pp. 813-822 in Fire Safety Science - Proc. of the Second International Symposium (1988). Hemisphere Publishing, New York (1989).

[4]. Braun, E., Gann, R.G., Levin, B.C., and Paabo, M., Combustion Product Toxic Potency Measurements: Comparison of a Small Scale Test and "Real-World" Fire, J. Fire Sciences. 8, 63-74 (1990).

[5]. Braun, E., Levin, B.C., Paabo, M., Gurman, J., Holt, T., and Steel, J.S., Fire Toxicity Scaling (NBSIR 87-3510). [U.S.] Natl. Bur. Stand. (1987).

[6]. Braun, E., Levin, B.C., Paabo, M., Gurman, J.L., Clark, H.M., and Yoklavich, M.F., LargeScale Compartment Fire Toxicity Study: Comparison with Small-Scale Toxicity Test Results (NBSIR 88-3764). [U.S.] Natl. Bur. Stand. (1988).

[7]. Babrauskas, V., Harris, R.H., Jr., Gann, R.G., Levin, B.C., Lee, B.T., Peacock, R.D., Paabo, M., Twilley, W., Yoklavich, M.F., and Clark, H.M., Fire Hazard Comparison of Fire-Retarded and Non-Fire-Retarded Products (NBS Special Publication SP 749). [U.S.] Natl. Bur. Stand. (1988).

[8]. Levin, B.C., Gurman, J.L., Paabo, M., Baier, L., and Holt, T., Toxicological Effects of Different Time Exposures to the Fire Gases: Carbon Monoxide or Hydrogen Cyanide or to Carbon Monoxide Combined with Hydrogen Cyanide or Carbon Dioxide. Proceedings of the U.S.-Japan Panel on Fire Research and Safety (UJNR), Natl. Bur. Stand. (1987). 
[9]. Levin, B.C., et al., Further Development of a Test Method for the Assessment of the Acute Inhalation Toxicity of Combustion Products (NBSIR 82-2532). [U.S.] Natl. Bur. Stand. (1982).

[10]. Babrauskas, V., Toxic Hazard from Fires: A Simple Assessment Method, pp. 16.1 to 16.10 in Fire: Control the Heat...Reduce the Hazard, QMC Fire \& Materials Centre, London (1988).

[11]. Toxicity of Combustion Products (PD 6503: Part 2: 1988). British Standards Institution, London (1988).

[12]. Alarie, Y., and Anderson, R.C., Toxicologic and Acute Lethal Hazard Evaluation of Thermal Decomposition Products of Synthetic and Natural Polymers, Toxicol. Appl. Pharmacol. 51, 341-362 (1979).

[13]. Nelson, G.L., Canfield, D.V., and Larsen, J.B., Carbon Monoxide - Study of Toxicity in Man, pp. 93-104 in Eleventh Intl. Conf. on Fire Safety, Product Safety Corp., San Francisco (1986).

[14]. Pitts, W.M., Executive Summary for the Workshop on Developing a Predictive Capability for CO Formation in Fires (NISTIR 89-4093). Natl. Instit. Stand. Technol. (1989).

[15]. Babrauskas, V., Levin, B.C., and Gann, R.G., A New Approach to Fire Toxicity Data for Hazard Evaluation, ASTM Standardization News. 14, 28-33 (Sept. 1986).

[16]. Bukowski, R.W., Peacock, R.D., Jones, W.W., and Forney, C.L., Technical Reference Guide for the HAZARD I Fire Hazard Assessment Method (NIST Handbook 146, Volume II). Natl. Inst. Stand. Technol. (1989).

[17]. Drysdale, D. An Introduction to Fire Dynamics, Wiley, Chichester, England (1985).

[18]. National Institute of Building Sciences, report to be issued.

[19]. Levine, R.S., and Nelson, H.E., Full-scale Simulation of a Fatal Fire and Comparison of Results with two Multi-room Models (NISTIR 90-4268). Natl. Inst. Stand. Technol. (1990).

[20]. The Fire Model, Draft Technical Report, ISO/TC 92/SC 3/WG 1 (1990).

[21]. Grand, A.F., Southwest Research Institute, private communication.

[22]. Litchfield, J.T., Jr. and Wilcoxon, F., A Simplified method of evaluating dose-effect experiments. J. Pharmacol. and Exp. Therapeut. 96, 99-113 (1949).

[23]. Paabo, M., Birky, M.M., and Womble, S.E., Analysis of hydrogen cyanide in fire environments. J. Comb. Tox. 6, 99-108 (1979).

[24]. Grand, A.F. and Switzer, W.G., Southwest Research Institute, private communication.

[25]. Babrauskas, V., Development of the Cone Calorimeter - A Bench-Scale Heat Release Rate Apparatus Based on Oxygen Consumption (NBSIR 82-2611). [U.S.] Natl. Bur. Stand. (1982). 
[26]. Huggett, C., Estimation of Rate of Heat Release by Means of Oxygen Consumption Measurements. Fire and Materials. 4, 61-65 (1980).

[27]. Babrauskas, V., and Mulholland, G., Smoke and Soot Data Determinations in the Cone Calorimeter, pp. 83-104 in Mathematical Modeling of Fires (ASTM STP 983). American Society for Testing and Materials, Philadelphia (1987).

[28]. Babrauskas, V., The Cone Calorimeter - A Versatile Bench-Scale Tool for the Evaluation of Fire Properties, pp. 78-87 in New Technology to Reduce Fire Losses \& Costs, S.J. Grayson and D.A. Smith, eds., Elsevier Applied Science Publishers, London (1986).

[29]. Standard Test Method for Heat and Visible Smoke Release Rates for Materials and Products using an Oxygen Consumption Calorimeter (E 1354). American Society for Testing and Materials, Philadelphia.

[30]. Twilley, W. H., and Babrauskas, V., User's Guide for the Cone Calorimeter (Spec. Publ. 745). [U.S.] Natl. Bur. Stand. (1988).

[31]. Babrauskas, V., Lawson, J.R., Walton, W.D., and Twilley, W.H., Upholstered Furniture Heat Release Rates Measured with a Furniture Calorimeter (NBSIR 82-2604). [U.S.] Natl. Bur. Stand. (1982).

[32]. Babrauskas, V., Free-burning Fires, pp. 2-1 to 2-15 in The SFPE Handbook of Fire Protection Engineering, Society of Fire Protection Engineers, Boston (1988).

[33]. Quintiere, J.G., and McCaffrey, B.J., The Burning of Wood and Plastic Cribs in an Enclosure, 2 vols. (NBSIR 80-2054) [U.S.] Natl. Bur. Stand. (1980).

[34]. Delichatsios, M.A., Fire Growth Rates in Wood Cribs, Combustion and Flame. 27, 267-278 (1976).

[35]. Babrauskas, V., Upholstered Furniture Room Fires - Measurements, Comparison with Furniture Calorimeter Data, and Flashover Predictions, J. of Fire Sciences. 2 5-19 (1984).

[36]. Levin, B.C., Paabo, M., Gurman, J.L., and Harris, S.E., Effects of exposure to single or multiple combinations of the predominant toxic gases and low oxygen atmospheres produced in fires. Fund. \& Appl. Tox. 9, 236-250 (1987).

[37]. Hartzell, G.E., Grand, A.F., and Switzer, W.G., Modeling of Toxicological Effects of Fire Gases: VII. Studies on Evaluation of Animal Models in Combustion Toxicology, J. Fire Sciences. 6, 411-431 (1988).

[38]. Tables and Charts, pp. 5-117 to 5-133 in Fire Protection Handbook, 16th edition, A.C. Cote and J.L. Linville, eds. National Fire Protection Assn., Quincy, MA (1986).

[39]. Babrauskas, V., and Mulholland, G., Smoke and Soot Data Determinations in the Cone Calorimeter, pp. 83-104 in Mathematical Modeling of Fires (ASTM STP 983). American Society for Testing and Materials, Philadelphia (1987). 
[40]. Proposed Standard Method for Room Fire Test of Wall and Ceiling Materials and Assemblies, 1982 Annual Book of Standards, American Society for Testing and Materials, Philadelphia (1982).

[41]. Galloway, F.M., and Hirschler, M.M., Model for the Mass Transfer and Decay of Hydrogen Chloride in a Fire Scenario, pp. 35-57 in Mathematical Modeling of Fires (ASTM STP 983). American Society for Testing and Materials (1988).

[42]. Jones, W.W., Refinement of a Model for Fire Growth and Smoke Transport, Tech. Note 1282 Natl. Inst. Stand. Technol. (1990).

[43]. Mulholland, G., private communication (1989).

[44]. Galloway, F.M., Hirschler, M.M., and Smith, G.F., Model for the Generation of Hydrogen Chloride from the Combustion of Poly(vinyl chloride) under Conditions of Forcefully Minimsed Decay, European Polymer J. 25, 149-158 (1989).

[45]. Levin, B.C., Paabo, M., Gurman, J.L., and Harris, S.E., Effects of Exposure to Single or Multiple Combinations of the Predominant Toxic Gases and Low Oxygen Atmospheres Produced in Fires, Fund. and Appl. Toxicology. 9, 236-250 (1987).

[46]. Hartzell, G.E., Grand, A.F., and Switzer, W.G., Modeling of Toxicological Effects of Fire Gases: VI. Further Studies on the Toxicity of Smokes Containing Hydrogen Chloride, J. Fire Sciences. 5, 368-391 (1987).

[47]. Levin, B.C., Babrauskas, V., Braun, E., Gurman, J., and Paabo, M., An Exploration of Combustion Limitations and Alternatives to the NBS Toxicity Test Method (NBSIR 85-3274). [U.S.] Natl. Bur. Stand. (1985).

[48]. Levin, B.C., data to be published. 



\section{Appendix A}

\section{Log of Large-scale Test Observations}

\section{Test: FS Analytical DF 2}

\section{Time(s) Event}

\begin{aligned} \hline-60 & data logger on \\ 0 & ignition of crib \\ 220 & upper smoke layer forming \\ 270 & wall involved \\ 315 & upper half of corridor obscured by \\ & smoke \\ 460 & fire almost obscured by smoke \\ 660 & smoke beginning to recede; visible wall \\ & completely engulfed in flame \\ 1153 & crib collapsed \\ 1250 & wall stopped burning \\ 2285 & remnants of crib still burning; video off \end{aligned}

\section{Test: FS Animal DF 1}

\section{Time(s) Event}

-60 data logger on

0 crib ignited

210 wall involved

300 smoke beginning to fill upper layer of corridor

370 smoke layer drifting downward almost half the height of the corridor

410 heavy black smoke starting to obscure corridor completely

570 corridor completely obscured

570-690 fire not visible because of heavy smoke

690 smoke lessening

820 visible wall completely engulfed in flame

1280 crib collapsed

1425 visible wall flames now out except for small flamelet at a seam; crib remnants still burning

2890 crib still burning at joints; video off

\section{Test: FS Animal DF 2}

Time(s) Event

-60 data logger on

0 ignition of crib

240 wall involved

290 smoke layer beginning to form

430 smoke layer half way down height of corridor

480 charred wall evident

665 visible wall completely engulfed

690 smoke obscuring whole corridor

728 corridor completely obscured

765 smoke receding

1260 crib starting to collapse

1380 wall out except at joints

2620 part of wall collapsed onto remnants of crib

3930 walls still burning; video off

\section{Test: FS Analytical RPU 1}

\section{Time(s) Event}

-60 data logger on

0 crib ignited

36 wall involved

47 black smoke filling upper layer

102 corridor obscured

260 smoke lessening

300 fire visible again

330 thick, black smoke billowing in corridor obscured fire again

505 fire visible again; thick black smoke still billowing in upper layer

720 visible flames out

1550 video off 


\section{Test: FS Animal RPU 1}

Time(s) Event

-60 data logger on

0 cribs ignited

40 wall involved

55 upper layer filling with black smoke

157

240

255

384

750

3610

\section{Test: FS Animal RPU 2}

\section{Time(s) Event}

-60 data logger on

0 cribs ignited

34 wall involved

60 upper layer filling with black smoke

105 corridor obscured

385 flames visible

720 flames out

2835 video off

\section{Test: FS Analytical PVC 1}

\section{Time(s) Event}

-60 data logger on

0 burner on

36 thick black smoke filling upper layer of corridor

106 corridor completely obscured

210 burner turned off

720 video off

\section{Test: FS Analytical PVC 2}

Time(s) Event

-60 data logger on

0 burner on

30 black smoke filling upper layer

115 corridor obscured

180 burner turned off

290 smoke beginning to recede

360 test wall visible

990 video off

\section{Test: FS Animal PVC 1}

\section{Time(s) Event}

-60 data logger on

0 burner on

35 upper layer filling with black smoke

135 corridor obscured

370 corridor beginning to clear

600 wall visible; flaming evident

450 burner turned off

2220 flames out

5120 video off

\section{Test: FS Animal PVC 2 PVC}

\section{Time(s) Event}

-60 data logger on

0 burner on

25 wall blackening

30 black smoke filling upper layer

130 corridor completely obscured

278 smoke receding

278-700 heavy black smoke in corridor, wall was burning

420-540 burner turned off

1090 last visible flame out

2190 video off 


\section{Test: FS Animal PVC 3}

Time(s) Event

\begin{aligned} \hline-60 & data logger on \\ 0 & burner on \\ 28 & wall behind burner charred \\ 33 & upper layer filling with smoke \\ 121 & corridor completely obscured \\ 280 & fire visible \\ $420-540 &$ burner turned off \\ 840 & fire out \\ 2400 & video off \end{aligned}





\section{Appendix B}

\section{Indirect calculation of specimen mass loss rates}

Since in the present series of real-scale tests it was not possible to equip the test room with a load cell which would measure specimen mass loss rates, an indirect technique needed to be adopted. A technique was developed whereby the specimen mass loss rate is calculated based on $\mathrm{X}_{\mathrm{CO}_{2}}, \mathrm{X}_{\mathrm{CO}}$, and smoke measurements in the exhaust duct.

This could be determined in a straightforward manner if concentrations of $\mathrm{CO}, \mathrm{CO}_{2}, \mathrm{O}_{2}, \mathrm{H}_{2} \mathrm{O}, \mathrm{HCl}$, $\mathrm{HCN}$, and soot were measured in the exhaust stack. Since $\mathrm{H}_{2} \mathrm{O}, \mathrm{HCl}, \mathrm{HCN}$, and soot are not measured in the real-scale exhaust stack, indirect information from the Cone Calorimeter must be used. In order to determine the $\mathrm{H}_{2} \mathrm{O}$ concentration in the exhaust duct, a $\mathrm{C} / \mathrm{H}$ ratio is derived from the measurements of $\mathrm{CO}, \mathrm{CO}_{2}$, and $\mathrm{H}_{2} \mathrm{O}$ in the Cone Calorimeter. The yields of $\mathrm{HCl}$ and $\mathrm{HCN}$ are assumed to be the same in the real-scale test as those measured in the Cone Calorimeter. To derive the real-scale soot yields, reliance is placed on the real-time smoke photometer. The relationship given in [39] is used. According to this relationship, the soot yield and the smoke specific extinction area are related by the constant of $12,000 \mathrm{~m}^{2}$ extinction area per $\mathrm{kg}$ of soot (as contrasted to the values reported in Table 11, which are the extinction areas per $\mathrm{kg}$ of sample burned).

\section{Nomenclature}

$\mathrm{f}_{\mathrm{z}} \quad$ yield of species $\mathrm{z}$, as determined from Cone Calorimeter measurements ( $\mathrm{kg} \mathrm{z} / \mathrm{kg}$ fuel)

$\mathrm{k} \quad$ extinction coefficient measured in exhaust stack stream $\left(\mathrm{m}^{-1}\right)$

m mass loss rate of specimen and ignition source $(\mathrm{kg} / \mathrm{s})$

$\dot{\mathrm{m}}_{\mathrm{z}} \quad$ flow rate of species $\mathrm{z}$ in exhaust stack $(\mathrm{kg} / \mathrm{s})$

$\dot{\mathrm{m}}_{\text {soot }}$ mass flow rate of soot in exhaust stack $(\mathrm{kg} / \mathrm{s})$

Q $\quad$ total heat release $(\mathrm{kW})$

$\mathrm{T}_{\mathrm{o}} \quad 273 \mathrm{~K}$

$\mathrm{T}_{\mathrm{S}} \quad$ exhaust stack temperature $(\mathrm{K})$

$\dot{V}$ volume flow rate in exhaust stack $\left(\mathrm{m}^{3} / \mathrm{s}\right)$, at the actual temperature where the photometer is located

X mole fraction ( $\mathrm{mol} / \mathrm{mol}$ ) 
$\gamma \quad$ molar $\mathrm{C} / \mathrm{H}$ ratio, as measured in the Cone Calorimeter $(-)$

$\rho_{\mathrm{s}} \quad$ soot density $\left(\mathrm{kg} / \mathrm{m}^{3}\right)$

$\sigma_{\mathrm{s}} \quad$ specific extinction area of soot $\left(12,000 \mathrm{~m}^{2} / \mathrm{kg}\right)$

superscript $\mathrm{A}$ - refers to concentrations in the analyzer

superscript $\mathrm{S}$ - refers to concentrations in the exhaust stack

The specimen mass loss rate is computed on the basis of having information about the molecular composition of the fuel pyrolysates and on being able to measure flow rates of certain products of combustion.

The mass loss rate of the specimen is identically equal to the mass flow rate of the combustion products being generated, minus the mass flow rate of the oxygen being removed:

$$
\begin{gathered}
\dot{m}=\dot{m}_{\mathrm{CO}_{2}}+\dot{m}_{C O}+\dot{m}_{\mathrm{H}_{2} \mathrm{O}}+\dot{m}_{\mathrm{soot}}+\dot{m}_{\mathrm{HCl}}+\dot{m}_{\mathrm{HCN}}-\left(\dot{m}_{\mathrm{O}_{2}}^{0}-\dot{m}_{\mathrm{O}_{2}}\right) \\
\dot{m}=\phi \frac{\dot{V}}{22.4}\left(\frac{T_{o}}{T_{s}}\right)+\frac{k \dot{V}}{\sigma_{s}}+f_{H C l} \dot{m}+f_{H C N} \dot{m}-\frac{\dot{Q}}{13100}
\end{gathered}
$$

where

$$
k=\sigma_{s} \rho_{s}
$$

and

$$
\phi=44 X_{\mathrm{CO}_{2}}^{s}+28 X_{\mathrm{CO}}^{s}+18 X_{\mathrm{H}_{2} \mathrm{O}}^{s}
$$

The concentrations measured in the $\mathrm{CO}$ and $\mathrm{CO}_{2}$ analyzers must be corrected to account for the trapping of the water, in order to determine their actual concentrations in the exhaust stack. Hence,

$$
\phi=\left(44 X_{\mathrm{CO}_{2}}^{A}+28 X_{\mathrm{CO}}^{A}\right)\left(1-X_{\mathrm{H}_{2} \mathrm{O}}^{S}\right)+18 X_{\mathrm{H}_{2} \mathrm{O}}^{S}
$$

Since the concentration of $\mathrm{H}_{2} \mathrm{O}$ is not being measured in the exhaust stack, its value will have to be estimated. 
A C/H ratio, $\gamma$, is defined as the molar ratio of carbon to hydrogen that is going into $\mathrm{CO}_{2}, \mathrm{CO}$, and $\mathrm{H}_{2} \mathrm{O}$; this does not include contributions of $\mathrm{C}$ or $\mathrm{H}$ which go into $\mathrm{HCl}$ or $\mathrm{HCN}$, since the latter are not measured in real scale.

$$
\gamma=\frac{X_{\mathrm{CO}_{2}}^{S}+X_{\mathrm{CO}}^{S}}{2 X_{\mathrm{H}_{2} \mathrm{O}}^{S}}=\left(X_{\mathrm{CO}_{2}}^{A}+X_{C O}^{A}\right) \frac{\left(1-X_{\mathrm{H}_{2} \mathrm{O}}^{S}\right)}{2 X_{\mathrm{H}_{2} \mathrm{O}}^{S}}
$$

Solving for $\mathrm{X}_{\mathrm{H}_{2} \mathrm{O}}^{\mathrm{S}}$

$$
X_{\mathrm{H}_{2} \mathrm{O}}^{S}=\frac{\left(X_{\mathrm{CO}_{2}}^{A}+X_{\mathrm{CO}}^{A}\right)}{2 \gamma+X_{\mathrm{CO}_{2}}^{A}+X_{C O}^{A}}
$$

Since the yields of $\mathrm{CO}_{2}, \mathrm{CO}$ and $\mathrm{H}_{2} \mathrm{O}$ (i.e., $\mathrm{f}_{\mathrm{CO}_{2}}, \mathrm{f}_{\mathrm{CO}}, \mathrm{f}_{\mathrm{H}_{2} \mathrm{O}}$ ) are measured in the Cone, the molar ratio $\gamma$ is expressed in terms of these yields:

$$
\begin{gathered}
\gamma=\frac{9}{4} \frac{\left(\frac{1}{11} f_{\mathrm{CO}_{2}}+\frac{1}{\tau} f_{C O}\right)}{f_{\mathrm{H}_{2} \mathrm{O}}} . \\
\phi=\left(44 X_{\mathrm{CO}_{2}}^{A}+28 X_{C O_{2}}^{A}\right)\left(1-\frac{X_{C O_{2}}^{A}+X_{C O_{2}}^{A}}{2 \gamma+X_{C O_{2}}^{A}+X_{C O}^{A}}\right)+\frac{18\left(X_{C O_{2}}^{A}+X_{C O}^{A}\right)}{2 \gamma+X_{C O_{2}}^{A}+X_{C O}^{A}} \\
\phi=\frac{\left(44 X_{C O_{2}}^{A}+28 X_{C O_{2}}^{A}\right)(2 \gamma)+18\left(X_{C O_{2}}^{A}+X_{C O}^{A}\right)}{2 \gamma+X_{C O_{2}}^{A}+X_{C O}^{A}} \\
\phi=\frac{(18+88 \gamma) X_{C O_{2}}+(18+56 \gamma) X_{C O}}{2 \gamma+X_{C O_{2}}+X_{C O}}
\end{gathered}
$$




$$
\dot{m}=\frac{\phi \frac{\dot{V}}{22.4}\left(\frac{T_{o}}{T_{s}}\right)+\frac{k \dot{V}}{\sigma_{s}}-\frac{\dot{Q}}{13100}}{1-f_{H C l}-f_{H C N}} .
$$

Finally giving:

$$
\dot{m}=\frac{\frac{2 \dot{V}}{22.4}\left(\frac{T_{o}}{T_{s}}\right)\left[\frac{\left.(44 \gamma+9) X_{\mathrm{CO}_{2}}^{A}+(28 \gamma+9) X_{C O}^{A}\right]}{X_{C O_{2}}^{A}+X_{C O}^{A}+2 \gamma}\right]+\frac{k \dot{V}}{\sigma_{s}}-\frac{\dot{Q}}{13100}}{1-f_{H C l}-f_{H C N}}
$$




\section{Appendix C}

\section{Computations with the FED}

\section{Basic computations}

From [10] we take that the toxic fire hazard can be represented as proportional to an exposure dose, specifically, the Fractional Effective Dose, FED, which for burning materials is computed as

$$
F E D=\frac{\dot{m}^{\prime \prime} \times A}{\dot{V} \times L C_{50(c)}}
$$

and where we take

$$
L C_{50(c)}=\left(\frac{\mathrm{kg}}{\mathrm{m}^{3}}\right)=\left(\frac{g}{l}\right)
$$

We have written an explicit '(c)' to remind us that the units here are a concentration.

The toxicity data from gases, however, as opposed to burning solids, are usually expressed in (vol/vol), specifically (ppm) units. To convert to volume units,

$$
L C_{50(v)}=\frac{29}{1.185} \frac{1000}{M W} L C_{50(c)}=\frac{24,500}{M W} L C_{50(c)}
$$

where MW is the molecular weight of the gas in question.

The basic measurement in a combustion test such as the Cone Calorimeter or the furniture calorimeter is the gas yield, $f$, being the $\mathrm{kg}$ of the particular gas produced, per $\mathrm{kg}$ of fuel burned. When more than one toxic gas is being evolved, the FED equation becomes

$$
F E D=\frac{\dot{m}^{\prime \prime} \times A}{\dot{V}} \sum_{x} \frac{f_{x}}{L C_{50-x(c)}}
$$


Converting this to the appropriate form so we could use $\mathrm{ppm}$ units for $\mathrm{LC}_{50}$ 's, gives

$$
F E D=\frac{\dot{m}^{\prime \prime} \times A}{\dot{V}} \sum_{x} \frac{f_{x} 24,500}{M W_{x} L C_{50-x(v)}}
$$

\section{Augmenting $\mathrm{CO}$ to correct value by post-computation}

Based on the equations shown above, it is also possible to set down a method for correcting benchscale toxicity test results to a required $\mathrm{CO}$ level. It has been adequately noted (e.g., in a recent NIST study [7]) that the yield of $\mathrm{CO}$ observed in various bench-scale test apparatuses tends to be much less than is produced in the real scale. Furthermore, this deficit is proportionately greater for non-FR materials, than FR ones. Thus, in addition to a general scaling error, there tends to be a further bias in bench-scale tests against FR materials. It may be possible to correct this by complicated physical measures, such as adding $\mathrm{CO}$ to the test box during the bench-scale or by carefully adjusting oxygen levels to encourage $\mathrm{CO}$ production. Such techniques would be difficult to implement for routine testing.

It has also recently been observed [43] that for post-flashover fires, a nearly constant $\mathrm{CO}$ yield is seen, provided that an effective secondary combustion ("re-incineration") plume does not form at the doorway or window opening. For preliminary hazard analysis purposes, it is conservative to neglect the possibility of such re-incineration of the $\mathrm{CO}$ produced. Then, the possibility emerges that for a bench-scale test such as the NIBS method, targeted at post-flashover fire conditions, the effect of a correct amount of $\mathrm{CO}$ may be restored by computational means.

Considering Equation C(1), above, let us suppose the material now has two components: that which is measured by animals in the $\mathrm{LC}_{50}$ determination, plus that due to the additional yield of $\mathrm{CO}$ which should have been induced in the apparatus, but was not.

Then,

$$
F E D=\frac{A}{\dot{V}}\left[\frac{\dot{m}^{\prime \prime}}{L C_{50}}+\frac{\dot{m}_{\Delta C O}^{\prime \prime}}{L C_{50-C O(c)}}\right]
$$

Here, the $\mathrm{LC}_{50-\mathrm{CO}(\mathrm{c})}$ is the toxic potency of $\mathrm{CO}$ in units of $\left(\mathrm{kg} / \mathrm{m}^{3}\right)$. The actual value of the $\mathrm{LC}_{50}$ $\mathrm{CO}$ (c) depends on the amount of $\mathrm{CO}_{2}$ which is simultaneously present in the atmosphere. This effect is not a very sensitive function of the quantity of $\mathrm{CO}_{2}$, and for this purpose it can be assumed that $\mathrm{LC}_{50-\mathrm{CO}(\mathrm{v})}=4000 \mathrm{ppm}$ for typical values of $\mathrm{CO}_{2}$ being present [48]. This can be converted to appropriate units by the use of Equation C(3). 
The mass evolution rate of this $\mathrm{CO}$-equivalent supplement term is:

$$
\dot{m}_{\Delta C O}^{\prime \prime}=\dot{m}^{\prime \prime} \times \Delta f_{C O}
$$

where

$$
\Delta f_{C O}=[\text { required yield of } \mathrm{CO}]-[\text { measured yield of } \mathrm{CO}] .
$$

For post-flashover fires examined by Mulholland, the typical value of [required yield of $\mathrm{CO}$ ] $\equiv 0.2$ $(\mathrm{kg} / \mathrm{kg})$. To within the experimental scatter of the data, this value is independent of the type of combustible that was burned.

Then,

$$
\begin{aligned}
& F E D=\frac{\dot{m}^{\prime \prime} \times A}{\dot{V}}\left[\frac{1}{L C_{50}}+\frac{\Delta f_{C O}}{L C_{50-C O(c)}}\right] \\
& \Delta f_{C O}=0.2-\frac{[C O] 0.200}{m_{100}} \times \frac{28}{24.5 \times 10^{6}}
\end{aligned}
$$

where

$[\mathrm{CO}]=$ Avg. $\mathrm{CO}$ measured in box (ppm)

$0.200=$ volume of $200 \mathrm{~L}$ box $\left(\mathrm{m}^{3}\right)$

$\mathrm{m}_{100}=$ mass of specimen burned $(\mathrm{kg})$

Combining above, gives final answer:

$$
F E D=\frac{\dot{m}^{\prime \prime} \times A}{\dot{V}}\left[\frac{1}{L C_{50}}+44-5.0 \times 10^{-5} \frac{[C O]}{m_{100}}\right] .
$$

Note that the units of $\mathrm{LC}_{50}$ above are $(\mathrm{g} / \ell)$. Converting to common units, get: 


$$
F E D=\frac{\dot{m}^{\prime \prime} \times A}{\dot{V}}\left[\frac{10^{3}}{L C_{50}}+44-5.0 \times 10^{-2} \frac{[C O]}{m_{100}}\right]
$$

where the units are:

$$
\begin{aligned}
& \mathrm{LC}_{50}=(\mathrm{mg} / \mathrm{l}) \\
& {[\mathrm{CO}]=(\mathrm{ppm})} \\
& \mathrm{m}_{100}=(\mathrm{g})
\end{aligned}
$$

Finally, $\dot{V}$ is a property of the room geometry, not of the combustible being burned. It is not known when comparing products by themselves. Furthermore, the expression for A would involve constants which are, again, extraneous for comparing two different materials. Therefore, for examining the performance of combustibles it is appropriate to derive a 'relative FED' by normalizing out $\mathrm{V}$ by setting it equal to 1.0 , and setting $A=1 / t_{\mathrm{ig}}$ :

$$
\text { relative } F E D=\frac{\dot{m}^{\prime \prime}}{t_{i g}}\left[\frac{10^{3}}{L C_{50}}+44-5.0 \times 10^{-2} \frac{[C O]}{m_{100}}\right]
$$

For some purposes it is desirable to express the results as a 'corrected $\mathrm{LC}_{50}$ ' From Eq. $\mathrm{C}(9)$, get:

$$
L C_{50}(\text { corr })=\frac{1}{\frac{1}{L C_{50}}+\frac{\Delta f_{C O}}{L C_{50-C O(c)}}}
$$

Giving,

$$
L C_{50}(\text { corr })=\frac{1}{\frac{1}{L C_{50}}+44 \times 10^{-3}-5.0 \times 10^{-5} \frac{[C O]}{m_{100}}}
$$

where the units of $\mathrm{LC}_{50}(\mathrm{corr})=(\mathrm{mg} / \ell)$. 


\begin{tabular}{|c|c|c|}
\hline \multirow[t]{3}{*}{$\begin{array}{l}\text { NIST-114A } \\
\text { (REV. 3-69) }\end{array}$} & \multirow{3}{*}{$\begin{array}{l}\text { U.S. DEPARTMENT OF COMMERCE } \\
\text { NATIONAL INSTITUTE OF STANDARDS AND TECHNOLOGY } \\
\text { BIBLIOGRAPHIC DATA SHEET }\end{array}$} & $\begin{array}{l}\text { 1. PUBLICATION OA AEPOAT NUMBEA } \\
\text { NIST/TN- }-1284\end{array}$ \\
\hline & & 2. PEAFOAMING ORGANIZATION AEFORT NUMBEE \\
\hline & & $\begin{array}{l}\text { 3. PUBLICATION DATE } \\
\text { January } 1991\end{array}$ \\
\hline
\end{tabular}

\section{TITLE AND SUBTITLE}

The Role of Bench-Scale Test Data in Assessing Real-Scale Fire moxicity

5. AUTHOR(S)

Vytenis Babrauskas, Richard H. Harris, Jr., Emil Braun, Barbara C. Levin, Maya Paabo, and Richard G. Gann

6. PERFORMING ORGANIZATION (IF JOINT OR OTHER THAN NIST, SEE INSTRUCTIONS)

U.S. DEPARTMENT OF COMMERCE

NATIONAL INSTITUTE OF STANDARDS AND TECHNOLOGY

GAITHERSBURG, MD 20899

9. SPONSORING ORGANIZATION NAME AND COMPLETE ADDRESS (STREET, CITY, STATE, ZIP)

Same as item \#6

10. SUPPLEMENTARY NOTES

DOCUMENT DESCRIBES A COMPUTER PAOGRAM; SF-185, EIPS SOFTWARE SUMMARY, IS ATTACHED.

11. ABSTRACT (A 200-WORD OR LESS FACTUAL SUMMARY OF MOST SIEINIFICANT INFORMATION. IF DOCUMENT INCLUDES A SIGNIFICANT BIBLIOGRAPHY OA LITERATURE SUAVEY, MENTION IT HERE.)

The need was seen for establishing a methodology by which bench-scale fire toxicity methods could be validated against real-scale room fires. The present study is the result of a pilot project in this area. Appropriate validation hypotheses have been put forth and examined in the context of some initial data. Three materials - Douglas fir, rigid polyurethane foam, and PVC - were examined in real-scale and bench-scale methods. The real-scale test environment was a post-flashover fire in a 3-compartment (room, corridor, room) geometry, with the test specimens comprising wall lining materials. The bench-scale methods examined were the NBS cup furnace method and a new developmental protocol referred to as the "SwRI/NIST" method. The N-gas Model was applied to the analysis of the data and was found to be consistent with most of the data. The methods were compared for similarity of gas yields, or primary gases, and of types of death. Differences were found in individual cases, but most of those were readily explainable on the basis of an understanding of the test conditions. As a result of these studies, a factor-of-3 agreement between bench-scale and real-scale results was established as both useful and practical.

12. KEY WORDS (6 TO 12 ENTRIES; ALPHABETICAL ORDER; CAPITALIZE ONLY PROPER NAMES; AND SEPARATE KEY WORDS BY SEMICOLONS)

Fire tests; fire toxicity; poly(vinyl chloride); radiant heat; rigid polyurethane foam; room fire tests; wood materials.

FOR OFFICIAL DISTRIBUTION. DO NOT RELEASE TO NATIONAL TECHNICAL INFOAMATION SERVICE (NTIS).

$X$ ORDER FROM SUPERINTENDENT OF DOCUMENTS, U.S. GOVERNMENT PRINTING OFFICE, WASHINGTON, DC 20402.

ORDER FROM NATIONAL TECHNICAL INFORMATION SEAVICE (NTIS), SPRINGFIELD, VA 22161.

\begin{tabular}{|l|}
\hline 14. NUMBER OF PRINTED PAGES \\
110 \\
\hline 15. PAICE \\
\hline
\end{tabular}




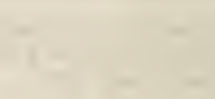






\section{Technical Publications}

\section{Periodical}

Journal of Research of the National Institute of Standards and Technology-Reports NIST research and development in those disciplines of the physical and engineering sciences in which the Institute is active. These include physics, chemistry, engineering, mathematics, and computer sciences. Papers cover a broad range of subjects, with major emphasis on measurement methodology and the basic technology underlying standardization. Also included from time to time are survey articles on topics closely related to the Institute's technical and scientific programs. Issued six times a year.

\section{Nonperiodicals}

Monographs-Major contributions to the technical literature on various subjects related to the Institute's scientific and technical activities.

Handbooks-Recommended codes of engineering and industrial practice (including safety codes) developed in cooperation with interested industries, professional organizations, and regulatory bodies.

Special Publications-Include proceedings of conferences sponsored by NIST, NIST annual reports, and other special publications appropriate to this grouping such as wall charts, pocket cards, and bibliographies.

Applied Mathematics Series-Mathematical tables, manuals, and studies of special interest to physicists, engineers, chemists, biologists, mathematicians, computer programmers, and others engaged in scientific and technical work.

National Standard Reference Data Series-Provides quantitative data on the physical and chemical properties of materials, compiled from the world's literature and critically evaluated. Developed under a worldwide program coordinated by NIST under the authority of the National Standard Data Act (Public Law 90-396). NOTE: The Journal of Physical and Chemical Reference Data (JPCRD) is published quarterly for NIST by the American Chemical Society (ACS) and the American Institute of Physics (AIP). Subscriptions, reprints, and supplements are available from ACS, 1155 Sixteenth St., NW., Washington, DC 20056. . .

Building Science Series-Disseminates technical information developed at the Institute on building materials, components, systems, and whole structures. The series presents research results, test methods, and performance criteria related to the structural and environmental functions and the durability and safety characteristics of building elements and systems.

Technical Notes-Studies or reports which are complete in themselves but restrictive in their treatment of a subject. Analogous to monographs but not so comprehensive in scope or definitive in treatment of the subject area. Often serve as a vehicle for final reports of work performed at NIST under the sponsorship of other government agencies.

Voluntary Product Standards-Developed under procedures published by the Department of Commerce in Part 10, Title 15, of the Code of Federal Regulations. The standards establish nationally recognized requirements for products, and provide all concerned interests with a basis for common understanding of the characteristics of the products. NIST administers this program as a supplement to the activities of the private sector standardizing organizations.

Consumer Information Series-Practical information, based on NIST research and experience, covering areas of interest to the consumer. Easily understandable language and illustrations provide useful background knowledge for shopping in today's technological marketplace.

Order the above NIST publications from: Superintendent of Documents, Government Printing Office, Washington, DC 20402.

Order the following NIST publications-FIPS and NISTIRs-from the National Technical Information Service, Springfield, VA 22161.

Federal Information Processing Standards Publications (FIPS PUB)-Publications in this series collectively constitute the Federal Information Processing Standards Register. The Register serves as the official source of information in the Federal Government regarding standards issued by NIST pursuant to the Federal Property and Administrative Services Act of 1949 as amended, Public Law 89-306 (79 Stat. 1127), and as implemented by Executive Order 11717 (38 FR 12315, dated May 11, 1973) and Part 6 of Title 15 CFR (Code of Federal Regulations).

NIST Interagency Reports (NISTIR)-A special series of interim or final reports on work performed by NIST for outside sponsors (both government and non-government). In general, initial distribution is handled by the sponsor; public distribution is by the National Technical Information Service, Springfield, VA 22161, in paper copy or microfiche form. 
U.S. Department of Commerce

National Institute of Standards and Technology

(formerly National Bureau of Standards)

Galthersburg, MD 20899

Official Business

Penalty for Private Use $\$ 300$ 